GÖTTINGER ZENTRUM

FÜR BIODIVERSITÄTSFORSCHUNG UND ÖKOLOGIE

- GÖTTINGEN CENTRE FOR BIODIVERSITY AND ECOLOGY -

\title{
Multitrophic interactions along a plant size gradient in Brassicaceae
}

\author{
Dissertation zur Erlangung des Doktorgrades der \\ Mathematisch-Naturwissenschaftlichen Fakultäten der \\ Georg-August-Universität Göttingen
}

\author{
vorgelegt von \\ Dipl.-Biol. \\ Hella Schlinkert \\ aus Hamm
}

Göttingen, Februar 2014 
Referent: Prof. Dr. Teja Tscharntke

Korreferent: Prof. Dr. Stefan Vidal

Tag der mündlichen Prüfung: 18. März 2014 


\section{CONTENTS}

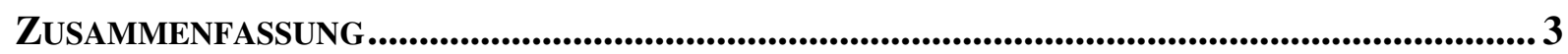

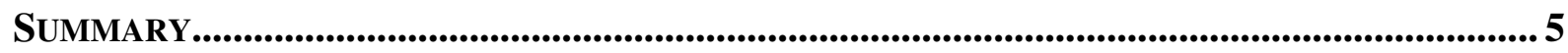

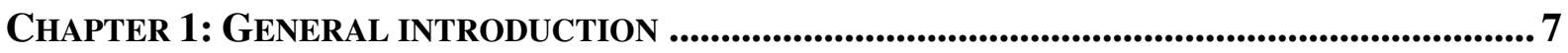

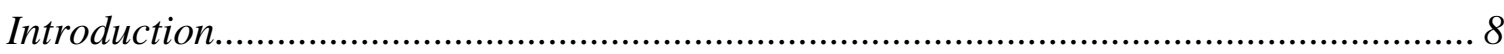

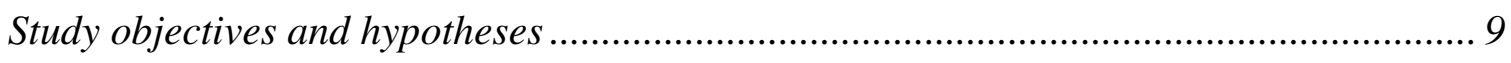

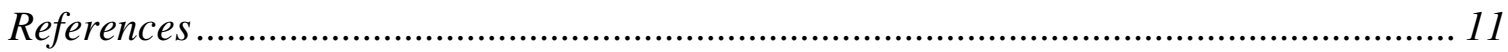

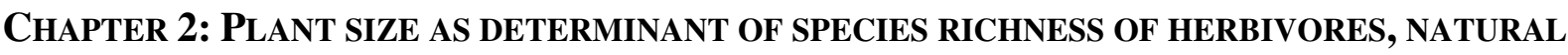

ENEMIES AND POLLINATORS ACROSS 21 BRASSICACEAE SPECIES ........................................... 13

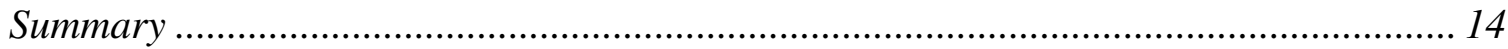

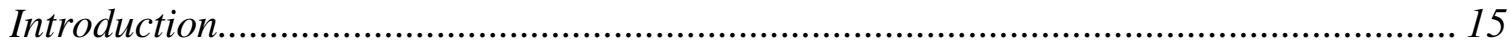

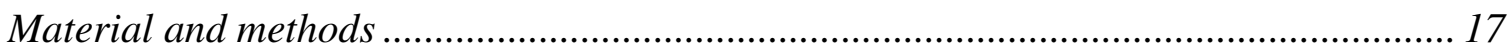

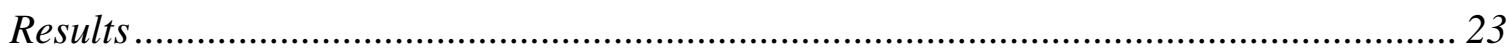

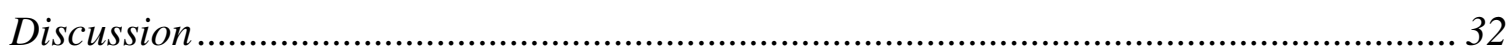

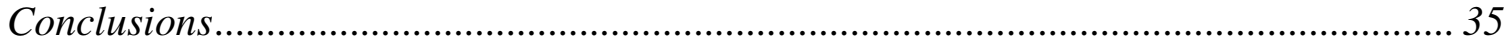

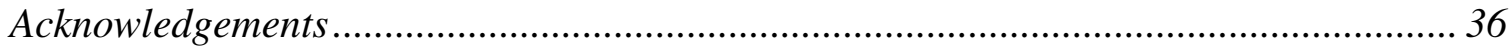

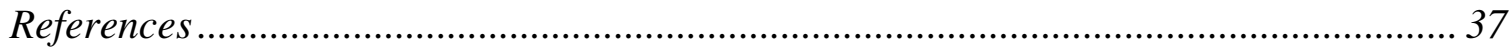

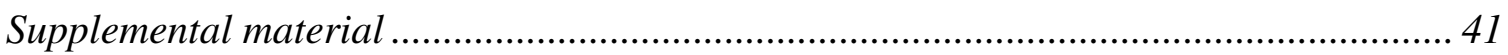

CHAPTER 3: HERBIVORY INCREASES WITH PLANT SIZE ACROSS 21 BRASSICACEAE SPECIES 49

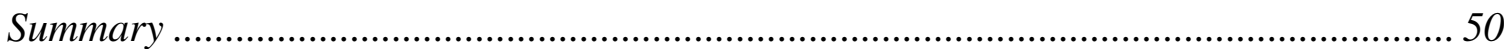

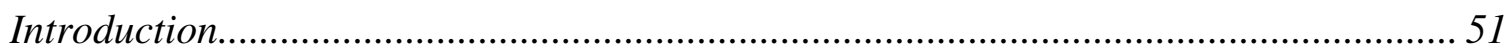

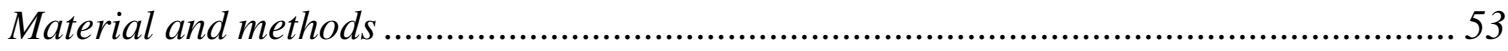

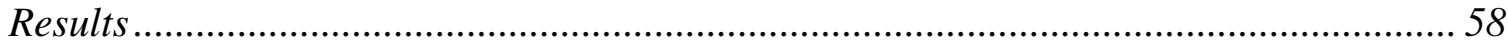

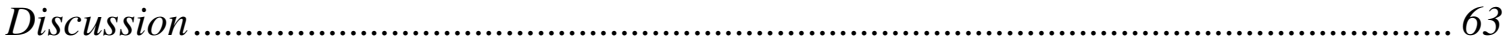

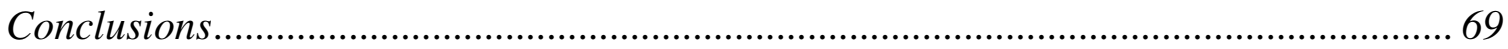

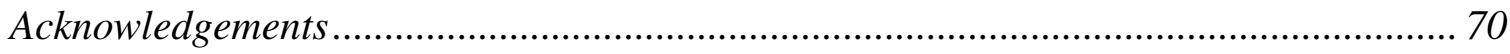

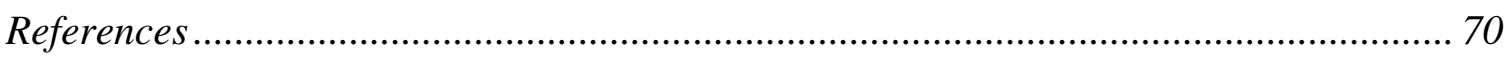

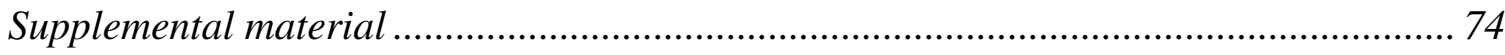


Chapter 4: Plant size as determinant of mutualistic versus antagonistic INTERACTIONS AND REPRODUCTIVE FITNESS ACROSS 21 BRASSICACEAE SPECIES .83

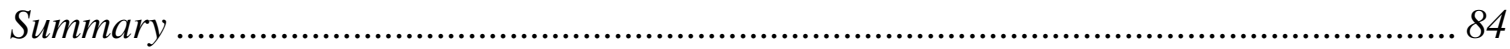

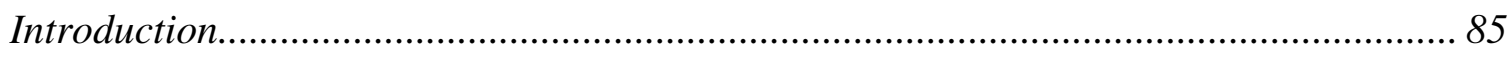

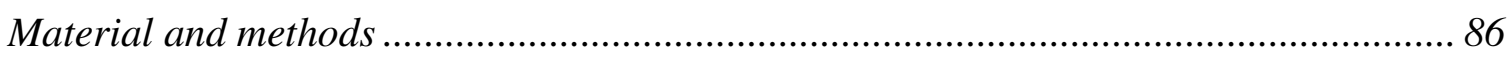

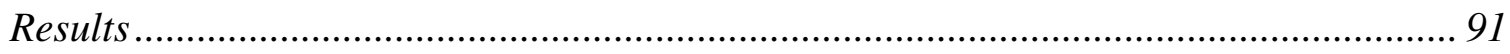

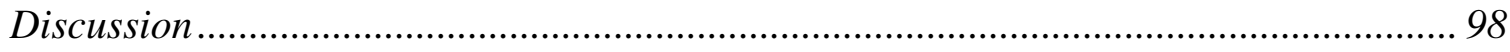

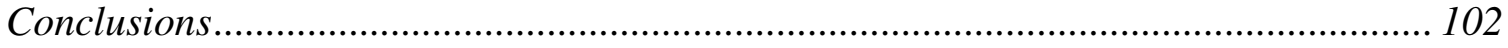

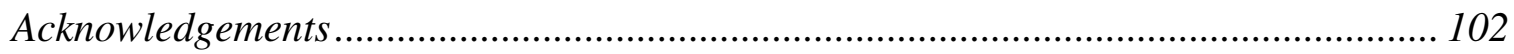

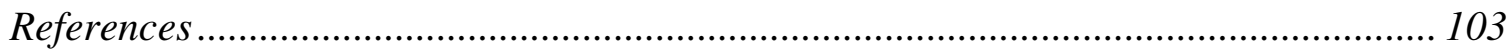

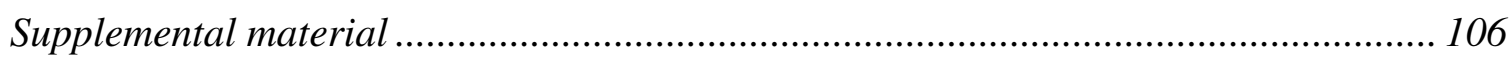

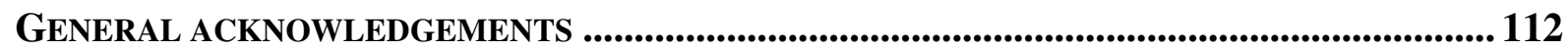

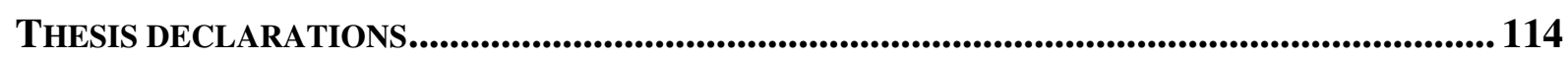

Declaration of the author's own contribution to manuscripts with multiple authors .... 114

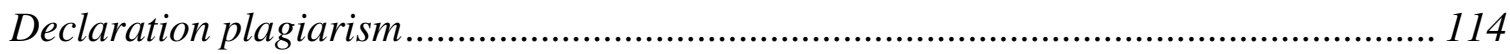




\section{ZUSAMMENFASSUNG}

Das Wissen über Mechanismen, die einen Einfluss auf Muster der Artenvielfalt und biotische Interaktionen haben, ist grundlegend für den Schutz von Biodiversität. Darüber hinaus kann es von direktem ökonomischem Nutzen sein, zum Beispiel im biologischen Pflanzenschutz oder bei Bestäubungsdienstleistungen. Die Größe eines Organismus kann ein solcher Faktor sein, der die Artenzahl und Interaktionen der assoziierten Organismen beeinflusst, denn große Organismen sind auffälliger als kleine und ihr Angebot an Ressourcen und Nischen für mit ihnen assoziierte Organismen ist oft reicher. Bezogen auf Pflanzen könnte daher die Größe einer Pflanze einen erheblichen Einfluss auf die Artenzahl der mit ihr assoziierten Arthropoden und ihre biotischen Interaktionen wie Herbivorie oder Bestäubung haben. Trotzdem ist der Einfluss der Pflanzengröße auf mutualistische und antagonistische Interaktionspartner der Pflanze und der sich daraus ergebende Einfluss auf die reproduktive Fitness der Pflanze bisher nicht umfassend und unter standardisierten Bedingungen untersucht worden.

In der vorliegenden Studie wurden die Auswirkungen der Pflanzengröße auf die Artenzahl von Herbivoren, deren Gegenspielern und Bestäubern untersucht, sowie die Auswirkungen dieser Interaktionspartner auf die Pflanzenfitness. Dabei wurde zusätzlich zwischen endophagen und ektophagen Herbivoren und deren Gegenspielern unterschieden. Außerdem wurden die Herbivoren einzelner Pflanzenkompartimente und deren Gegenspieler separat analysiert. Des Weiteren wurde der Einfluss der Pflanzengröße auf den Herbivorieschaden an den verschiedenen Pflanzenkompartimenten und deren Einfluss auf die reproduktive Fitness der Pflanze, d.h. auf ihre Samenzahl, Tausendkorngewicht und Samengesamtgewicht, untersucht. Zuletzt wurde besonderes Augenmerk auf den Einfluss der Pflanzengröße auf mutualistische und antagonistische Blütenbesucher und deren Einfluss auf die reproduktive Fitness gelegt und untersucht, ob und inwiefern die reproduktive Fitness letztendlich von der Pflanzengröße abhängig ist.

Zur Untersuchung dieser Fragen wurde ein „Common Garden“-Experiment angelegt. Um einen interspezifischen Pflanzengrößengradienten $\mathrm{zu}$ erzeugen, wurden 21 annuelle Pflanzenarten aus der Familie der Kreuzblütler (Brassicaceae) ausgewählt, deren Größe von 10 bis $130 \mathrm{~cm}$ reichte (gemessen als Pflanzenhöhe vom Boden bis zur Spitze). So konnten die Einflüsse des Habitats und der umgebenden Landschaft für alle Pflanzenarten standardisiert 
und trotzdem ein breiter Gradient realisiert werden. Dadurch hebt sich diese Studie von den bisherigen ab, die den Effekt von meist intraspezifischer Pflanzengröße auf die assoziierten Tiere anhand wild wachsender Pflanzen untersucht haben. Pflanzengröße sowie Zahl, Biomasse und Größe der unterschiedlichen überirdischen Pflanzenkompartimente (Blüten, Schoten, Blätter, Stängel) sowie Blütendeckung und -farbe wurden aufgenommen. Der Herbivorieschaden an diesen Pflanzenkompartimenten und die reproduktive Fitness (Samenzahl, Tausendkorngewicht und Gesamtsamengewicht) wurden gemessen. An und in Blüten, Schoten, Blättern und Stängeln wurden herbivore, räuberische, parasitäre und bestäubende Arthropoden gezählt.

Die Pflanzengröße hatte einen positiven Einfluss auf die Artenzahl von Herbivoren, deren Gegenspielern und Bestäubern. Das traf ebenso auf endophage und ektophage sowie auf mit Blättern und Schoten assoziierte Herbivore und deren Gegenspieler zu. Des Weiteren konnte ein Anstieg des Herbivorieschadens an Blüten und Schoten mit zunehmender Pflanzengröße festgestellt werden, wohingegen der Schaden an Blättern und Stängeln von der Biomasse des entsprechenden Kompartiments positiv beeinflusst wurde. Der Schaden an Blüten hatte den stärksten Einfluss auf die reproduktive Fitness und reduzierte neben der Samenzahl auch das Tausendkorngewicht und das Gesamtsamengewicht der Pflanze. Die genaue Analyse der blütenbesuchenden Insekten ergab einen positiven Einfluss der Pflanzengröße auf die Abundanz und Artenzahl von Bestäubern (allerdings nicht bei extrem großem Blütenangebot), wie auch auf die Abundanz der adulten und juvenilen Rapsglanzkäfer und deren Parasitierungsrate. Steigende Rapsglanzkäferzahlen verringerten die Samenzahl sowie das Tausendkorngewicht, während die Bestäuber sich lediglich auf die Samenzahl positiv auswirkten. Insgesamt führte ein Anstieg der Pflanzenhöhe zu einer Abnahme des Tausendkorngewichts, aber nicht zu einer Veränderung der Samenzahl oder des Gesamtsamengewichts, was auf einen Ausgleich der Effekte von zunehmender Antagonistenzahl und zunehmender Mutualistenzahl hindeutet.

Großen Pflanzen entstehen also durch ihre Auffälligkeit und Attraktivität für Herbivore hohe Fitnesskosten, wobei insbesondere der Blütenschaden durch Rapsglanzkäfer einen starken negativen Einfluss auf Samenzahl, Tausendkorngewicht und Gesamtsamengewicht hat. Diesen Fitnesskosten großer Pflanzen wirkt der Nutzen durch ihre Auffälligkeit und Attraktivität für Bestäuber entgegen, die die Samenzahl positiv beeinflussen. Hinsichtlich der Samenzahl sollten also große Pflanzen gegenüber kleineren im Vorteil sein, wenn die 
Insektengemeinschaft des Habitats von Bestäubern dominiert wird. Wird sie aber von herbivoren Blütenbesuchern dominiert, sollten kleine Pflanzen gegenüber großen einen Vorteil haben. Im Gegensatz dazu sollten große Pflanzen immer einen Nachteil bezüglich des Tausendkorngewichts haben, das von Antagonisten, nicht aber von Mutualisten beeinflusst wurde. Der Einfluss der Pflanzengröße auf biotische Interaktionen wurde bisher oft unterschätzt, obwohl er sich auf komplexe Weise über die mutualistischen und antagonistischen Insekten auf die reproduktive Fitness der Pflanze auswirkt.

\section{SUMMARY}

Plant size is hypothesised to be a major driver of biotic interactions, as larger plants are more conspicuous and offer a wider range of resources and niches for associated animals. However, the role of interspecific differences in plant size for associated animals (antagonists or mutualists) and the resulting plant reproductive fitness is little explored. In this thesis effects of plant size on species richness of herbivores and their natural enemies as well as on species richness of pollinators were tested. Endophytic and ectophytic herbivores and their natural enemies were considered separately as were herbivores and their natural enemies associated with different plant components. Further, the effect of plant size was studied for feeding damage to different plant components and the associated impact on plant reproductive fitness parameters, namely seed number, thousand seed weight and total seed weight per plant individual. Finally, the focus was placed on the effect of plant size on antagonistic and mutualistic flower associated insects and their impact on plant reproductive fitness along the plant size gradient.

A common garden experiment with an interspecific plant size gradient (from 10 to $130 \mathrm{~cm}$ length) among 21 annual Brassicaceae species was established. In this way, we realised a broad gradient in plant size across different plant species with standardisation of the habitat and the surrounding landscape features, overcoming a common problem flaw in the analysis of within-species variation and naturally grown plants. Plant size, number, biomass and the size of the different aboveground plant components (flowers, fruits, leaves and stems) were quantified along with flower cover and colour. Relative feeding damage to the different plant components and the resulting reproductive fitness of each plant species were assessed. Finally 
arthropods on and in flowers, fruits, leaves and stems were sampled, including herbivores, their natural enemies and pollinators.

Plant size was positively related to the species richness of herbivores, of their natural enemies and to the species richness of pollinators. This was likewise true for endophagous and ectophagous herbivores and their natural enemies as well as for fruit and leaf associated herbivores and their natural enemies. Furthermore, data showed increasing feeding damage to flowers and fruits with increasing plant size, while feeding damage to leaves and stems was driven by their biomass rather than by plant size. Feeding damage to flowers had the strongest effect on reproductive fitness, decreasing seed number, thousand seed weight and total seed weight. Focusing on flower associated insects, plant size had a positive effect on abundance and species richness of pollinators (but only when flowers were not superabundant) and also on pollen beetle abundance, despite the associated higher rates of parasitism of pollen beetles. Pollen beetles reduced seed number and thousand seed weight. Pollinators positively affected seed number only. Overall, increasing plant size led to decreasing thousand seed weight but did not significantly alter seed number and total seed weight, indicating a balance between increasing pollen beetle damage and positive effects of increasing pollinator visits.

In conclusion, increased detectability and attractiveness to herbivores leads to important fitness costs for large plants, including flower damage by pollen beetles, which had the strongest negative impact on plant reproductive fitness in terms of seed number, thousand seed weight and total seed weight. These fitness costs for large plants may be counteracted by their detectability and attractiveness to pollinators, which positively influenced seed number. Purely in terms of seed numbers, being large is advantageous in places dominated by pollinators, while being small is advantageous in places dominated by herbivorous flower visitors. Contrarily, plants suffer from being large with regard to their thousand seed weight, which was driven by herbivores only. In general, plant size is a hitherto underestimated driver of interactions, and its effects on plant fitness through interacting insects are highly complex. 


\section{Chapter 1}

\section{GENERAL INTRODUCTION}

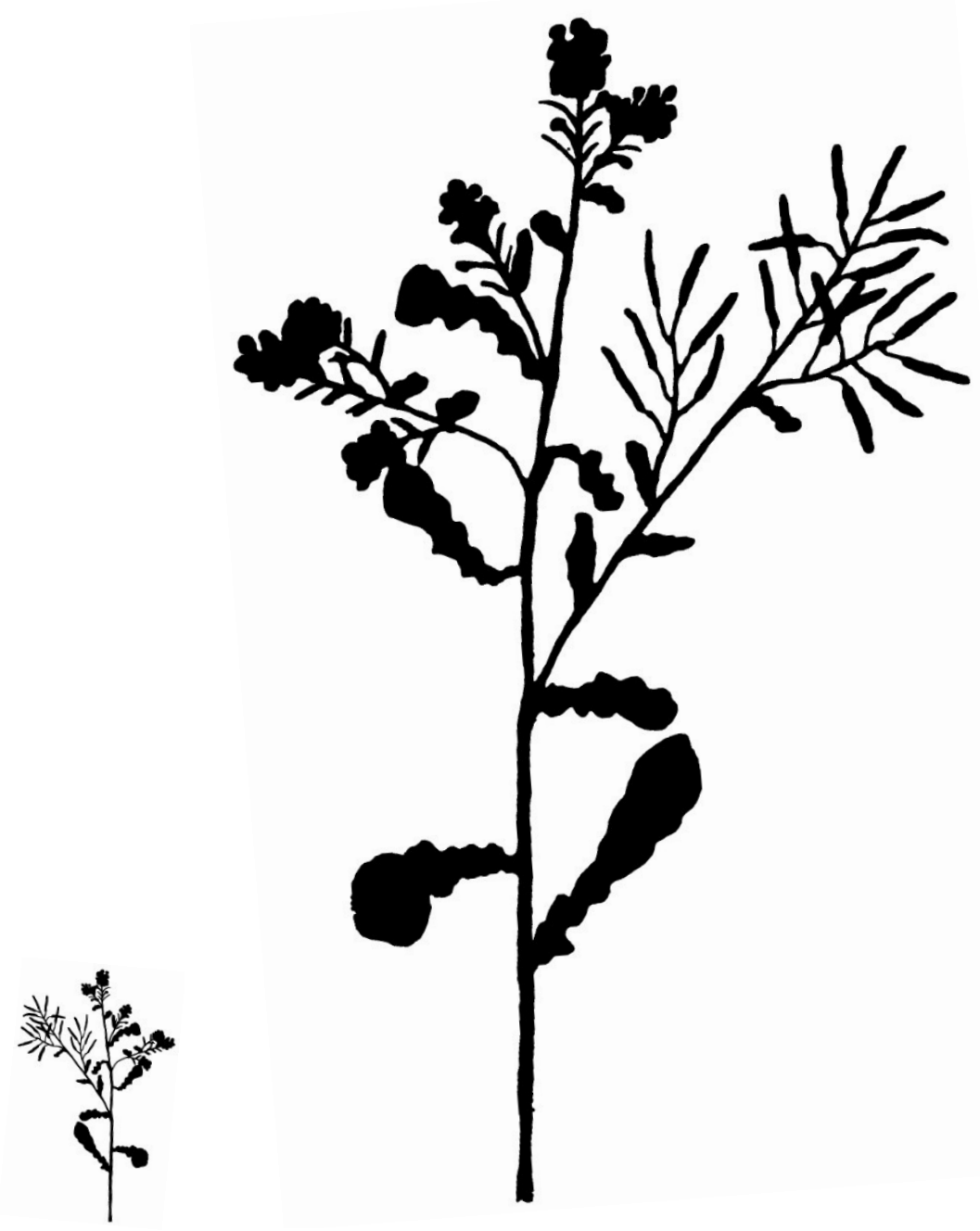




\section{INTRODUCTION}

Body size is an important driver of patterns and processes in ecology, affecting most organisms at genetic, physiological and ecological levels (Peters, 1983). Interactions between organisms are influenced by body size; for example body mass of predator and prey organisms determines population dynamics and food-webs (Brose, 2010; Kalinkat et al., 2013), competitiveness for resources (Brown and Maurer, 1986) and conspicuousness to associated organisms (Blanckenhorn, 2000; Remmel and Tammaru, 2009). This not only applies to animals, but also to plants, as large plants are easily found and colonised by herbivores due to enhanced conspicuousness and an attractive offer of various resources and niches (Feeny, 1976; Lawton, 1983; Strong et al., 1984). Plant size positively influences richness of associated organisms, which was often shown for herbivores or single herbivorous insect families only and on the basis of naturally grown plants differing in local conditions (Haysom and Coulson, 1998; Lawton and Price, 1979; Moran, 1980; Neuvonen and Niemelä, 1981).

Although a positive effect of plant size on species richness of herbivores has been shown, the effect of plant size on feeding damage has rarely been investigated. Existing studies have focused only on single plant species, single plant components and feeding damage of single herbivore families or even species (Alonso and Herrera, 1996; Ehrlén et al., 2012; Hainsworth et al., 1984; Sletvold and Grindeland, 2008; Tenow and Larsson, 1987; Williams and Free, 1979). The effect of plant size on feeding damage may vary between different plant components. Furthermore, the effect of feeding damage on plant fitness may be component dependent. To my knowledge there are no studies on the comparison of interspecific plant size effects on feeding damage to the different plant components and their relation to plant reproductive fitness.

Mutualists as well may have an effect on the plant fitness. Pollinating insects may enhance seed set of plants (Bommarco et al., 2012) and may be attracted by large plants, which has been shown for intraspecific plant size gradients only (Donnelly et al., 1998; Geber, 1985; Gómez, 2003). Plant size may be of particular importance for flower visiting insects, whether they are mutualists or antagonists, if optically attractive flowers are positioned at the top of the plant. Mutualistic and antagonistic flower visiting insects directly affect a component of great importance for plant reproductive fitness and therefore may be of particular importance 
for the plant. Are both, pollinators and flower herbivores, attracted by large plants? And which group has a stronger effect on plant reproductive fitness? Is it an overall disadvantage or an advantage for a plant to be large? Studies investigating the relative importance of flower visiting insects in relation to plant size and the overall effects on plant fitness are scarce, limited only to the effect of intraspecific plant size on single parts (flower damage: Williams and Free 1979, Sletvold and Grindeland 2008; pollinator abundance: Geber 1985, Donnelly et al. 1998; final plant fitness: O'Connell and Johnston 1998, Dickson and Petit 2006; combination of pollination success or pollinator abundance and the final outcome: Gómez 2003, Ehrlén et al. 2012).

\section{STUDY OBJECTIVES AND HYPOTHESES}

This thesis aims to draw a comprehensive picture of the effects of plant size (measured as plant height) on associated arthropods and on the plant reproductive fitness. A common garden experiment with 21 plant species was conducted in a standardised environment, covering a plant size gradient from 10 to $130 \mathrm{~cm}$. Species richness of all arthropods associated to aboveground plant components was investigated with respect to endophagous and ectophagous herbivores of the different plant components and their natural enemies, as well as species richness of flower visiting pollinators (Chapter 2). The proportional feeding damage to the different aboveground plant components was studied. Furthermore we focused on consequences of feeding damage to the different components on plant reproductive fitness, i.e. on seed number, thousand seed weight and total seed weight of plants (Chapter 3). Finally the effect of plant size on mutualistic and antagonistic flower visiting insects was examined and the relative importance of flower visiting insects for plant reproductive fitness parameters (podless stalks, seed number, thousand seed weight and total seed weight) was determined. The net effect on plant reproductive fitness was considered in detail in terms of the overall disadvantage or advantage for a plant to be large (Chapter 4). The following hypotheses were tested: 
CHAPTER 2 - Plant SIZE AS DETERMINANT OF SPECIES RICHNESS OF HERBIVORES, NATURAL ENEMIES AND POLLINATORS ACROSS 21 BRASSICACEAE SPECIES:

(1) Species richness of herbivores increases with plant size. This is also true for (1.1) ectophagous and (1.2) endophagous herbivores and for herbivores associated with single plant components, namely (1.3) leaves and (1.4) fruits. Further, species richness of herbivores is positively affected by component availability (biomass and number of leaves and fruits).

(2) Species richness of natural enemies increases with plant size and prey/host availability. This is likewise true for species richness of natural enemies of (2.1) ectophagous and (2.2) endophagous herbivores and for species richness of natural enemies of herbivores associated with single plant components, namely leaves (2.3) and fruits (2.4).

(3) Species richness of pollinating insects increases with plant size, while also flower characteristics, namely number, biomass and colour, contribute to the explanation of differences in pollinator species richness.

(4) The overall effects of plant size on species richness of herbivores, their natural enemies and pollinators are all positive, while these effects regarding herbivores and pollinators are more pronounced in comparison to natural enemies of herbivores, as they directly depend on the plant as resource.

\section{CHAPTER 3 - HERBIVORY INCREASES WITH PLANT SIZE ACROSS 21 BRASSICACEAE SPECIES:}

(1) Proportional feeding damage to the different plant components increases with increasing plant size, as well as with increasing resource availability, i.e. component number and biomass.

(2) Proportional feeding damage to the different plant components, particularly to reproductive components (flowers and fruits), negatively affects plant reproductive fitness.

(3) Plant reproductive fitness decreases with increasing plant size. 
CHAPTER 4 - PlANT SIZE AS DETERMINANT OF MUTUALISTIC VERSUS ANTAGONISTIC INTERACTIONS AND REPRODUCTIVE FITNESS ACROSS 21 BRASSICACEAE SPECIES:

(1) Increasing plant size enhances the abundance and species richness of flower visiting pollinators, the abundance of pollen beetle adults and larvae and parasitism rates of pollen beetle larvae.

(2) Mutualistic and antagonistic interactions tend to have contrasting effects on the plant reproductive fitness, measured as number of seeds, proportion of podless stalks, thousand seed weight and total seed weight per individual.

Finally, we address the question whether there is a trade-off between beneficial and detrimental effects of mutualists and antagonists along the plant size gradient.

\section{REFERENCES}

Alonso, C., Herrera, C.M., 1996. Variation in herbivory within and among plants of Daphne laureola (Thymelaeaceae): correlation with plant size and architecture. J. Ecol. 84, 495502.

Blanckenhorn, W.U., 2000. The evolution of body size: what keeps organisms small? Q. Rev. Biol. 75, 385-407.

Bommarco, R., Marini, L., Vaissière, B.E., 2012. Insect pollination enhances seed yield, quality, and market value in oilseed rape. Oecologia 169, 1025-1032.

Brose, U., 2010. Body-mass constraints on foraging behaviour determine population and food-web dynamics. Funct. Ecol. 24, 28-34.

Brown, J.H., Maurer, B.A., 1986. Body size, ecological dominance and Cope's rule. Nature $324,248-250$.

Dickson, C.R., Petit, S., 2006. Effect of individual height and labellum colour on the pollination of Caladenia (syn. Arachnorchis) behrii (Orchidaceae) in the northern Adelaide region, South Australia. Plant Syst. Evol. 262, 65-74.

Donnelly, S.E., Lortie, C.J., Aarssen, L.W., 1998. Pollination in Verbascum thapsus (Scrophulariaceae): the advantage of being tall. Am. J. Bot. 85, 1618-1625.

Ehrlén, J., Borg-Karlson, A.-K., Kolb, A., 2012. Selection on plant optical traits and floral scent: Effects via seed development and antagonistic interactions. Basic Appl. Ecol. 13, $509-515$. 
Feeny, P., 1976. Plant apparency and chemical defense, in: Wallace, J.W., Mansell, R.L. (Eds.), Biochemical Interaction Between Plants and Insects. Springer US, New York, pp. $1-40$.

Geber, M.A., 1985. The relationship of plant size to self-pollination in Mertensia ciliata. Ecology 66, 762-772.

Gómez, J.M., 2003. Herbivory reduces the strength of pollinator-mediated selection in the Mediterranean herb Erysimum mediohispanicum: consequences for plant specialization. Am. Nat. 162, 242-256.

Hainsworth, F.R., Wolf, L.L., Mercier, T., 1984. Pollination and pre-dispersal seed predation: net effects on reproduction and inflorescence characteristics in Ipomopsis aggregata Oecologia 63, 405-409.

Haysom, K.A., Coulson, J.C., 1998. The Lepidoptera fauna associated with Calluna vulgaris: effects of plant architecture on abundance and diversity. Ecol. Entomol. 23, 377-385.

Kalinkat, G., Schneider, F.D., Digel, C., Guill, C., Rall, B.C., Brose, U., 2013. Body masses, functional responses and predator-prey stability. Ecol. Lett. 16, 1126-1134.

Lawton, J.H., 1983. Plant architecture and the diversity of phytophagous insects. Annu. Rev. Entomol. 28, 23-39.

Lawton, J.H., Price, P.W., 1979. Species richness of parasites on hosts: agromyzid flies on the British Umbelliferae. J. Anim. Ecol. 48, 619-637.

Moran, V.C., 1980. Interactions between phytophagous insects and their Opuntia hosts. Ecol. Entomol. 5, 153-164.

Neuvonen, S., Niemelä, P., 1981. Species richness of Macrolepidoptera on Finnish deciduous trees and shrubs. Oecologia 51, 364-370.

O’Connell, L.M., Johnston, M.O., 1998. Male and female pollination success in a deceptive orchid, a selection study. Ecology 79, 1246-1260.

Peters, R.H., 1983. The ecological implications of body size. Cambridge University Press, Cambridge.

Remmel, T., Tammaru, T., 2009. Size-dependent predation risk in tree-feeding insects with different colouration strategies: a field experiment. J. Anim. Ecol. 78, 973-980.

Sletvold, N., Grindeland, J.M., 2008. Floral herbivory increases with inflorescence size and local plant density in Digitalis purpurea. Acta Oecologica 34, 21-25.

Strong, D.R., Lawton, J.H., Southwood, T.R.E., 1984. Insects on plants: community patterns and mechanisms. Blackwell Scientific Publications, Oxford.

Tenow, O., Larsson, S., 1987. Consumption by needle-eating insects on Scots pine in relation to season and stand age. Ecography. 10, 249-260.

Williams, I.H., Free, J.B., 1979. Compensation of oil-seed rape (Brassica napus L.) plants after damage to their buds and pods. J. Agric. Sci. 92, 53-59. 


\section{Chapter 2}

\section{Plant SIZE AS DETERMINANT OF SPECIES RICHNESS}

OF HERBIVORES, NATURAL ENEMIES AND POLLINATORS

ACROSS 21 BRASSICACEAE SPECIES

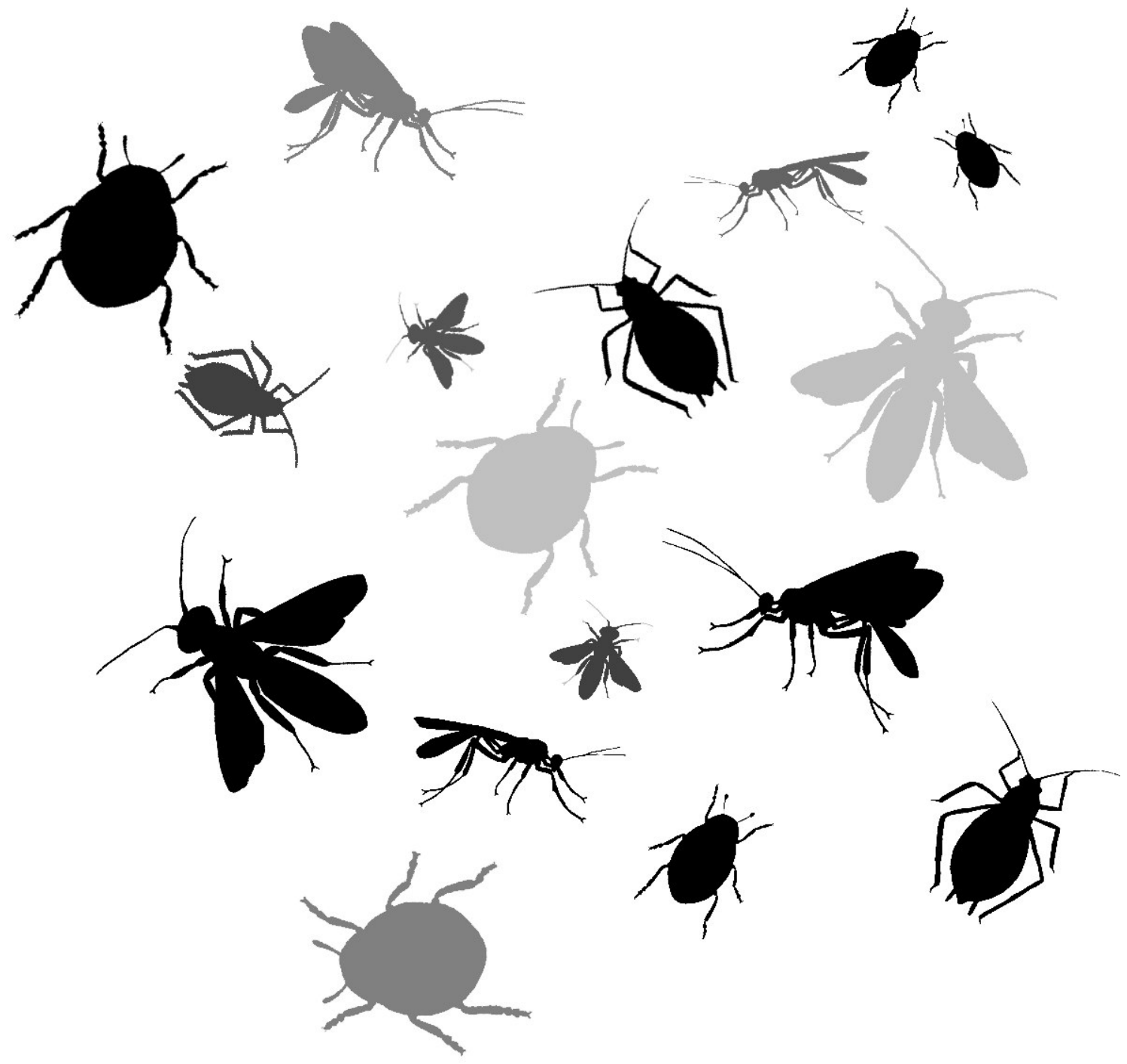

Hella Schlinkert, Catrin Westphal, Yann Clough, 


\section{SUMMARY}

Large plants are often more conspicuous for associated animals and offer a wider range of resources and niches than small plants. Therefore, plant size can positively affect species richness of associated animals, as shown for single groups of herbivores, but studies usually considered intraspecific size differences of plants in unstandardised environments. As comprehensive tests of interspecific plant size differences under standardised conditions are missing so far, we investigated the effects of plant size on species richness of all associated animals using a common garden experiment with 21 Brassicaceae species covering an interspecific plant size gradient from 10 to $130 \mathrm{~cm}$ height. We recorded plant associated ectoand endophagous herbivores, their natural enemies and pollinators on and in each aboveground plant component, i.e. flowers, fruits, leaves and stems. Plant size (measured as height from the ground), the number of entities of the different plant components and their biomass were assessed. Increasing plant size led to increased species richness of associated herbivores, natural enemies and pollinating insects. We found similar slopes and a higher $\mathrm{R}^{2}$ for herbivores and pollinators compared to natural enemies, which do not directly depend on the plant resource. Overall, the increase in plant height from 10 to $130 \mathrm{~cm}$ led to a triplication of predicted total arthropod species richness. This pattern was found for ectophagous and for endophagous herbivores and their natural enemies as well as for herbivores associated with leaves and fruits and their natural enemies, independent of the additional positive effects of resource availability (i.e. component biomass or number of entities and, regarding natural enemies, herbivore species richness). In conclusion, plant size is a comprehensive driver of species richness of the plant associated arthropods, including pollinators, herbivores and their natural enemies, whether they are endophagous or ectophagous or associated with leaves or fruits.

\section{Keywords}

ectophagous, endophagous, parasitoids, predators, plant height, resource availability 


\section{INTRODUCTION}

The body size of organisms has a large impact at the physiological, genetic and ecological levels (Peters, 1983). Large body size is often related to greater dispersal ability, enhanced competitiveness for resources (Brown and Maurer, 1986; Hemptinne et al., 2012) and can affect communities of associated organisms due to e.g. increased conspicuousness (Blanckenhorn, 2000; Remmel and Tammaru, 2009). Size of plants is supposed to be a driver of species richness of the associated organisms as differences in plant size can lead to differences in not only conspicuousness, but also in quantity and variety of resources and niches (Feeny, 1976; Lawton, 1983). Consequently a positive correlation between plant size and species richness of associated animals has been shown several times (Haysom and Coulson, 1998; Lawton and Price, 1979; Neuvonen and Niemelä, 1981). However, these studies focus on single insect groups only, mostly on herbivores, and lack standardisation as they sample plants in fields with different local conditions, species pools and surrounding landscapes. Data collected in the field (in contrast to those resulting from standardised common garden experiments) may suffer from a bias as mean plant size increases with successional stage of the vegetation and thereby with overall biodiversity, so that larger plant species typically grow in more diverse environments (Southwood, 1988).

Research on general drivers of species diversity patterns is an important basis for conserving biodiversity, improving pest control and pollination services (Crowder and Jabbour, 2014; Hoehn et al., 2008). Differentiated conclusions thereby require a comprehensive investigation of different groups of associated animals, such as endophagous and ectophagous herbivores of different plant components (e.g. leaves and fruits), their natural enemies and pollinators. Espírito-Santo et al. (2007) reported increasing species richness of ectophagous herbivores with increasing plant size. However, they found only a positive effect of resource availability and no effect of plant size on species richness of endophagous herbivores (but see Lawton and Price, 1979; Tscharntke and Greiler, 1995). Most herbivore species are specialised on certain plant components (Strong et al., 1984) and are known to be affected by characteristics of their resource components, such as biomass and number (Araujo et al., 2006; Reudler Talsma et al., 2008). High quantity or biomass of the relevant components may increase their attractiveness and conspicuousness to associated organisms. Additionally, also plant size may affect conspicuousness of single components, because components of large plants are often less hidden in the surrounding vegetation than those of small plants. Accordingly, caterpillar 
densities on leaves of Calluna vulgaris (L.) HULL were reported to increase with increasing intraspecific plant height (Haysom and Coulson, 1998).

Not only herbivore species richness is often driven by resource availability, but also species richness of predators and parasitoids can be positively affected by species richness of herbivores (Hunter and Price, 1992; Knops et al., 1999). Additionally, plant characteristics can affect prey and host location of herbivores' natural enemies (Hodek, 1993; Williams and Cook, 2010). Prey and host location strategy can differ between natural enemies of endophagous and ectophagous herbivores, since the degree of concealment of endophagous and ectophagous insects differs. Consequently, a potential effect of plant size on species richness of natural enemies of ectophagous and endophagous herbivores may differ (Hawkins and Lawton, 1987).

Another important group of mutualists are pollinating insects. Pollinators are influenced by flower characteristics such as number, size and colour (Cohen and Shmida, 1993; Hegland and Totland, 2005; Leong and Thorp, 1999). Additionally, they can be affected by plant size when inflorescence height increases with plant size and flowers of large plants thereby gain in conspicuousness. A positive effect of plant size is up to now only shown for pollinator abundance or visitation rates along intraspecific plant size gradients (Donnelly et al., 1998; Geber, 1985; Gómez, 2003), but not for pollinator species richness and along interspecific plant size gradients so far.

The genetic determination of plant size differences is one of the advantages of interspecific over intraspecific plant size gradients. The range of plant size in interspecific gradients can be broader than it could be in intraspecific gradients without strong bias by factors such as nutrient availability, competitive pressure or influence of interaction partners (e.g. Buchanan and Underwood, 2013). Furthermore, generality of conclusions drawn by patterns across species can be higher than those of intraspecific case studies. One disadvantage of interspecific studies, potential phylogenetic interferences, can be moderated by using numerous species with high degree of relationship.

The effect of interspecific differences in plant size on herbivores, their natural enemies and pollinators has never been studied comprehensively under standardised conditions up to now. In this study, we compared 21 brassicaceous plant species of different size regarding species richness of associated herbivores, natural enemies and pollinators. We experimentally 
standardised habitat and landscape characteristics in a common garden experiment, avoiding variable influences on plant size by fertilisation or interspecific competition and differences in the species pool of potentially colonising organisms. All these factors typically confound comparisons in field studies, but have been avoided here by testing the ecological significance of interspecific plant size along a broad gradient in an experimentally standardised approach. We further accounted for component characteristics and resource availability when appropriate to disentangle their effects from those of plant size. The following hypotheses are tested:

(1) Species richness of herbivores increases with plant size. This is also true for (1.1) ectophagous and (1.2) endophagous herbivores and for herbivores associated with single plant components, namely (1.3) leaves and (1.4) fruits. Further, species richness of herbivores is positively affected by component availability (biomass and number of leaves and fruits).

(2) Species richness of natural enemies increases with plant size and prey/host availability. This is likewise true for species richness of natural enemies of (2.1) ectophagous and (2.2) endophagous herbivores and for species richness of natural enemies of herbivores associated with single plant components, namely leaves (2.3) and fruits (2.4).

(3) Species richness of pollinating insects increases with plant size, while also flower characteristics, namely number, biomass and colour, contribute to the explanation of differences in pollinator species richness.

(4) The overall effects of plant size on species richness of herbivores, their natural enemies and pollinators are all positive, while these effects regarding herbivores and pollinators are more pronounced in comparison to natural enemies of herbivores, as they directly depend on the plant as resource.

\section{MATERIAL AND METHODS}

\section{Study site and sampling design}

The study site was located in Göttingen (Lower Saxony, Germany) in a grassland with different brassicaceous herbs. We chose 25 Brassicaceae species covering a plant size gradient and established a common garden experiment in summer 2010. Plant species which 
could not be brought to full flowering between mid-June and mid-July 2010 were excluded from the data set to avoid phenological differences in the local insect community of the study area. The remaining 21 plant species covered a plant size gradient from $12.65 \mathrm{~cm} \pm 1.05 \mathrm{~cm}$ (Diplotaxis muralis (L.) DC.) to $120.50 \mathrm{~cm} \pm 2.95 \mathrm{~cm}$ (Raphanus sativus L. oleiformis). Chosen species have many features in common such as the family typical flower shape, secondary plant substances (glucosinolates) and pollination ecology, since insect pollination increases their seed set (http://www.floraweb.de, last visited January 2014). All species are annuals, wide-spread in Germany and belong to either indigenous weeds (nine species), cultivated plants (eight species) or neophytes (four species). The common garden experiment consisted of 100 plots with a size of $1 \mathrm{~m}^{2}$ and a distance of $30 \mathrm{~cm}$ to each other (for a photo of the experimental site see Supplemental material Figure S1). Four plots per plant species were established in monoculture in a completely randomised design. All plots were once fertilised (NPK fertiliser with the ratio of 15:6:12) and regularly irrigated and weeded. Plants were managed in their density to not exceed plot borders and to reach a plant cover about $100 \%$ of the plot until the time of full blossom. The plot based approach led to a standardisation of plant area (i.e. area covered by a certain plant species) and thereby to the possibility to disentangle effects of plant area from effects of plant size (measured as height). This approach further implied an inverse correlation of plant density per plot and plant size, representing a common effect under natural conditions ("self-thinning rule").

\section{Arthropod surveys}

Free living arthropods on the different plant components (flowers, fruits, stems and leaves) were assessed from five randomly chosen and individually marked plant individuals per plot once at its time of full blossom. Flower visiting Hymenoptera, Diptera and Lepidoptera were thereby omitted and separately sampled (see below). Parasitised animals, such as mummified aphids or cabbage moth pupae, were collected alive and parasitoids were reared.

To assess endophagous arthropods we harvested all leaves of plant individuals from one quarter of every plot, counting the respective plant individuals, and also harvested the stems of five randomly selected plant individuals per plot. The harvest of leaves and stems took place at the time of early ripening for each plot. Thereby the five individually marked plant individuals were excluded from this sampling so that they could develop pods, which we 
harvested at the time of full ripening of each plot to assess their endophagous arthropods. All free living arthropods from collected fruits, stems and leaves were removed with exception of larvae and eggs of Aleyrodes proletella L., which can be easily overlooked in the field and are ecologically close to endophagous arthropods with regard to their host plant choice (their egglaying mother chooses their host plant which they generally are not able to leave). Animals from collected leaves and fruits were reared, while stems of first and second order were dissected and animals collected.

All animals (ectophagous and endophagous) were identified to species level and classified into herbivores, natural enemies and others based on the stage at which animals were observed in the field. We added the parasitised herbivores to the dataset, based on parasitoidhost relationship from literature. Species richness of herbivores and natural enemies was calculated for five plant individuals per plot, either by pooling animals of the five plant individuals or, in the case of leaf associated endophagous arthropods, by rarefying species richness to five plant individuals using the vegan-package in R (Oksanen et al., 2011). Subsets of the dataset were then created for ectophagous and endophagous herbivores and their natural enemies separately, and for herbivores associated with leaves and fruits (as the two best sampled plant components in our study) and their natural enemies.

Flower visiting Hymenoptera, Diptera and Lepidoptera were sampled thrice on every plot at its time of full blossom during a $5 \mathrm{~min}$. observation period and a net $5 \mathrm{~min}$. catching period (handling time not included). Pollinators were identified as accurately as possible without disturbance during the observation period, while during the catching period we caught every pollinator that could not immediately be identified to species level for later identification. Pollinators from the three runs were pooled for each plot and pollinator species richness per plot was calculated including both periods.

\section{Plant traits}

During the specific period of full blossom of each plot we recorded plant size (height from the ground to the top of the plant), number of flowers and leaves and their size (petal length in $\mathrm{mm}$, area of the lowest living leaf per plant in $\mathrm{cm}^{2}$ ) of five randomly selected plant individuals for each plot. Number and size of fruits (length times width in $\mathrm{mm}^{2}$ ) was recorded at the five 
randomly selected plant individuals of each plot at the time of full ripening. To assess the biomass of the different components we collected all flowers, leaves and fruits of all plant individuals in one quarter of every plot (in the case of flowers of two randomly selected plots per plant species) and counted harvested plant individuals. Harvest of flowers took place at the time of full blossom of each plot, harvest of leaves at the time of early ripening and harvest of fruits at the time of full ripening, but not before arthropod samplings. Plant individuals with harvested components were excluded from further observations, e.g. harvest of fruits was not performed on plant individuals whose flowers have already been collected. Collected plant components were oven-dried for $48 \mathrm{~h}$ at $60{ }^{\circ} \mathrm{C}$ before dry biomass was assessed.

Averages of plant size and size of flowers, leaves and fruits were calculated for each plot. Because herbivores and natural enemies were surveyed on five plant individuals per plot, we consequently assessed number of leaves and fruits on these five plant individuals per plot. Likewise biomass of leaves and fruits per five plant individuals was calculated by quintuplicating the mean dry component biomass per plant individual for every plot. Flower parameters were important variables for plotwise sampled pollinators. Therefore we extrapolated number and biomass of flowers to plot level by extrapolating the mean value per plant individual of the relevant plot to the number of its plant individuals (for the two unsampled plots we thereby used the mean flower biomass per plant individual of the sampled plots of the relevant plant species). Flower colour was categorised as yellow or white, dependent on the plant species.

\section{Statistics}

Linear mixed effects models integrated in the nlme R package (Pinheiro et al., 2011) of R version 2.12.2 (R Development Core Team, 2011) were used to test the effects of plant size on species richness of plant associated arthropods. The total species richness of herbivores, species richness of endophagous and ectophagous herbivores and species richness of herbivores associated with fruits and leaves of five plant individuals of every plot were utilised as response variables. We used plant size as explanatory variable and added in the case of herbivore species richness of fruits and leaves the number and biomass of the relevant plant component per five plant individuals of every plot and all two-way interactions as 
covariables. Plant species was included as random effect in each model to account for the non-independence of the four plots per plant species. To test the effect of plant size on species richness of natural enemies of five plant individuals per plot, we proceeded analogously and added the relevant species richness of herbivores of five plant individuals of every plot (in total, endophagous, ectophagous, of fruits or leaves) and all two-way interactions as additional covariables. To test the effect of plant size on pollinator species richness per plot, we used linear mixed effects models with the covariates flower number per plot, flower biomass per plot and flower colour with all two way interactions as explanatory variables and plant species as random effect. All covariables regarding component characteristics and resource availability were added to the models to disentangle their effects from effects of plant size and to account for potential species specific differences in these characteristics.

As some explanatory variables of different models were not independent of each other (Table 1), we tested the variance inflation factor for every model of this study using the HHpackage of R (Heiberger, 2009). Since the covariance of explanatory variables did not exceed considerably the value of 3 for the variance inflation factor in the models (the model testing influences on natural enemy species richness of leaves exceeded the value of 3 as the only model by 0.5 ), the parallel use of the explanatory variables in the models was statistically sound (Zuur et al., 2010). The additional incorporation of component size would have raised the variance inflation factor significantly and was correlated to several other plant characteristics (Supplemental material Table S2). We used log- or square-roottransformations of variables or standard classes of variance function structures implemented in the nlme-package of $\mathrm{R}$ whenever necessary to avoid heteroscedasticity and non-normal error distribution. AICc values were compared of simplified models with all possible combinations of the full model variables using the dredge function incorporated in the MuMIn package of $\mathrm{R}$ (Barton, 2011). The models with the lowest AICc in a delta 2 range were averaged to obtain parameter weights for every explanatory variable (Burnham and Anderson, 2002; Grueber et al., 2011). Given the covariance of explanatory variables we used parameter weights rather than p-values for the detection of variables which explain a significant part of the response variance. Since dependences between explanatory variables were partly strong, every explanatory variable with a parameter weight exceeding the value of 0.5 will be discussed as important for the response variable. We extracted centred and standardised estimates and standard errors for improved interpretability (Schielzeth, 2010) 
from the summary table of the model with the lowest AICc including all important (parameter weight $\geq 0.5$ ) explanatory variables.

In order to compare the overall effects of plant size on species richness of herbivores, their natural enemies and pollinators, we calculated additional linear mixed effects models (species richness with square-root-transformation, plant species as random effect) and extracted slopes from the summary table as well as conditional and marginal $\mathrm{R}^{2}$ using the $1 \mathrm{mmR} 2$ function incorporated in the lmmfit package of R (Maj, 2011).

Finally, we used the common unconstrained ordination method of non-metric multidimensional scaling (NMDS) (Minchin, 1987; Oksanen et al., 2011) to detect a potential interrelation between plant size and the community composition of plant associated arthropods. The matrix of arthropod species and plant species (based on presence absence data of herbivores, their natural enemies and pollinators per plant species, Jaccard dissimilarity) was calculated independently of plant size. Then, the p-value of interrelation between the matrix and plant size was computed by 1000 permutations. 
Table 1. Correlations among explanatory variables. Species richness $=S R$, herbivores $=H$. Pearson correlation coefficients and levels of significance are given with $* \mathrm{p}<0.05, * * \mathrm{p}<0.01$ and $* * * \mathrm{p}<$ 0.001 . Number and biomass of flowers refer to plot level, while number and biomass of leaves and fruits and species richness of herbivores refer to five plant individuals per plot. Number and biomass of flowers, fruits and leaves were log-transformed, species richness of leaf herbivores was sqrttransformed. Not tested combinations of variables are marked as grey cells.

\begin{tabular}{|c|c|c|c|c|c|c|c|c|}
\hline & 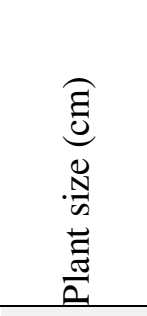 & 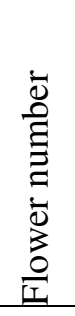 & 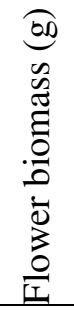 & 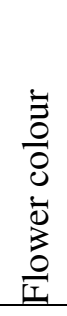 & 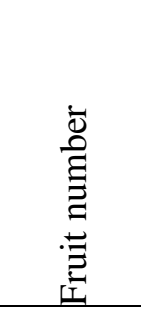 & 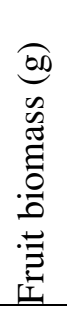 & 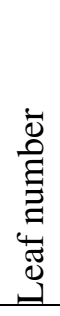 & 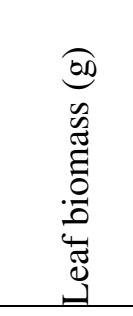 \\
\hline Plant size $(\mathrm{cm})$ & & $\mathrm{ns}$ & $\mathrm{ns}$ & ns & $-0.48^{*}$ & $\mathrm{~ns}$ & ns & $0.63^{* *}$ \\
\hline Flower number & ns & & $\mathrm{ns}$ & ns & & & & \\
\hline Flower biomass (g) & ns & $\mathrm{ns}$ & & ns & & & & \\
\hline Flower colour & ns & ns & $\mathrm{ns}$ & & & & & \\
\hline Fruit number & $-0.48 *$ & & & & & $\mathrm{~ns}$ & & \\
\hline Fruit biomass (g) & ns & & & & ns & & & \\
\hline Leaf number & ns & & & & & & & ns \\
\hline Leaf biomass $(\mathrm{g})$ & $0.63 * *$ & & & & & & ns & \\
\hline H SR leaves & $0.74 * * *$ & & & & & & ns & $0.79 * * *$ \\
\hline H SR fruits & $0.53 *$ & & & & $-0.62 * *$ & $\mathrm{~ns}$ & & \\
\hline H SR & $0.75 * * *$ & & & & & & & \\
\hline Endophagous H SR & $0.80 * * *$ & & & & & & & \\
\hline Ectophagous H SR & $0.66^{* *}$ & & & & & & & \\
\hline
\end{tabular}

\section{RESULTS}

We recorded overall 13,449 herbivores of 24 species (arithmetic mean \pm SE: $5.37 \pm 0.28$ species per five plant individuals), 1758 natural enemies of 56 species $(3.13 \pm 0.25$ species per five plant individuals) and 3538 pollinators of 79 species $(8.49 \pm 0.43$ species per plot) (see Supplemental material Table S3 for all; see Supplemental material Table S4 for a list of observed species). Among herbivores, we sampled $2.25 \pm 0.18$ endophagous species per five plant individuals (1.98 \pm 0.20 natural enemy species of endophagous prey or hosts) and $3.80 \pm$ 0.21 ectophagous species per five plant individuals $(1.15 \pm 0.13$ natural enemy species of endophagous prey or hosts). $2.89 \pm 0.21$ herbivore species were found in and on leaves (1.01 \pm 0.13 natural enemy species) and $1.36 \pm 0.10$ herbivore species in and on fruits of five plant individuals $(1.71 \pm 0.17$ natural enemy species $)$. 
Plant size had a positive effect on species richness of the plant herbivores and their natural enemies (Figure 1a-b, Table 2a), while species richness of natural enemies was additionally positively affected by herbivore species richness (Figure 1c, Table 2a). Thus, data collected in the field on respectively five plant individuals per plot showed similar pattern as estimated species richness of herbivores per plant species (as it is hypothesised to be under ideal sampling intensity), which likewise increased with increasing plant size (Supplemental material S5). Estimated species richness of natural enemies per plant species was positively affected by estimated herbivore species richness (Supplemental material S5). Plant size also had a positive impact on pollinator species richness at plot level, which was enhanced by increasing flower biomass (Figure 1d, Table $2 \mathrm{~b}$ ) and additionally increased with increasing flower number (Figure 1e, Table 2b). Flower colour (yellow/white) had no effect on species richness of flower visiting pollinators.

The positive effect of plant size on species richness of herbivores and natural enemies was also true for ectophagous and endophagous herbivores and their natural enemies (Figure 2a-b, d-e, Table 2a). Species richness of natural enemies additionally increased with increasing herbivore species richness (Figure 2c, f, Table 2a).

Focusing on single plant components, namely leaves and fruits, plant size remained an important driver of species richness of associated herbivores and their natural enemies. Species richness of leaf associated herbivores increased with increasing plant size and leaf biomass (Figure 3a-b, Table 3), while number of leaves had no effect on species richness of herbivores (Table 3). Species richness of their natural enemies increased with increasing plant size and herbivore species richness (Figure $3 \mathrm{c}-\mathrm{d}$, Table 3 ) and was unaffected by biomass and number of leaves (Table 3). Species richness of fruit associated herbivores increased with increasing plant size, decreased with increasing fruit number and remained unaffected by fruit biomass (Figure 4a-b, Table 4). The positive effect of plant size on species richness of their natural enemies was enhanced by increasing fruit biomass, while the number of fruits had a negative effect (Figure 4c-d, Table 4). Here again, herbivore species richness had a positive effect on species richness of natural enemies (Figure 4e, Table 4).

Comparing the overall effects of plant size on species richness of herbivores, their natural enemies and pollinators (all p-values $<0.0001$ ), we found similar slopes (herbivores: 0.010, their natural enemies: 0.013, pollinators: 0.012) and a higher conditional $\mathrm{R}^{2}$ in case of 
herbivores and pollinators compared to natural enemies (conditional $\mathrm{R}^{2}$ of herbivores: 0.739 , their natural enemies: 0.627 , pollinators: 0.725 ; marginal $\mathrm{R}^{2}$ of herbivores: 0.417 , their natural enemies: 0.403 , pollinators: 0.262 ).

Despite these effects of plant size on species richness of different groups of associated organisms, we could not detect any effect of plant size on community composition of plant associated arthropods using NMDS (stress-value $=0.180 ;$-value $=0.104$ ) 

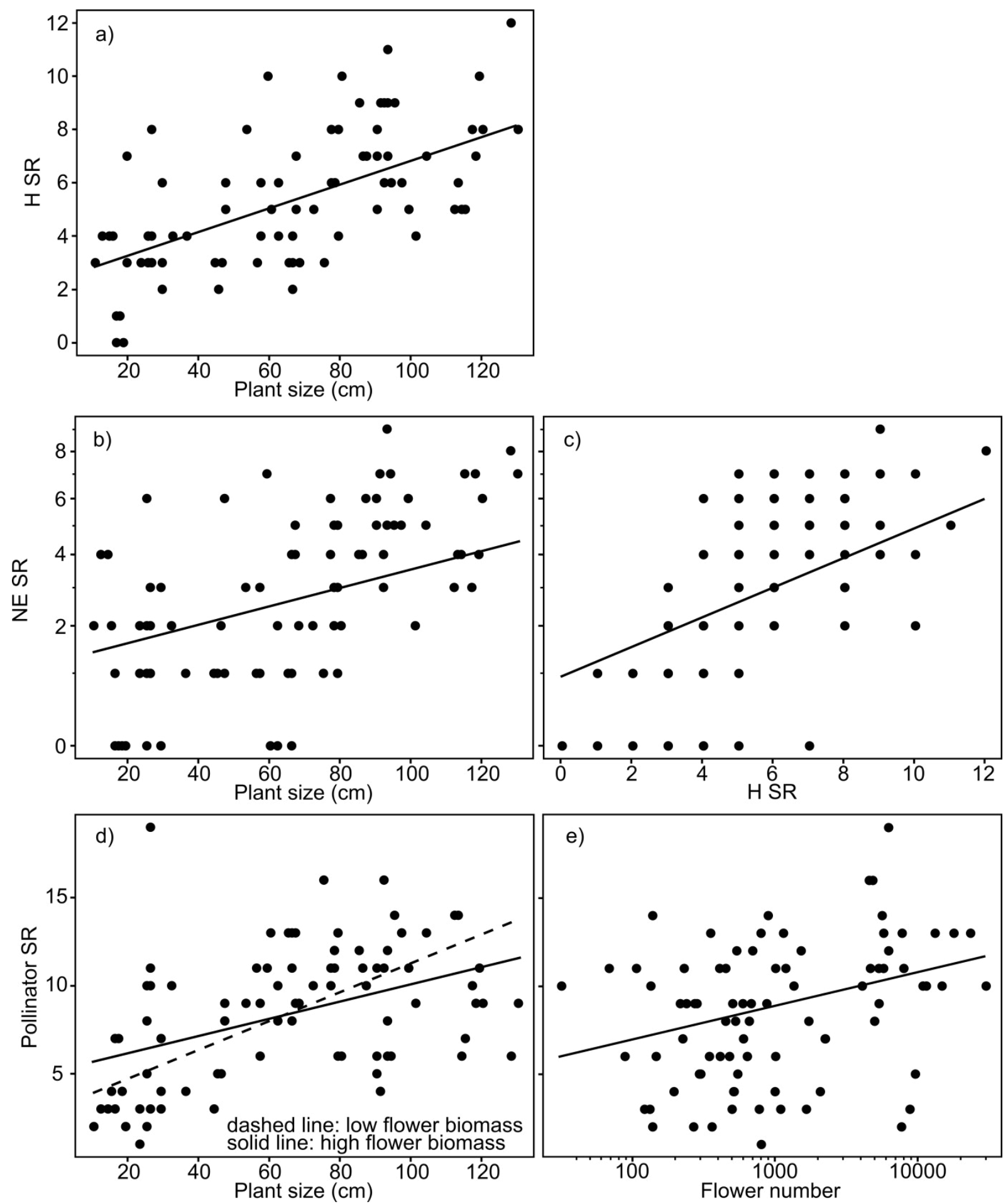

Figure 1. Effects of plant size on species richness of a) herbivores, b) their natural enemies and d) pollinators. Additionally, effects of important covariables representing the amount of food resource for c) natural enemies and for e) pollinators are shown. $\mathrm{SR}=$ species richness, $\mathrm{H}=$ herbivores, $\mathrm{NE}=$ natural enemies. Number of flowers and species richness of pollinators refer to plot level, while species richness of herbivores and natural enemies refer to five plant individuals per plot. Axes of variables were transformed corresponding to analyses (flower number: log-transformation; species richness of natural enemies: sqrt-transformation). Predictions derive from the lme-model with the lowest AICc including all explanatory variables with a parameter weight $\geq 0.5$. To visualise interactions of two continuous explanatory variables (d), we converted one of them into a categorical variable, using the medians of the upper and the lower half of the data (dashed line: low flower biomass $=13 \mathrm{~g}$, solid line: high flower biomass $=38 \mathrm{~g}$ ). 

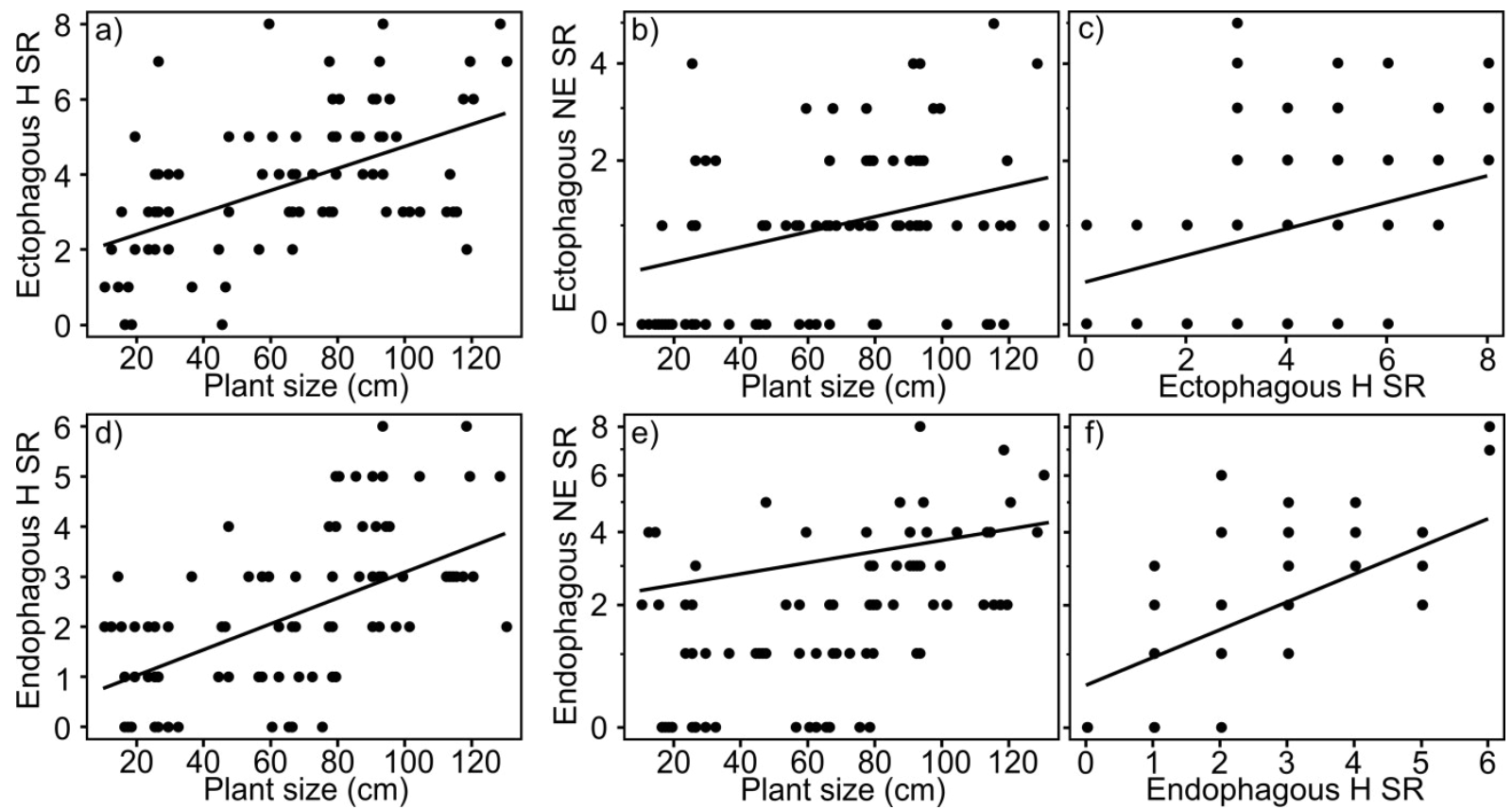

Figure 2. Effects of plant size on species richness of a) ectophagous and d) endophagous herbivores and of $\mathbf{b}$, e) their respective natural enemies. c, f) Additionally, effects of important covariables representing the amount of food resource for natural enemies are shown. $\mathrm{SR}=$ species richness, $\mathrm{H}=$ herbivores, $\mathrm{NE}=$ natural enemies. Species richness of herbivores and natural enemies refer to five plant individuals per plot. Axes of variables were transformed corresponding to analyses (species richness of natural enemies: sqrt-transformation). Predictions derive from the lme-model with the lowest AICc including all explanatory variables with a parameter weight $\geq 0.5$. 

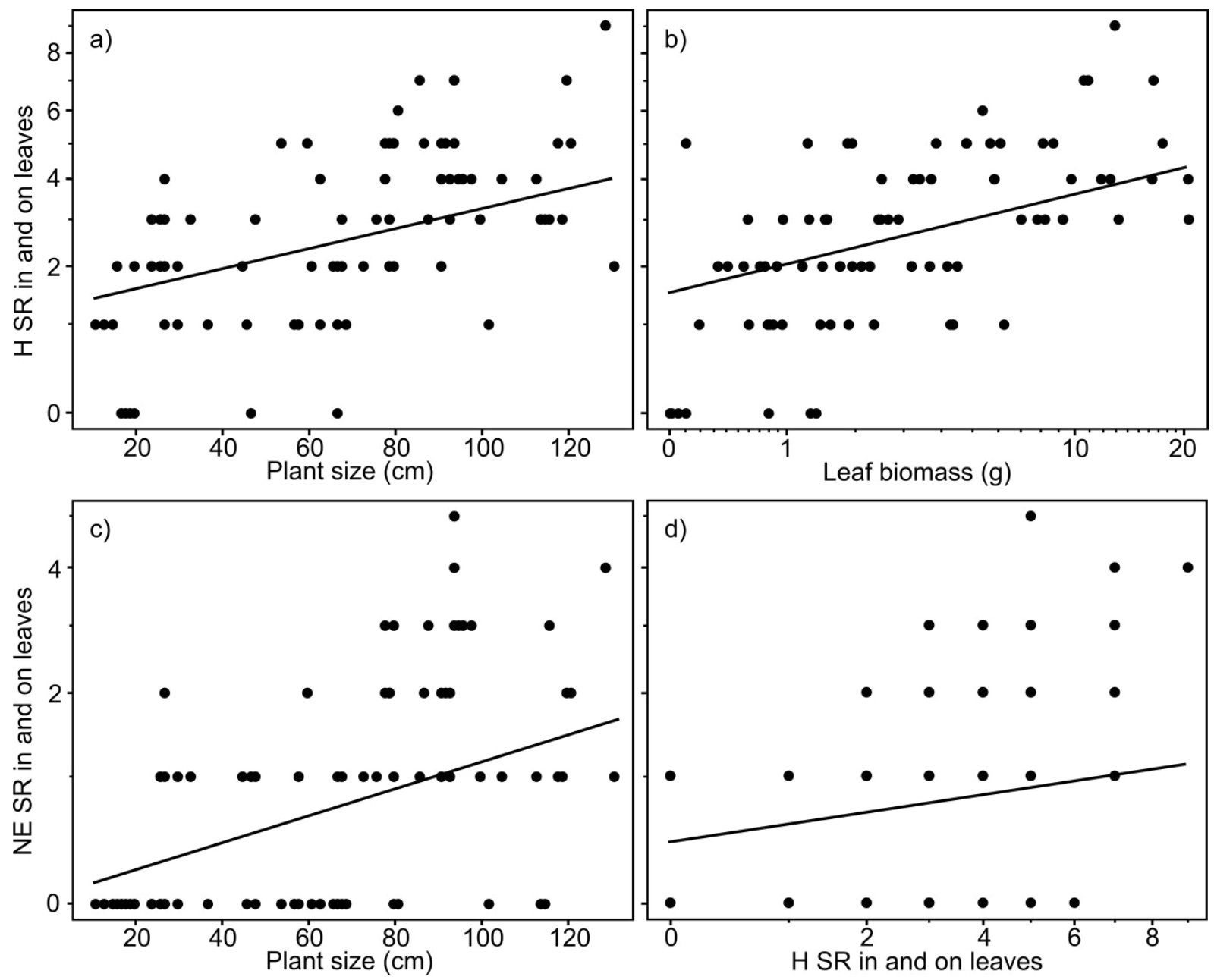

Figure 3. Effects of plant size on species richness of a) leaf associated herbivores and c) their natural enemies. Additionally, effects of important covariables representing the amount of food resource for b) herbivores and for d) their natural enemies are shown. $\mathrm{SR}=$ species richness, $\mathrm{H}=$ herbivores, $\mathrm{NE}=$ natural enemies. Leaf biomass as well as species richness of herbivores and natural enemies refer to five plant individuals per plot. Axes of variables were transformed corresponding to analyses (species richness of leaf associated herbivores and species richness of their natural enemies: sqrttransformation, leaf biomass: log-transformation). Predictions derive from the lme-model with the lowest AICc including all explanatory variables with a parameter weight $\geq 0.5$. 


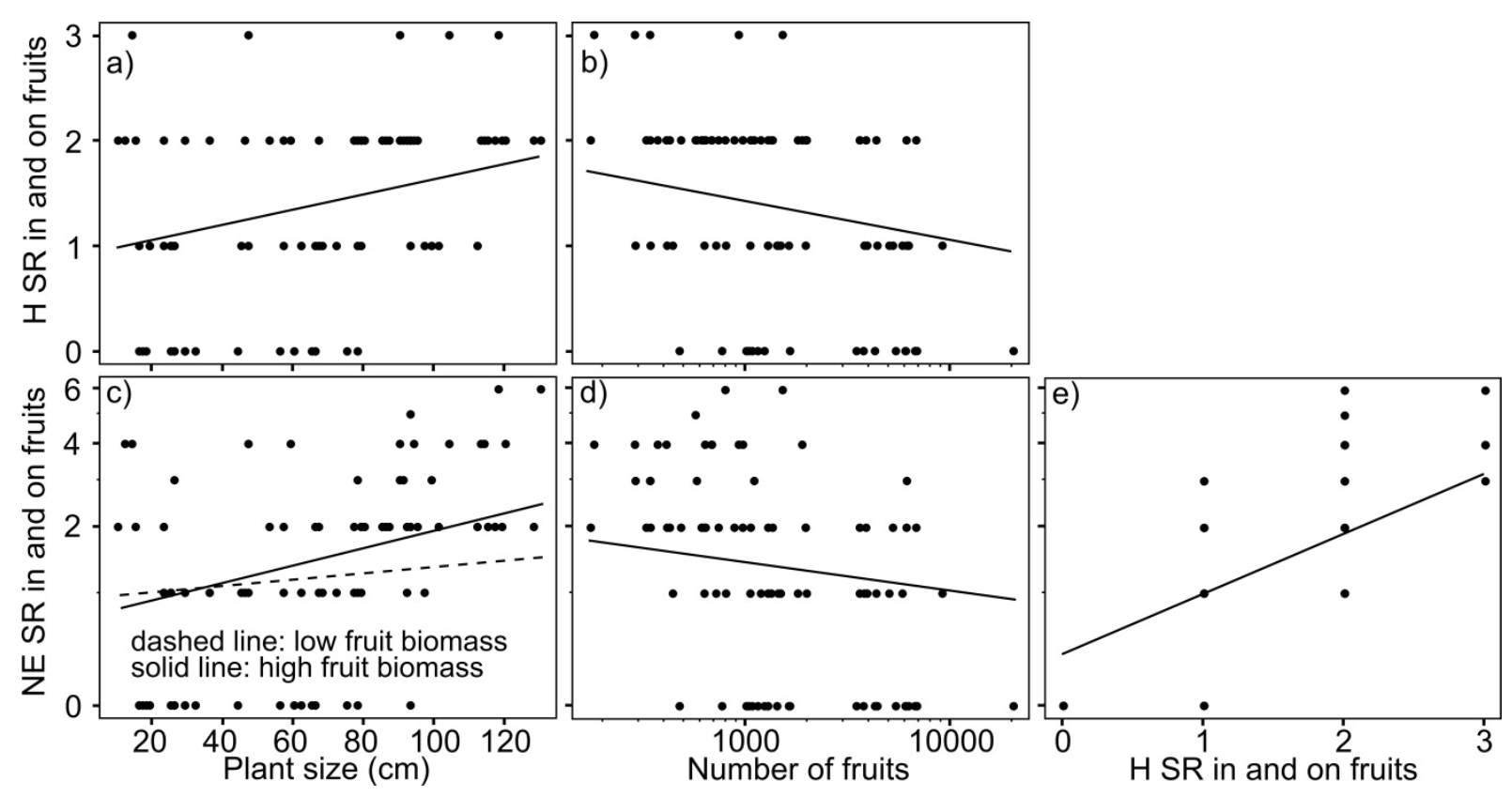

Figure 4. Effects of plant size on species richness of a) fruit associated herbivores and c) their natural enemies. Additionally, effects of important covariables representing the amount of food resource for b) herbivores and for d-e) their natural enemies are shown. $\mathrm{SR}=$ species richness, $\mathrm{H}=$ herbivores, $\mathrm{NE}$ = natural enemies. Number of fruits and species richness of herbivores and natural enemies refer to five plant individuals per plot. Axes of variables were transformed corresponding to analyses (species richness of natural enemies and number of fruits: log-transformation). Predictions derive from the lmemodel with the lowest AICc including all explanatory variables with a parameter weight $\geq 0.5$. To visualise interactions of two continuous explanatory variables (c), we converted one of them into a categorical variable, using the medians of the upper and the lower half of the data (dashed line: low fruit biomass $=9.20 \mathrm{~g}$, solid line: high fruit biomass $=39.38 \mathrm{~g}$ ). 


\begin{tabular}{|c|c|c|c|c|}
\hline & & 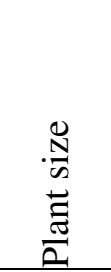 & $\begin{array}{l}\widetilde{\alpha} \\
\widetilde{\Omega} \\
I\end{array}$ & 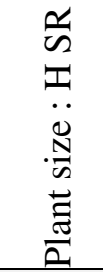 \\
\hline \multirow[t]{3}{*}{$\overline{\mathrm{H} \mathrm{SR}}$} & pw & 1.000 & & \\
\hline & est. & 1.491 & & \\
\hline & SE & 0.319 & & \\
\hline \multirow[t]{3}{*}{ Ectophagous } & pw & 1.000 & & \\
\hline & est. & 0.986 & & \\
\hline & $\mathrm{SE}$ & 0.260 & & \\
\hline \multirow[t]{3}{*}{ Endophagous } & pw & 1.000 & & \\
\hline & est. & 0.866 & & \\
\hline & SE & 0.211 & & \\
\hline \multirow[t]{3}{*}{ NE SR } & pw & 1.000 & 1.000 & 0.000 \\
\hline & est. & 0.240 & 0.292 & - \\
\hline & SE & 0.076 & 0.069 & - \\
\hline \multirow[t]{3}{*}{ Ectophagous } & pw & 1.000 & 1.000 & 0.000 \\
\hline & est. & 0.142 & 0.142 & - \\
\hline & SE & 0.058 & 0.055 & - \\
\hline \multirow[t]{3}{*}{ Endophagous } & pw & 0.760 & 1.000 & 0.022 \\
\hline & est. & 0.143 & 0.338 & - \\
\hline & SE & 0.065 & 0.046 & - \\
\hline
\end{tabular}

Table 2a. Effects of plant size and covariables on species richness $(\mathrm{SR})$ of herbivores $(\mathrm{H})$ and their natural enemies (NE). Species richness of herbivores and natural enemies refer to five plant individuals per plot. Species richness of natural enemies (in total and of ectophagous vs endophagous prey/hosts) were sqrttransformed. Parameter weights (pw) refer to a delta 2 AICc range. Explanatory variables and interactions with a parameter weight $\geq 0.5$ (bold) were defined as important for the relevant response variable and are discussed. Estimates (est.) with standard errors (SE) were assessed from the summary table of the lmemodel with the lowest AICc including all explanatory variables with a parameter weight $\geq 0.5$ and are centred and standardised to improve their interpretability. Variables which were not involved in the relevant full model are marked as grey cells.

Table 2b. Effects of plant size and covariables in species richness (SR) of pollinators. Number and biomass of flowers and species richness of pollinators refer to plot level. Number and biomass of flowers were log-transformed. For further information see caption of Table 2a.

\begin{tabular}{|c|c|c|c|c|c|c|c|c|c|c|c|}
\hline & & 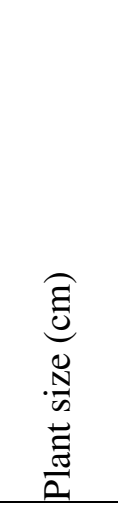 & 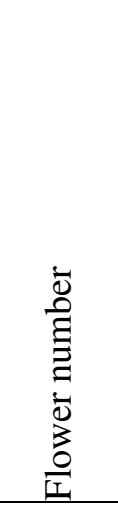 & 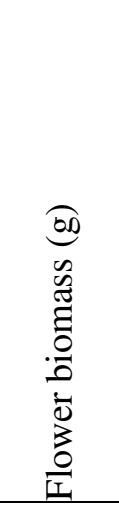 & $\begin{array}{l}\bar{\Xi} \\
\frac{0}{0} \\
0 \\
\overline{0} \\
\overline{0} \\
\frac{0}{\Sigma}\end{array}$ & 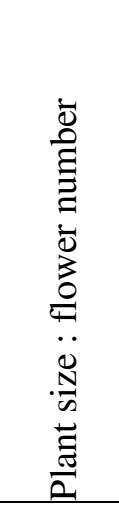 & 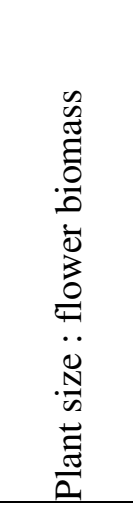 & 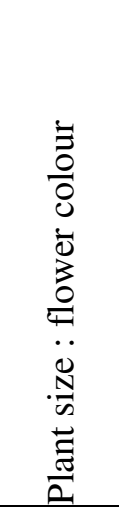 & 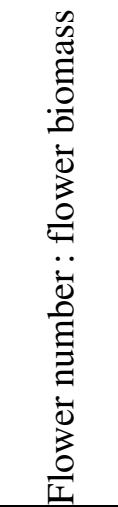 & 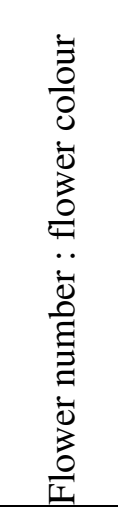 & 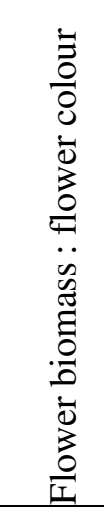 \\
\hline \multirow[t]{3}{*}{ Pollinator SR } & pw & 1.000 & 1.000 & 0.820 & 0.160 & 0.150 & 0.680 & 0.000 & 0.000 & 0.000 & 0.000 \\
\hline & est. & 2.230 & 1.304 & 0.040 & - & - & -0.934 & - & - & - & - \\
\hline & SE & 0.444 & 0.424 & 0.490 & - & - & 0.481 & - & - & 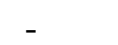 & - \\
\hline
\end{tabular}


Table 3. Effects of plant size and covariables on species richness (SR) of leaf associated herbivores $(\mathrm{H})$ and their natural enemies $(\mathrm{NE})$. Number and biomass of leaves and species richness of herbivores and natural enemies refer to five plant individuals per plot. Number and biomass of leaves were log-transformed, species richness of leaf associated herbivores and of their natural enemies were sqrt-transformed. For further information see caption of Table 2a.

\begin{tabular}{|c|c|c|c|c|c|c|c|c|c|c|c|}
\hline & & 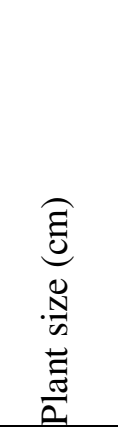 & 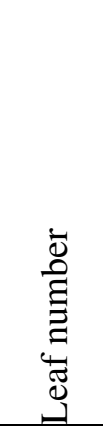 & 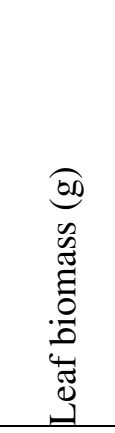 & 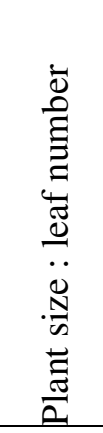 & 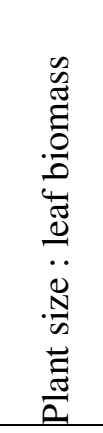 & 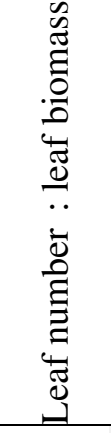 & $\begin{array}{l}\frac{v}{v} \\
I\end{array}$ & 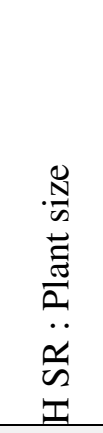 & 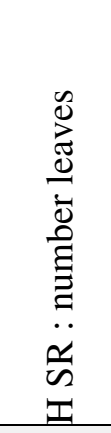 & 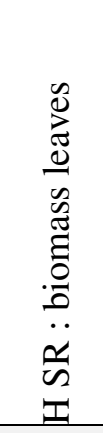 \\
\hline \multirow[t]{3}{*}{ H SR leaves } & pw & 1.000 & 0.000 & 1.000 & 0.000 & 0.000 & 0.000 & & & & \\
\hline & est. & 0.212 & - & 0.210 & - & - & - & & & & \\
\hline & $\mathrm{SE}$ & 0.068 & - & 0.061 & - & - & - & & & & \\
\hline \multirow[t]{3}{*}{ NE SR leaves } & pw & 1.000 & 0.000 & 0.340 & 0.000 & 0.000 & 0.000 & 1.000 & 0.000 & 0.000 & 0.000 \\
\hline & est. & 0.202 & - & - & - & - & - & 0.079 & - & - & - \\
\hline & $\mathrm{SE}$ & 0.058 & - & - & - & - & - & 0.040 & - & - & - \\
\hline
\end{tabular}

Table 4. Effects of plant size and covariables on species richness (SR) of fruit associated herbivores $(\mathrm{H})$ and their natural enemies (NE). Number and biomass of fruits and species richness of herbivores and natural enemies refer to five plant individuals per plot. Number and biomass of fruits and species richness of fruit associated natural enemies were logtransformed. For further information see caption of Table 2a.

\begin{tabular}{|c|c|c|c|c|c|c|c|c|c|c|c|}
\hline & & 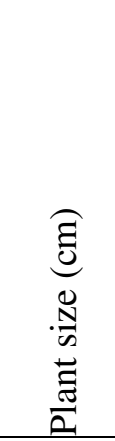 & 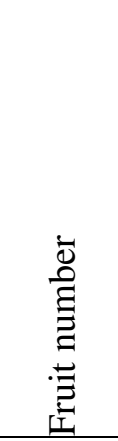 & 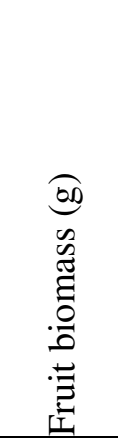 & 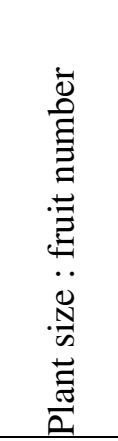 & 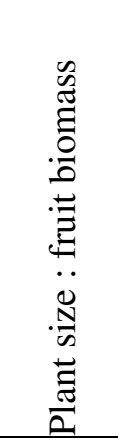 & 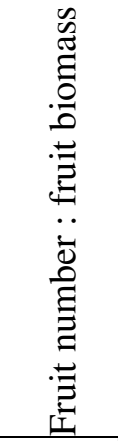 & $\begin{array}{l}\widetilde{1} \\
\widetilde{\sim} \\
I\end{array}$ & 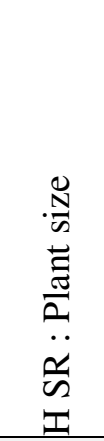 & 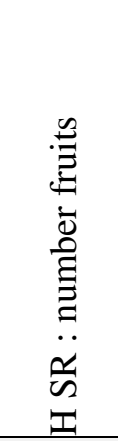 & 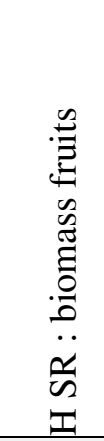 \\
\hline \multirow[t]{3}{*}{ H SR fruits } & pw & 0.750 & 0.750 & 0.240 & 0.130 & 0.000 & 0.000 & & & & \\
\hline & est. & 0.242 & -0.165 & - & - & - & - & & & & \\
\hline & SE & 0.130 & 0.112 & - & - & - & - & & & & \\
\hline \multirow[t]{3}{*}{ NE SR fruits } & pw & 1.000 & 0.610 & 0.720 & 0.090 & 0.530 & 0.000 & 1.000 & 0.090 & 0.000 & 0.000 \\
\hline & est. & 0.126 & -0.079 & 0.070 & - & 0.069 & - & 0.324 & - & - & - \\
\hline & SE & 0.055 & 0.046 & 0.042 & - & 0.038 & - & $\mathbf{0 . 0 3 7}$ & - & - & - \\
\hline
\end{tabular}




\section{DiSCUSSION}

In broad support of our three hypotheses' core, plant size had a positive impact on species richness of plant associated herbivores (first hypothesis), natural enemies (second hypothesis) and pollinators (third hypothesis). As community composition of associated arthropods (based on presence-absence data) did not change significantly with plant size, occurrence of single species was not significantly determined by the size of the plants. Consequently, higher arthropod species richness of large plants was rather attributable to higher abundance (following attractiveness and conspicuousness of large plants to individuals of the different arthropod species) than to the recruitment of more species with a specialisation on large plants. The likelihood of being found and colonised by associated arthropod species increases with increasing plant size due to increasing conspicuousness and a wider range of resources and niches of large plants (Feeny, 1976; Lawton, 1983). Studies showing an increase in insect species richness with increasing plant size focused generally on herbivores (Haysom and Coulson, 1998; Lawton and Price, 1979; Neuvonen and Niemelä, 1981), rarely on parasitoids (Hawkins et al., 1990) and, to the best of our knowledge, never on species richness of predators. As natural enemy species, parasitoids and predators, often depend on specific prey species, high species richness of herbivorous insects promotes species richness of natural enemies (Hunter and Price, 1992; Knops et al., 1999), which is supported by our findings of a positive effect of herbivore species richness on species richness of their natural enemies throughout all analyses. Predators and parasitoids locate their prey and hosts via direct, e.g. olfactorial, cues or in an indirect way e.g. by choosing the habitat of their prey or host, often in a combination of both (Hodek, 1993; Williams and Cook, 2010). As shown by our results, not only the herbivorous prey and hosts, but also plant characteristics like plant size can therefore influence the species richness of natural enemies, parasitoids and predators, since large plants may offer highly conspicuous microhabitats for their prey or hosts.

Size of plants is shown to be of interest for pollinators when intraspecific variability is high (Geber 1985, Donnelly et al. 1998, Gómez 2003, but see Klinkhamer et al. 1989). Petals of flowers have little other purpose than to attract optically pollinating animals, and their attractiveness should be enhanced by a position superior to other flowers (Cohen and Shmida, 1993). Plant size therefore can play an important role in plants with inflorescences located at the very top of the plant, like in the tested Brassicaceae, where flowers of large plants were more exposed than those of small plants. Flower characteristics were additional important 
determinants of pollinator species richness. Flower number had a positive influence on pollinator species richness, as numerous flowers not only support the flowers' conspicuousness to pollinators, but additionally provide a wide offer of pollen and nectar resources with low foraging distances between flowers and a low competition among pollinators (Klinkhamer et al., 1989; Ohashi and Yahara, 2002). The generally positive effect of plant size on pollinator species richness was weaker on plants with high flower biomass than on plants with low flower biomass. High flower biomass combined the positive effects of flower number and flower size. Large flowers are not only highly conspicuous but also attractive to pollinators as they often signal high production of nectar and pollen (Cohen and Shmida, 1993 and studies cited therein; Hegland and Totland, 2005). High flower biomass weakened the positive effect of plant size on pollinator species richness, suggesting that the conspicuousness and attractiveness of plants with high flower biomass was already high and was only weakly increased by a high position on the flowers due to high plant size. Although single species of pollinators can have flower colour preferences for e.g. yellow (Kay, 1976), flower colour (yellow vs. white, i.e. without considering other characteristics such as UV signals) turned out to have no effect on pollinator species richness in this study.

Comparing the slopes and magnitudes of the overall positive effects of plant size on species richness of herbivores, their natural enemies and pollinators, we found similar slopes and a higher conditional $\mathrm{R}^{2}$ in case of herbivores and pollinators compared to natural enemies. The similarity of slopes supports our idea of an analogy in causes and mechanisms, attractiveness and conspicuousness, of the positive effect of plant size on species richness of the different arthropod groups. The differences in $\mathrm{R}^{2}$ indicate that this positive effect of plant size on species richness is more pronounced in arthropod groups, which directly depend on the plant resource (herbivores and pollinators), in comparison to those with only indirect dependence on the plant (natural enemies of herbivores).

Supporting the subtleties of our first and second hypotheses, the positive effect of plant size on species richness of plant associated arthropods held for both ectophagous and endophagous herbivores and their natural enemies. The response strength was similar for ectophagous and endophagous herbivores, indicating similar mechanisms of host plant choice. Accordingly, some studies found increasing herbivore species richness in endophagous insect larvae with 
increasing plant size (Lawton and Price, 1979; Tscharntke and Greiler, 1995), while other studies showed a positive effect of plant size on ectophagous herbivore species richness (Bach, 1981; Haysom and Coulson, 1998; Neuvonen and Niemelä, 1981). Endophagous larvae have to utilise the host plant their egg-laying mother chose and are not able to switch to another plant, although it may offer a wider range of resources and niches. However, adults of endophagous larvae may prefer large plants because they are conspicuous and likely offer more resources to their offspring leading to a positive effect of plant size on species richness in endophagous species as well.

Natural enemy species richness of both endophagous and ectophagous herbivores increased with increasing plant size, suggesting that large plants are attractive foraging sites for natural enemies. This is in accordance to Hawkins et al. (1990), showing a positive effect of host food plant size on species richness of parasitoids of ectophagous and endophagous hosts. Species richness of natural enemies of ectophagous herbivores (mainly composed of predators) was promoted by herbivore species richness in a similar degree as by plant size, while species richness of natural enemies of endophagous herbivores (composed of parasitoids) was more influenced by their hosts' species richness than by plant size. Parasitoids are usually highly specialised on single herbivore taxa and react sensitively on kairomones of their hosts (Rutledge, 1996; Williams and Cook, 2010), while predators are usually less specialised using a wider range of prey species (Tscharntke and Greiler, 1995; Ulber et al., 2010).

After closer inspection of herbivores on single plant components (leaves and fruits) and their natural enemies, plant size still and consistently had a positive effect on species richness of herbivores and their natural enemies according to hypotheses (1.3-1.4) and (2.3-2.4). Increasing plant size may lead to increased conspicuousness of single plant components, particularly of those positioned at the top of a plant. Given that large plants offer a wider range of resources and niches than small plants (Lawton, 1983), large plants can be highly attractive even to herbivores with interest in components which are hidden inside the vegetation. Accordingly, caterpillar densities on leaves of Calluna vulgaris (L.) HULL were reported to increase with increasing intraspecific plant height (Haysom and Coulson, 1998).

Species richness of leaf-feeding herbivores and their natural enemies was found to be additionally positively influenced by the availability of food resources: herbivores by leaf 
biomass, enemies by herbivore species richness. High leaf biomass indicates large food resources followed by lowered competition among herbivores and can decrease predation risk as dense and complex foliage structure can provide refuge from natural enemies (Lawton, 1983; Riihimaeki et al., 2006).

Similarly, species richness of fruit associated herbivores (exclusively endophagous herbivores) and species richness of their natural enemies (exclusively parasitoids) increased with increasing plant size. Fruit biomass had no influence on species richness of fruit herbivores, while the positive effect of plant size on their parasitoids was reinforced by high fruit biomass, indicating numerous and large fruits. This enhancement of conspicuousness by many and large fruits at the plant's top can be of not only visual, but also of olfactorial nature, as fruits of many plant species contain oils and semiochemicals attracting natural enemies (Murchie et al., 1997; Rutledge, 1996). The mere fruit number was negatively related to species richness of fruit herbivores and their enemies, but it was negatively correlated with fruit size. It is likely that the negative effect of fruit number represented a positive effect of fruit size, as large fruits are highly conspicuous and offer much space and food resources to mining herbivores. Consecutively it seems to be worthwhile for their natural enemies to follow herbivores in the selection of large fruits. Here again we showed a close relation between herbivore species richness and species richness of natural enemies.

\section{CONCLUSiOnS}

Our detailed results of insect species richness along an interspecific plant size gradient in a standardised common garden experiment exhibit a strong pattern: large plants harbour more arthropod species regarding herbivores (whether they are endophagous or ectophagous, associated with leaves or fruits), their natural enemies and pollinators on and in all aboveground plant components than small plants. An increase in plant size from 10 to $130 \mathrm{~cm}$ height led to a triplication in predicted total species richness from nine to 26 associated arthropods (Figure 5). This positive effect of plant size on species richness prevailed even under simultaneous consideration of resource availability for the different functional groups (i.e. component biomass for herbivores, herbivore species richness for natural enemies and number of flowers for pollinators). In general, plant size turned out to be a comprehensive driver of species richness of the arthropod community. These findings are highly relevant as 
they result from a broad gradient in plant size across 21 species of Brassicaceae in a common garden experiment without confounding influences of landscape or habitat. Plant size should be better acknowledged in studies focusing on diversity of arthropod communities associated with plant species and factors driving the structure of these communities. On the other hand, effects of plant size on associated arthropods can have ecological consequences for individual plants, since plant fitness might be affected by size effects on mutualistic and antagonistic interaction partners.

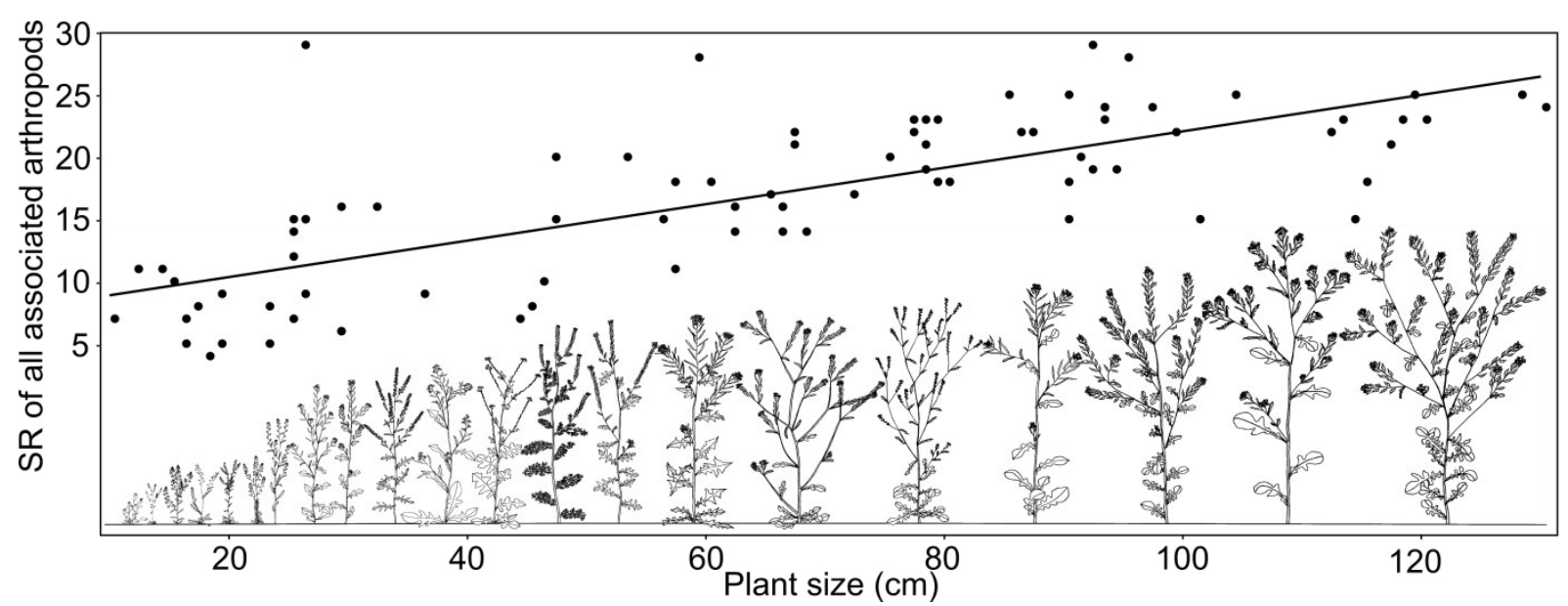

Figure 5. Effects of plant size on total species richness of arthropods. The total species richness of arthropods was calculated by summing up species richness of herbivores and their natural enemies per five plant individuals of every plot and species richness of pollinators per plot. $\mathrm{SR}=$ species richness. Predictions derive from the lme-model with the lowest AICc (single model in a delta AICc range of 2, parameter weight $=1$, standardised and centred estimate $=4.925$, standard error $=0.688$ ). Size of the different plant species of this study is illustrated relative to one another but independent of the $\mathrm{x}$-axis by modified drawings from Schlinkert (2014).

\section{ACKNOWLEDGEMENTS}

Many thanks go to Klaus Hövemeyer, Peter Sprick, Ines Vollhardt and Jochen Fründ for help with identification of collected animals and to Carsten Thies for contribution to the sampling design. We particularly thank Susanne Jahn, Brigitte Jünemann and Ulrike Kierbaum for help in the field and laboratory, further we thank Christiane and Eugen Schlinkert, Verena Rösch, Barbara Scheid, Christina Fischer, Georg Everwand, Jenny Osterburg, Anna-Katharina Franke, Annabelle Rohlfing, Nicola Holm, Petra Kubisch, Felix Steinmeyer, Carina Burmeister and Alexandra Arndt. We further thank Kristy Udy for linguistic improvements of the manuscript. KWS SAAT AG and the botanical gardens of the universities of Bayreuth and 
Göttingen supplied parts of the seeds. H.S. was supported by the Ministry of Science and Culture of Lower Saxony.

\section{REFERENCES}

Araujo, A.P.A., D’arc de Paula, J., Carneiro, M.A.A., Schoereder, J.H., 2006. Effects of host plant architecture on colonization by galling insects. Austral Ecol. 31, 343-348.

Bach, C.E., 1981. Host plant growth form and diversity: effects on abundance and feeding preference of a specialist herbivore, Acalymma vittata (Coleoptera: Chrysomelidae). Oecologia 50, 370-375.

Barton, K., 2011. MuMIn: multi-model inference. R package version 1.5.2. http://CRAN.Rproject.org/package=MuMIn.

Blanckenhorn, W.U., 2000. The evolution of body size: what keeps organisms small? Q. Rev. Biol. 75, 385-407.

Brown, J.H., Maurer, B.A., 1986. Body size, ecological dominance and Cope's rule. Nature $324,248-250$.

Buchanan, A.L., Underwood, N., 2013. Attracting pollinators and avoiding herbivores: insects influence plant traits within and across years. Oecologia 173, 473-82.

Burnham, K.P., Anderson, D.R., 2002. Model selection and multi-model inference: a practical information-theoretic approach, 2nd ed. Springer New York, New York.

Cohen, D., Shmida, A., 1993. The evolution of flower display and reward. Evol. Biol. 27, 197-243.

Crowder, D.W., Jabbour, R., 2014. Relationships between biodiversity and biological control in agroecosystems: Current status and future challenges. Biol. Control 75, 8-17.

Donnelly, S.E., Lortie, C.J., Aarssen, L.W., 1998. Pollination in Verbascum thapsus (Scrophulariaceae): the advantage of being tall. Am. J. Bot. 85, 1618-1625.

Espírito-Santo, M.M., Neves, F.D.S., Andrade-Neto, F.R., Fernandes, G.W., 2007. Plant architecture and meristem dynamics as the mechanisms determining the diversity of gallinducing insects. Oecologia 153, 353-364.

Feeny, P., 1976. Plant apparency and chemical defense, in: Wallace, J.W., Mansell, R.L. (Eds.), Biochemical Interaction Between Plants and Insects. Springer US, New York, pp. $1-40$. 
Geber, M.A., 1985. The relationship of plant size to self-pollination in Mertensia ciliata. Ecology 66, 762-772.

Gómez, J.M., 2003. Herbivory reduces the strength of pollinator-mediated selection in the Mediterranean herb Erysimum mediohispanicum: consequences for plant specialization. Am. Nat. 162, 242-256.

Grueber, C.E., Nakagawa, S., Laws, R.J., Jamieson, I.G., 2011. Multimodel inference in ecology and evolution: challenges and solutions. J. Evol. Biol. 24, 699-711.

Hawkins, B.A., Askew, R.R., Shaw, M.R., 1990. Influences of host feeding-niche and foodplant type on generalist and specialist parasitoids. Ecol. Entomol. 15, 275-280.

Hawkins, B.A., Lawton, J.H., 1987. Species richness for parasitoids of British phytophagous insects. Nature 326, 788-790.

Haysom, K.A., Coulson, J.C., 1998. The Lepidoptera fauna associated with Calluna vulgaris: effects of plant architecture on abundance and diversity. Ecol. Entomol. 23, 377-385.

Hegland, S.J., Totland, Ø., 2005. Relationships between species' floral traits and pollinator visitation in a temperate grassland. Oecologia 145, 586-594.

Heiberger, R.M., 2009. HH: statistical analysis and data display: Heiberger and Holland. R package version 2.1-32. http://CRAN.R-project.org/package=HH.

Hemptinne, J.-L., Magro, A., Evans, E.W., Dixon, A.F.G., 2012. Body size and the rate of spread of invasive ladybird beetles in North America. Biol. Invasions 14, 595-605.

Hodek, I., 1993. Habitat and food specificity in aphidophagous predators. Biocontrol Sci. Technol. 3, 91-100.

Hoehn, P., Tscharntke, T., Tylianakis, J.M., Steffan-Dewenter, I., 2008. Functional group diversity of bee pollinators increases crop yield. Proc. R. Soc. B 275, 2283-2291.

Hunter, M.D., Price, P.W., 1992. Playing chutes and ladders: heterogeneity and the relative roles of bottom-up and top-down forces in natural communities. Ecology 73, 724-732.

Kay, Q.O.N., 1976. Preferential pollination of yellow-flowered morphs of Raphanus raphanistrum by Pieris and Eristalis spp. Nature 261, 230-232.

Klinkhamer, P.G.L., de Jong, T.J., de Bruyn, G.-J., 1989. Plant size and pollinator visitation in Cynoglossum officinale. Oikos 54, 201-204.

Knops, J.M.H., Tilman, D., Haddad, N.M., Naeem, S., Mitchell, C.E., Haarstad, J., Ritchie, M.E., Howe, K.M., Reich, P.B., Siemann, E., Groth, J., 1999. Effects of plant species richness on invasion dynamics, disease outbreaks, insect abundances and diversity. Ecol. Lett. 2, 286-293. 
Lawton, J.H., 1983. Plant architecture and the diversity of phytophagous insects. Annu. Rev. Entomol. 28, 23-39.

Lawton, J.H., Price, P.W., 1979. Species richness of parasites on hosts: agromyzid flies on the British Umbelliferae. J. Anim. Ecol. 48, 619-637.

Leong, J.M., Thorp, R.W., 1999. Colour-coded sampling: the pan trap colour preferences of oligolectic and nonoligolectic bees associated with a vernal pool plant. Ecol. Entomol. 24, 329-335.

Maj, A., 2011. lmmfit: Goodness-of-fit-measures for linear mixed models with one-levelgrouping. R package version 1.0. http://CRAN.R-project.org/package=lmmfit.

Minchin, P.R., 1987. An evaluation of relative robustness of techniques for ecological ordination. Vegetatio 71, 145-146.

Murchie, A.K., Smart, L.E., Williams, I.H., 1997. Responses of Dasineura brassicae and its parasitoids Platygaster subuliformis and Omphale clypealis to field traps baited with organic isothiocyanates. J. Chem. Ecol. 23, 917-926.

Neuvonen, S., Niemelä, P., 1981. Species richness of Macrolepidoptera on Finnish deciduous trees and shrubs. Oecologia 51, 364-370.

Ohashi, K., Yahara, T., 2002. Visit larger displays but probe proportionally fewer flowers: counterintuitive behaviour of nectar-collecting bumble bees achieves an ideal free distribution. Funct. Ecol. 16, 492-503.

Oksanen, J., Blanchet, F.G., Kindt, R., Legendre, P., Minchin, P.R., O’Hara, R.B., Simpson, G.L., Solymos, P.H., Stevens, M.H., Wagner, H., 2011. vegan: community ecology package. R package version 2.0-1. http://CRAN.R-project.org/package=vegan.

Peters, R.H., 1983. The ecological implications of body size. Cambridge University Press, Cambridge.

Pinheiro, J., Bates, D., DebRoy, S., Sarkar, D., R Development Core Team, 2011. nlme: linear and nonlinear mixed effects models. R package version 3.1-98.

R Development Core Team, 2011. R: a language and environment for statistical computing. R Foundation for Statistical Computing, Vienna, Austria. ISBN 3-900051-07-0, URL http://www.R-project.org/.

Remmel, T., Tammaru, T., 2009. Size-dependent predation risk in tree-feeding insects with different colouration strategies: a field experiment. J. Anim. Ecol. 78, 973-980.

Reudler Talsma, J.H., Biere, A., Harvey, J.A., van Nouhuys, S., 2008. Oviposition cues for a specialist butterfly-plant chemistry and size. J. Chem. Ecol. 34, 1202-1212. 
Riihimaeki, J., Vehvilaeinen, H., Kaitaniemi, P., Koricheva, J., 2006. Host tree architecture mediates the effect of predators on herbivore survival. Ecol. Entomol. 31, 227-235.

Rutledge, C.E., 1996. A survey of identified kairomones and synomones used by insect parasitoids to locate and accept their hosts. Chemoecology 7, 121-131.

Schielzeth, H., 2010. Simple means to improve the interpretability of regression coefficients. Methods Ecol. Evol. 1, 103-113.

Schlinkert, H., 2014. Plant size gradient in Brassicaceae. Figshare, http://dx.doi.org/10.6084/m9.figshare.12.

Southwood, T.R.E., 1988. Tactics, strategies and templets. Oikos 52, 3-18.

Strong, D.R., Lawton, J.H., Southwood, T.R.E., 1984. Insects on plants: community patterns and mechanisms. Blackwell Scientific Publications, Oxford.

Tscharntke, T., Greiler, H.-J., 1995. Insect communities, grasses, and grasslands. Annu. Rev. Entomol. 40, 535-558.

Ulber, B., Williams, I.H., Klukowski, Z., Luik, A., Nilsson, C., 2010. Parasitoids of oilseed rape pests in Europe: key species for conservation biocontrol, in: Williams, I.H. (Ed.), Biocontrol-Based Integrated Management of Oilseed Rape Pests. Springer Netherlands, Dordrecht, pp. 45-76.

Williams, I.H., Cook, S.M., 2010. Crop location by oilseed rape pests and host location by their parasitoids, in: Williams, I.H. (Ed.), Biocontrol-Based Integrated Management of Oilseed Rape Pests. Springer Netherlands, Dordrecht, pp. 215-244.

Zuur, A.F., Ieno, E.N., Elphick, C.S., 2010. A protocol for data exploration to avoid common statistical problems. Methods Ecol. Evol. 1, 3-14. 


\section{SUPPLEMENTAL MATERIAL}

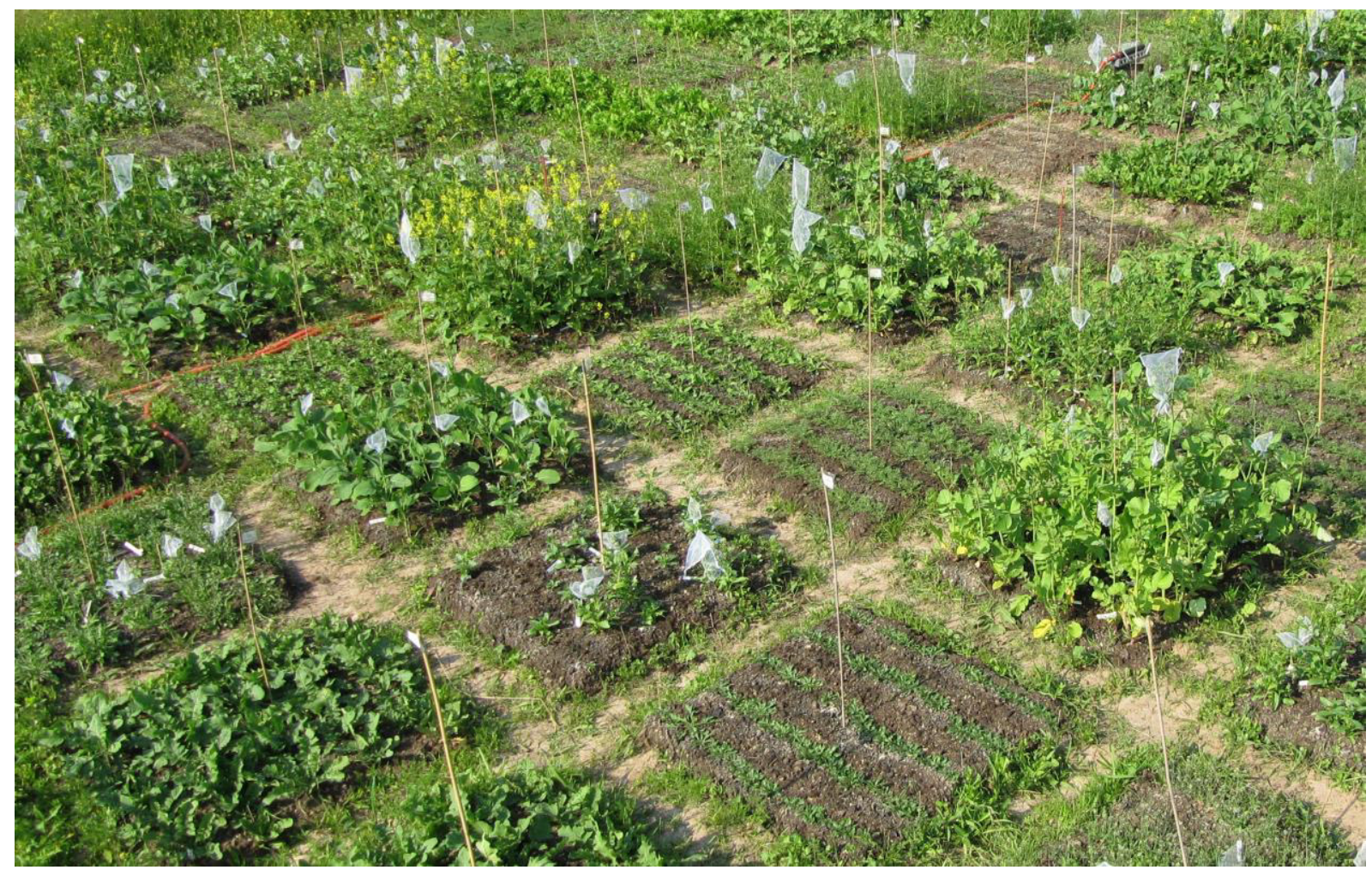

Figure S1. Photo of the common garden experiment. Four $1 \mathrm{~m}^{2}$ plots per plant species were arranged in a randomised design. We excluded plant species from the data set that could not be (1) managed to reach a plant cover of approximately $100 \%$ of the plot or (2) brought to full flowering between midJune and mid-July 2010 in order to avoid phenological differences in the local insect community of the study area. Plant individuals with pollinator exclusion bags were part of another experiment and were excluded from insect and plant trait samplings.

Table S2. Correlations between component size and other plant characteristics. Correlation coefficients and levels of significance are given with $* \mathrm{p}<0.05, * * \mathrm{p}<0.01$ and $* * * p<0.001$. Number and biomass of flowers refer to plot level, while number and biomass of leaves and fruits refer to five plant individuals per plot. Number and biomass of flowers, fruits and leaves, petal length and fruit size were log-transformed. Not tested combinations of variables are marked as grey cells.

\begin{tabular}{|c|c|c|c|c|c|c|c|c|}
\hline & 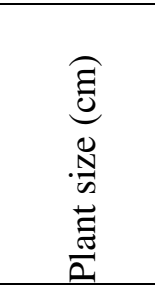 & $\begin{array}{l}\dot{\bar{D}} \\
\bar{\Xi} \\
\bar{\Xi} \\
\overline{0} \\
\overline{0} \\
\overline{0} \\
\frac{0}{I}\end{array}$ & 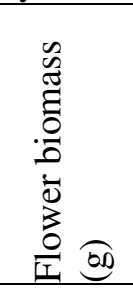 & $\begin{array}{l}\vdots \\
0 \\
0 \\
0 \\
\overline{0} \\
\frac{0}{0} \\
\frac{0}{I}\end{array}$ & 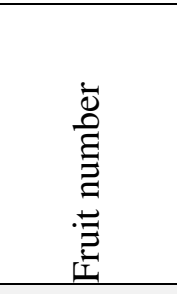 & 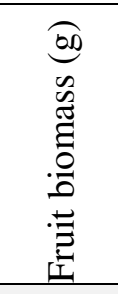 & 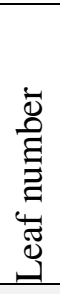 & 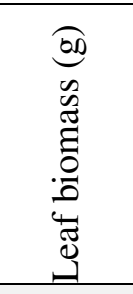 \\
\hline Petal length (mm) & $0.514 *$ & $-0.639 * *$ & $0.466^{*}$ & ns & & & & \\
\hline Fruit size (sqmm) & $0.464^{*}$ & & & & $-0.835 * * *$ & $0.514 *$ & & \\
\hline Leaf area $(\mathrm{sqcm})$ & $0.823 * * *$ & & & & & & $\mathrm{~ns}$ & $0.585^{* *}$ \\
\hline
\end{tabular}




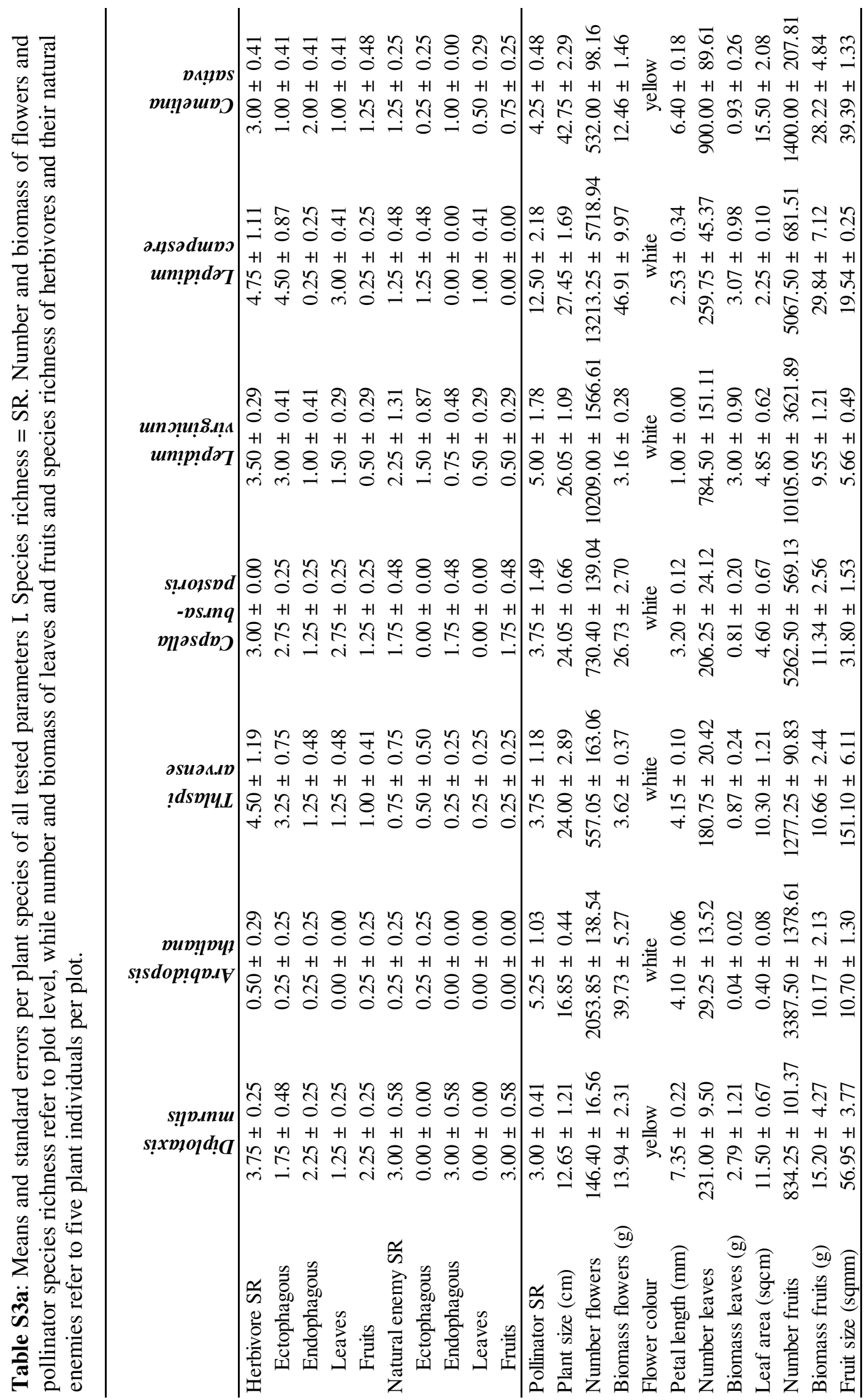




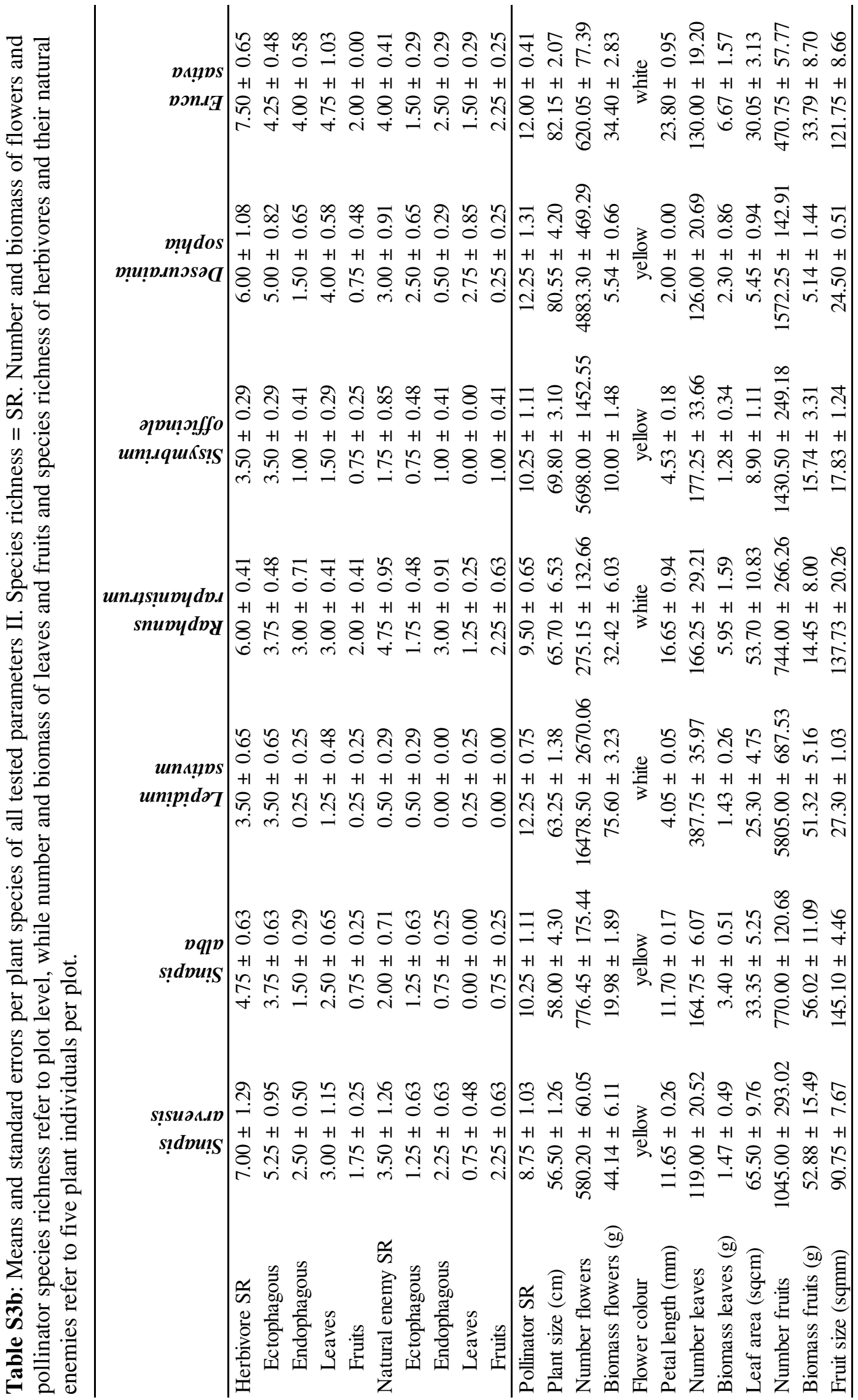




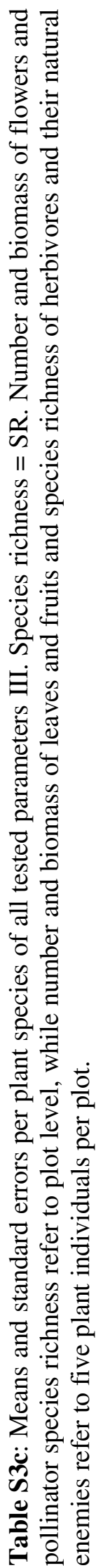

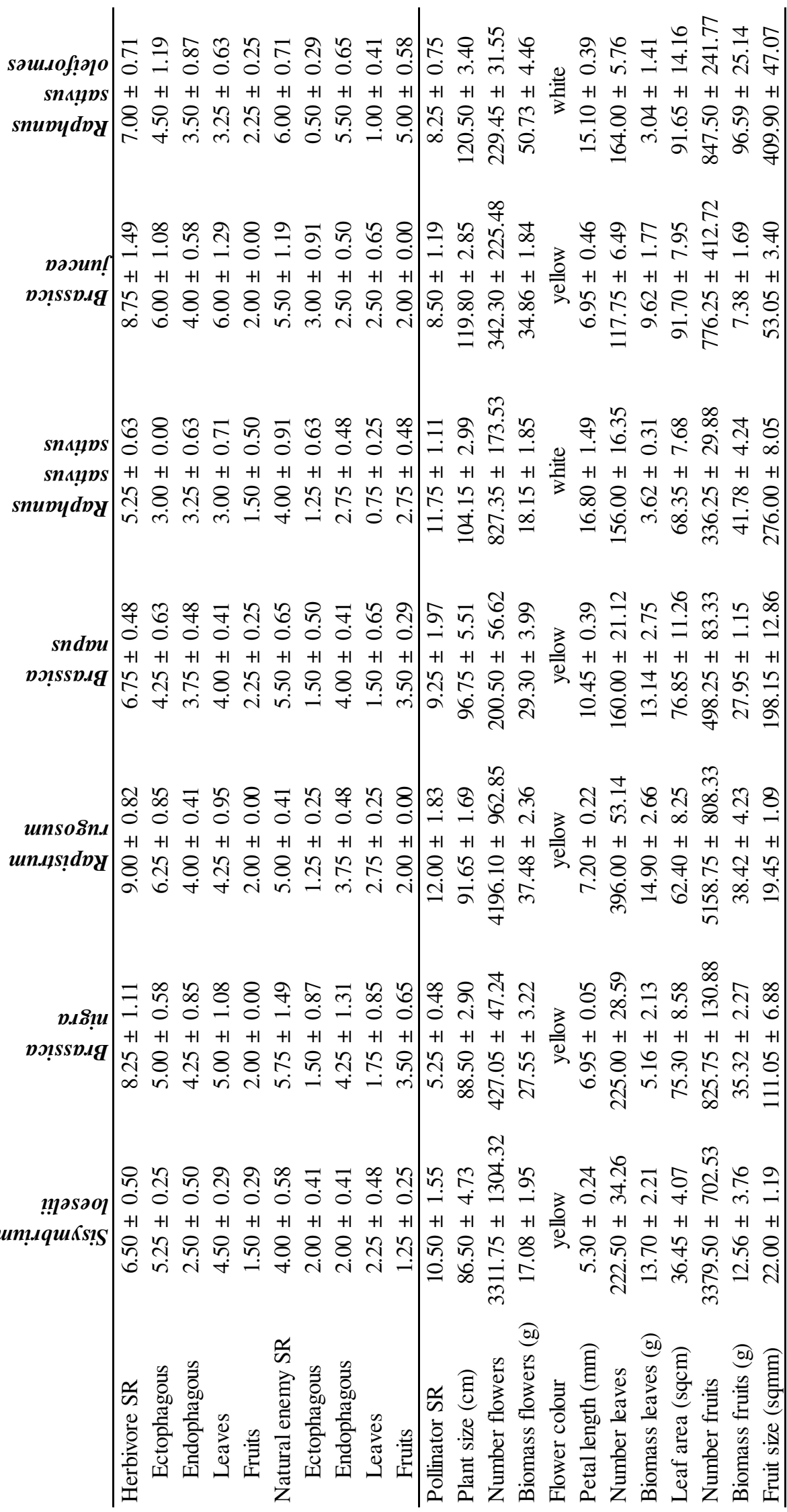


Table S4. Species list of observed individuals. MS = morphospecies.

\begin{tabular}{|c|c|c|}
\hline & Species & Order \\
\hline \multirow[t]{24}{*}{ Herbivores } & Ceutorhynchus floralis (Paykull 1792) & Coleoptera \\
\hline & Ceutorhynchus obstrictus (Marsham 1802) & Coleoptera \\
\hline & Ceutorhynchus pallidactylus (Marsham 1802) & Coleoptera \\
\hline & Longitarsus kutscherae (Rye 1872) & Coleoptera \\
\hline & Meligethes aeneus (Fabricius 1775) & Coleoptera \\
\hline & Phyllotreta atra (Fabricius 1775) & Coleoptera \\
\hline & Phyllotreta nemorum (Linnaeus 1758) & Coleoptera \\
\hline & Phyllotreta nigripes (Fabricius 1775) & Coleoptera \\
\hline & Dasineura brassicae Winnertz 1853 & Diptera \\
\hline & Phytomyza horticola Goureau 1851 & Diptera \\
\hline & Phytomyza sp. MS1 & Diptera \\
\hline & Scaptomyza flava Fallen 1823 & Diptera \\
\hline & Aleyrodes proletella Linnaeus 1758 & Hemiptera \\
\hline & Aphidoidea MS3 & Hemiptera \\
\hline & Brevicoryne brassicae (Linnaeus 1758) & Hemiptera \\
\hline & Lipaphis cf. erysimi (Kaltenbach 1843) & Hemiptera \\
\hline & Lygocoris pabulinus (Linnaeus 1761) & Hemiptera \\
\hline & Lygus pratensis (Linnaeus 1758) & Hemiptera \\
\hline & Lygus rugulipennis Poppius 1911 & Hemiptera \\
\hline & Myzus persicae (Sulzer 1776) & Hemiptera \\
\hline & Cnephasia interjectana (Haworth 1811) & Lepidoptera \\
\hline & Pieris rapae Linnaeus 1758 & Lepidoptera \\
\hline & Plutella xylostella (Linnaeus 1758) & Lepidoptera \\
\hline & Frankliniella sp. & Thysanoptera \\
\hline \multirow[t]{32}{*}{ natural enemies } & Araneae MS1 & Araneae \\
\hline & Araneidae MS1 & Araneae \\
\hline & Araneus diadematus Clerck 1757 & Araneae \\
\hline & cf. Anelosimus sp. & Araneae \\
\hline & cf. Mangora acalypha (Walckenaer 1802) & Araneae \\
\hline & Enoplognatha ovata (Clerck 1757) & Araneae \\
\hline & Linyphiidae MS1 & Araneae \\
\hline & Lycosidae MS1 & Araneae \\
\hline & Metellina segmentata (Clerck 1787) & Araneae \\
\hline & Ozyptila cf. trux (Blackwall 1846) & Araneae \\
\hline & Adalia bipunctata (Linnaeus 1758) & Coleoptera \\
\hline & Cantharis bicolor Linnaeus 1763 & Coleoptera \\
\hline & Cantharis fusca Linnaeus 1758 & Coleoptera \\
\hline & Cantharis livida Linnaeus 1758 & Coleoptera \\
\hline & Cantharis rufa Linnaeus 1758 & Coleoptera \\
\hline & Coccinella septempunctata Linnaeus 1758 & Coleoptera \\
\hline & Harmonia axyridis Pallas 1773 & Coleoptera \\
\hline & Propylaea quatuordecimpunctata (Linnaeus 1758) & Coleoptera \\
\hline & Psilothrix viridicoeruleus (Geoffroy in Fourcroy 1785) & Coleoptera \\
\hline & Rhagonycha fulva Scopoli 1763 & Coleoptera \\
\hline & Thea vigintiduopunctata Moscardini 1954 & Coleoptera \\
\hline & Episyrphus balteatus (de Geer 1776) & Diptera \\
\hline & Syrphidae MS3 & Diptera \\
\hline & Himacerus mirmicoides (O. Costa 1834) & Hemiptera \\
\hline & Orius minutus (Linneaus 1758) & Hemiptera \\
\hline & Alysiinae MS1 & Hymenoptera \\
\hline & Anaphes fuscipennis Haliday 1833 & Hymenoptera \\
\hline & Aprostocetus epicharmus Walker 1839 & Hymenoptera \\
\hline & Bracon fulvipes Nees 1834 & Hymenoptera \\
\hline & Diadegma sp. & Hymenoptera \\
\hline & Diaeretiella rapae (McIntosh 1855) & Hymenoptera \\
\hline & Diglyphus isaea (Walker 1838) & Hymenoptera \\
\hline
\end{tabular}




\begin{tabular}{|c|c|c|}
\hline & Species & Order \\
\hline \multirow[t]{24}{*}{ natural enemies (continuation) } & Encarsia tricolor Forster 1878 & Hymenoptera \\
\hline & Eupelmus urozonus Dalman 1821 & Hymenoptera \\
\hline & Ichneumoninae MS1 & Hymenoptera \\
\hline & Inostemma walkeri Kieffer 1914 & Hymenoptera \\
\hline & Lasius niger (Linnaeus 1758) & Hymenoptera \\
\hline & Mesopolobus gemellus Baur Muller 2007 & Hymenoptera \\
\hline & Mesopolobus morys Walker 1848 & Hymenoptera \\
\hline & Microplitis sp. & Hymenoptera \\
\hline & Necremnus tidius (Walker 1839) & Hymenoptera \\
\hline & Omphale clypealis (Thomson 1878) & Hymenoptera \\
\hline & Opius sp. & Hymenoptera \\
\hline & Phradis gibbus Holmgren 1860 & Hymenoptera \\
\hline & Pseudotorymus napi Amerling Kirchner 1860 & Hymenoptera \\
\hline & Pteromalus sp. & Hymenoptera \\
\hline & Stenomalina gracilis Walker 1834 & Hymenoptera \\
\hline & Stibeutes curvispina Thomson 1884 & Hymenoptera \\
\hline & Telenomus sp. & Hymenoptera \\
\hline & Temelucha decorata Gravenhorst 1829 & Hymenoptera \\
\hline & Trichogramma sp. & Hymenoptera \\
\hline & Trichomalus perfectus Walker 1835 & Hymenoptera \\
\hline & Trichopria sp. & Hymenoptera \\
\hline & Opilio canestrinii (Thorell 1876) & Opiliones \\
\hline & Phalangium opilio Linnaeus 1761 & Opiliones \\
\hline & Aeolothrips intermedius Bagnall 1934 & Thysanoptera \\
\hline \multirow[t]{35}{*}{ pollinators } & Agromyzidae MS1 & Diptera \\
\hline & Anthomyiidae MS1 & Diptera \\
\hline & Anthomyiidae MS2 & Diptera \\
\hline & Anthomyiidae MS3 & Diptera \\
\hline & Anthomyiidae MS4 & Diptera \\
\hline & Chloropidae MS1 & Diptera \\
\hline & Chloropidae MS2 & Diptera \\
\hline & Conopidae MS1 & Diptera \\
\hline & Dasineura brassicae Winnertz 1853 & Diptera \\
\hline & Drosophilidae MS1 & Diptera \\
\hline & Drosophilidae MS2 & Diptera \\
\hline & Drosophilidae MS3 & Diptera \\
\hline & Episyrphus balteatus (de Geer 1776) & Diptera \\
\hline & Eristalinus aeneus (Scopoli 1763) & Diptera \\
\hline & Eristalinus sepulchralis (Linnaeus 1758) & Diptera \\
\hline & Eristalis arbustorum (Linnaeus 1758) & Diptera \\
\hline & Eristalis tenax (Linnaeus 1758) & Diptera \\
\hline & Eupeodes corollae (Fabricius 1794) & Diptera \\
\hline & Fanniidae MS1 & Diptera \\
\hline & Helophilus pendulus (Linnaeus 1758) & Diptera \\
\hline & Helophilus trivittatus (Fabricius 1805) & Diptera \\
\hline & Lauxaniidae MS1 & Diptera \\
\hline & Lucilia sp. & Diptera \\
\hline & Melanostoma mellinum (Linnaeus 1758) & Diptera \\
\hline & Muscidae MS1 & Diptera \\
\hline & Muscidae MS2 & Diptera \\
\hline & Scaeva pyrastri (Linnaeus 1758) & Diptera \\
\hline & Sepsidae MS1 & Diptera \\
\hline & Sphaerophoria scripta Linnaeus 1758 & Diptera \\
\hline & Stratiomyidae MS1 & Diptera \\
\hline & Syritta pipiens Linnaeus 1758 & Diptera \\
\hline & Syrphus vitripennis Meigen 1822 & Diptera \\
\hline & Tachinidae MS1 & Diptera \\
\hline & Tachinidae MS2 & Diptera \\
\hline & Tachinidae MS3 & Diptera \\
\hline
\end{tabular}




\begin{tabular}{|c|c|c|}
\hline & Species & Order \\
\hline \multirow[t]{44}{*}{ pollinators (continuation) } & Tachinidae MS5 & Diptera \\
\hline & Tephritidae MS1 & Diptera \\
\hline & Volucella bombylans (Linnaeus 1758) & Diptera \\
\hline & Andrena agilissima (Scopoli 1770) & Hymenoptera \\
\hline & Andrena cf. minutuloides Perkins 1914 & Hymenoptera \\
\hline & Andrena cineraria (Linnaeus 1758) & Hymenoptera \\
\hline & Andrena dorsata (Kirby 1802) & Hymenoptera \\
\hline & Andrena flavipes Panzer 1799 & Hymenoptera \\
\hline & Andrena strohmella Illiger 1806 & Hymenoptera \\
\hline & Anthophora plumipes (Pallas 1772) & Hymenoptera \\
\hline & Apis mellifera Linnaeus 1758 & Hymenoptera \\
\hline & Bombus lapidarius Linnaeus 1758 & Hymenoptera \\
\hline & Bombus pascuorum Scopoli 1763 & Hymenoptera \\
\hline & Bombus terrestris (Linnaeus 1758) & Hymenoptera \\
\hline & Cerceris rybyensis (Linnaeus 1771) & Hymenoptera \\
\hline & Colletes daviesanus Smith 1846 & Hymenoptera \\
\hline & Halictus tumulorum (Linnaeus 1758) & Hymenoptera \\
\hline & Hylaeus communis Cookerell 1937 & Hymenoptera \\
\hline & Hylaeus gredleri Foerster 1871 & Hymenoptera \\
\hline & Hylaeus hyalinatus Smith 1843 & Hymenoptera \\
\hline & Hylaeus signatus (Panzer 1798) & Hymenoptera \\
\hline & Hylaeus sinuatus (Schenck 1853) & Hymenoptera \\
\hline & Hylaeus variegatus (Fabricius 1798) & Hymenoptera \\
\hline & Lasioglossum calceatum (Scopoli 1763) & Hymenoptera \\
\hline & Lasioglossum laticeps Schenk 1870 & Hymenoptera \\
\hline & Lasioglossum minutissimum Kirby 1802 & Hymenoptera \\
\hline & Lasioglossum minutulum (Schenck 1853) & Hymenoptera \\
\hline & Lasioglossum morio (Fabricius 1793) & Hymenoptera \\
\hline & Lasioglossum pauxillum (Schenck 1853) & Hymenoptera \\
\hline & Lindenius albilabris (Fabricius 1793) & Hymenoptera \\
\hline & Osmia brevicornis (Fabricius 1798) & Hymenoptera \\
\hline & Oxybelus bipunctatus Olivier 1812 & Hymenoptera \\
\hline & Phradis interstitialis (Thomson 1889) & Hymenoptera \\
\hline & Polistes dominulus (Christ 1791) & Hymenoptera \\
\hline & Rhogogaster viridis (Linnaeus 1758) & Hymenoptera \\
\hline & Terebrantia MS1 & Hymenoptera \\
\hline & Vespidae MS1 & Hymenoptera \\
\hline & Vespidae MS2 & Hymenoptera \\
\hline & Adela reaumurella Linnaeus 1758 & Lepidoptera \\
\hline & Aglais urticae Linnaeus 1758 & Lepidoptera \\
\hline & Mamestra brassicae (Linnaeus 1758) & Lepidoptera \\
\hline & Pieris brassicae Linnaeus 1758 & Lepidoptera \\
\hline & Pieris napi Linnaeus 1758 & Lepidoptera \\
\hline & Pieris rapae Linnaeus 1758 & Lepidoptera \\
\hline
\end{tabular}




\section{Supplemental material S5: abundance-based coverage estimators}

We computed the abundance-based coverage estimator (ACE) of herbivore and natural enemy species richness per plant species, referring to the estimated species richness of every plant species under ideal sampling intensity using EstimateS (Colwell 2005). These values of estimated species richness for herbivores and natural enemies (sqrt-transformed) were used as response variables within multiple regressions with plant size and, testing natural enemy species richness, estimated herbivore species richness (Pearson's correlation coefficient of the significant correlation between these explanatory variables: 0.73) and their two-way interaction as explanatory variables. Results show increasing estimated species richness of herbivores with increasing plant size (parameter weight $=1.00$; estimate with SE of centred and standardised data $=3.763 \pm 0.798$, Figure S5a), while estimated species richness of their natural enemies was positively related to estimated herbivore species richness (parameter weight $=0.57$; estimate with $\mathrm{SE}=0.454 \pm 0.166$, Figure $\mathrm{S} 5 \mathrm{~b}$ ) and not to plant size (parameter weight $=0.43)$ or the interaction of both (parameter weight $=0.00)$.
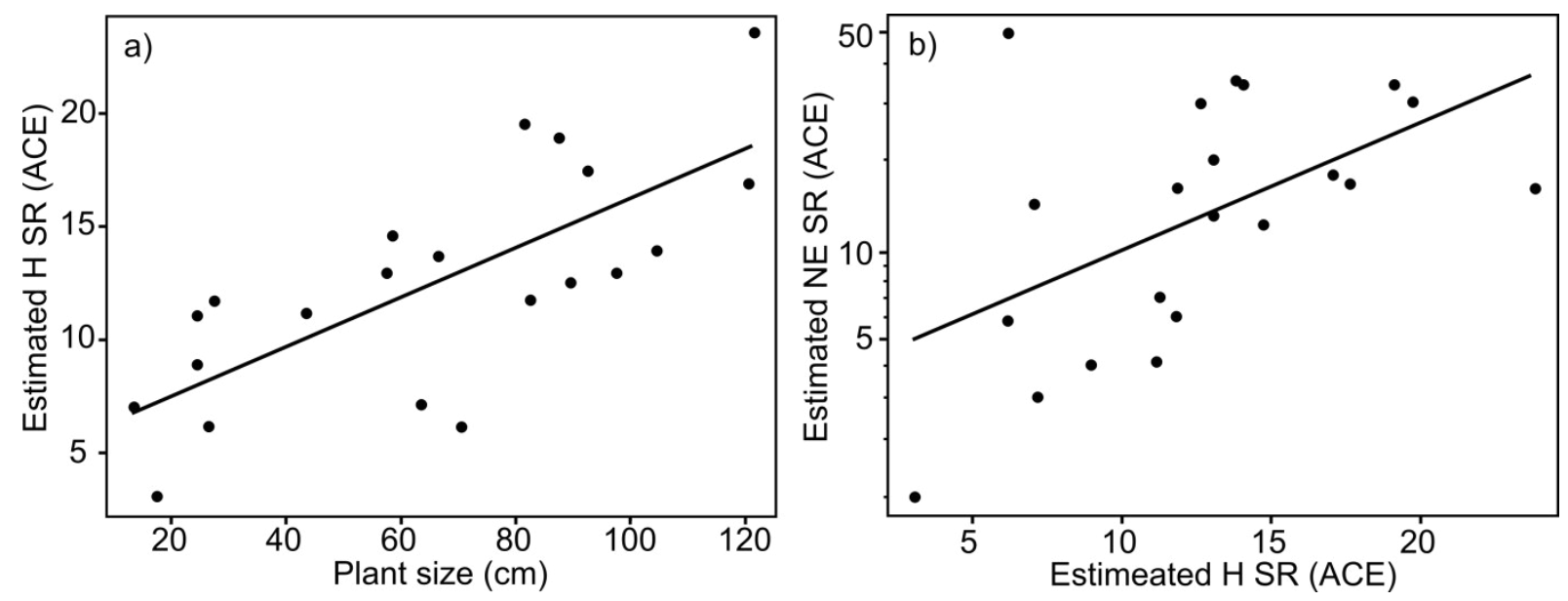

Figure S5. Effects of plant size and covariables on estimated species richness (ACE) of a) herbivores and b) their natural enemies. $\mathrm{SR}=$ species richness, $\mathrm{H}=$ herbivores, $\mathrm{NE}=$ natural enemies. Axes of variables were transformed corresponding to analyses (estimated species richness of natural enemies: log-transformation). 


\section{Chapter 3}

\section{HERBIVORY INCREASES WITH PLANT SIZE}

\section{ACROSS 21 BRASSICACEAE SPECIES}

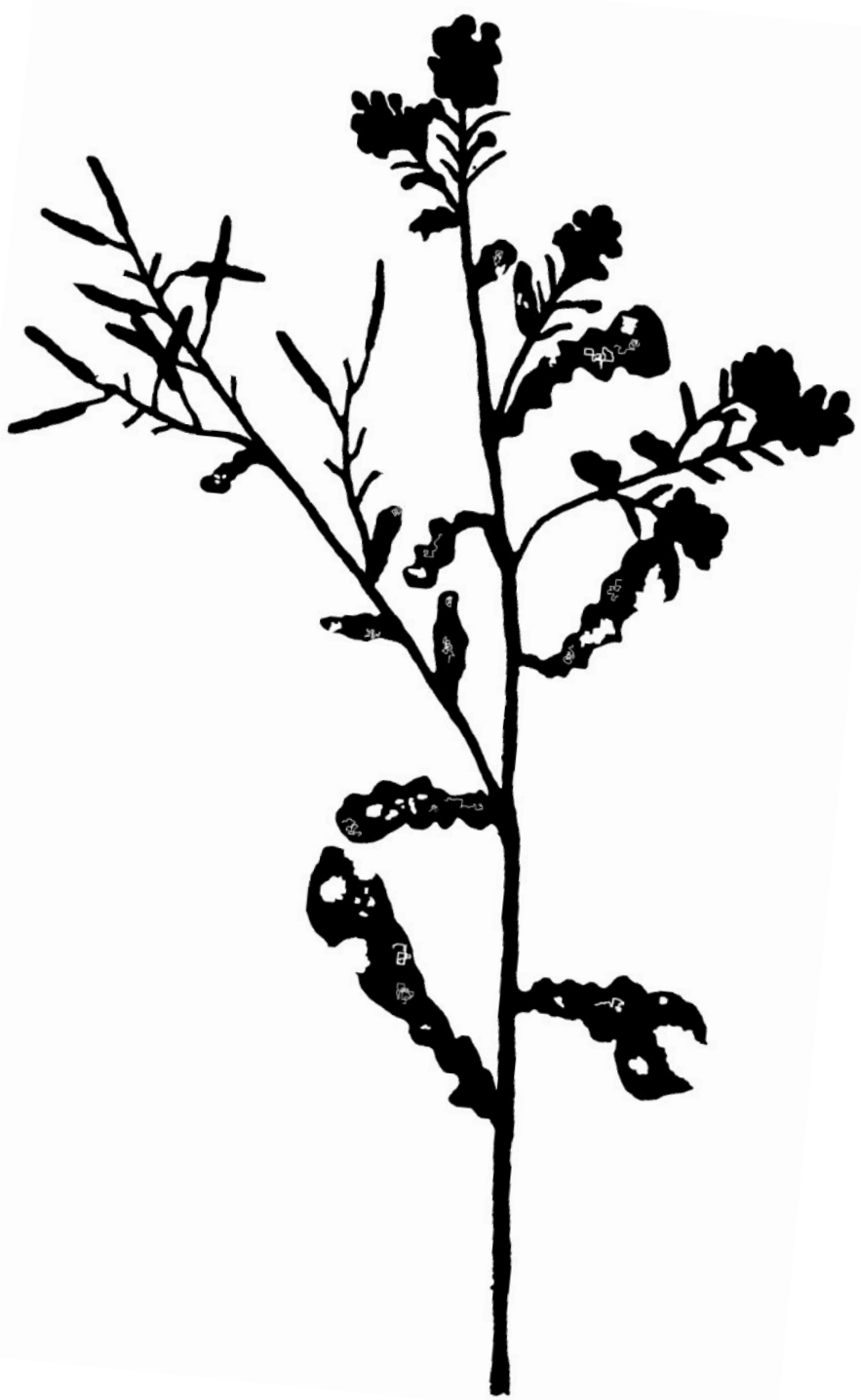

Hella Schlinkert, Catrin Westphal, Yann Clough,

Martin Ludwig, Patrick Kabouw, Teja Tscharntke 


\section{SUMMARY}

Plant size is a major predictor of ecological functioning. We tested the hypothesis that herbivory increases with plant size, as conspicuousness of large plants makes resource finding and colonisation easier. Further, large plants can be attractive to herbivores, as they offer greater amounts and larger ranges of resources and niches, but direct evidence from experiments testing size effects on herbivory and consequently on plant fitness is missing so far. We established a common garden experiment with a plant size gradient $(10$ to $130 \mathrm{~cm}$ plant height) using 21 annual Brassicaceae species and quantified plant size, biomass and number of and feeding damage to all aboveground plant components (flowers, fruits, leaves, stems). Plant reproductive fitness was measured using seed number, thousand seed weight and total seed weight. Proportional feeding damage to the different plant components increased with plant size or component biomass, with mean damage levels being approximately $30 \%$ for flowers, $5 \%$ for fruits and $1 \%$ for leaves and stems. Proportional herbivory affected plant reproductive fitness depending on feeding damage type, with flower damage having the strongest effect, shown by greatly reduced seed number, thousand seed weight and total seed weight. Finally, we found an overall negative effect of plant size on thousand seed weight, but not on seed number and total seed weight. In conclusion, being conspicuous and attractive to herbivores causes important fitness costs for large plants, which partly can be counterbalanced by benefits such as enhanced competitive or compensatory abilities or more mutualistic pollinator visits.

\section{Keywords}

antagonists, feeding damage, plant fitness, pollen beetles, trophic interactions 


\section{INTRODUCTION}

Body size is of great importance in most organisms at physiological, genetic and ecological levels (Peters, 1983). Large body size has various inherent benefits such as high dispersal ability (Hemptinne et al., 2012) and high competitiveness (Brown and Maurer, 1986), but also has costs such as higher energy requirements or high conspicuousness to enemies (Blanckenhorn, 2000; Remmel and Tammaru, 2009). Large plants are very apparent and offer a wide range of resources and niches to associated animals, and are consequently easy to locate and attractive for herbivores (Feeny, 1976; Lawton, 1983). This can lead to increasing herbivore species richness with increasing plant size, as shown by several studies for naturally grown plants, where focus was on single groups of associated animals and mainly on an intraspecific plant size gradient (Haysom and Coulson, 1998; Lawton and Price, 1979; Neuvonen and Niemelä, 1981).

To analyse the effects of plant conspicuousness and attractiveness to herbivores on the plant, it is useful to consider not only herbivore presence, but also feeding damage. Feeding damage directly refers to the process of herbivory including feeding intensity, since herbivores that are present on plants do not necessarily feed on them. The extent of feeding damage may increase with plant size due to the more dominant appearance of large plants. Furthermore, high abilities to compensate for feeding damage of fast-growing plant species can contrast with high investments in defensive compounds of slow-growing plant species (growth-defence trade-off; Endara and Coley, 2011; Herms and Mattson, 1992). If this growth-defence tradeoff is related to plant size with a more effective defence against herbivores of small compared to large plant species, it consequently may result in overall higher herbivory levels of large compared to small plant species. Several studies have explored the effects of variation in intraspecific plant size on feeding damage and found increased herbivory with an increase in plant size when focusing on single plant components, such as flowers or leaves (Hainsworth et al., 1984; Tenow and Larsson, 1987; Williams and Free, 1979). However, so far no studies have analysed the effect of interspecific differences in plant size on feeding damage to different plant components simultaneously.

Studying effects of plant size along an interspecific gradient has several advantages over intraspecific studies. Differences in plant size of interspecific gradients are genetically determined. Therefore, interspecific gradients can have a much broader range of plant size 
irrespective of environmental parameters such as nutrient availability, competition or the influence of other organisms in comparison to intraspecific plant size gradients (e.g. Buchanan and Underwood, 2013). Interspecific experiments may also lead to more general conclusions than intraspecific studies as they offer the possibility to detect patterns across species. On the other hand they have to cope with phylogenetic influences, which may be minimised by choosing a high number of closely related species. Using a large interspecific plant size gradient and a plant component based approach, the effects of plant size on feeding damage can be analysed in great detail and will allow more comprehensive conclusions about potential effects of plant size on feeding damage to different components.

Not only plant size, but also different component characteristics, such as size, biomass and number may be of importance for herbivores specialised on a specific component (EspíritoSanto et al., 2007). Plants with many large components, particularly plants with high component biomass, should be highly attractive because of high food availability for herbivores. For this reason these parameters should be considered in studies focusing on plant size effects.

Different plant characteristics can influence feeding damage, while feeding damage can oppositely influence the plants' reproductive fitness. The effect of feeding damage on plant reproductive fitness may depend on the damaged plant component. While a negative impact of feeding damage on reproductive components by florivores and seedeaters on seed number is not surprising (Moyes and Raybould, 1997; Williams, 2010), the effect on reproductive fitness by vegetative damage may be negative, neutral or even positive via (over)compensation or induced resistance to other herbivores (McArt et al., 2013; Puentes and Ågren, 2012; Strauss and Agrawal, 1999). Given a negative effect of feeding damage on plant reproductive fitness, plant size consequently may have an overall negative effect on plant reproductive fitness due to increased herbivory with increasing plant size.

Up to now, complex interactions between feeding damage, plant size and reproductive fitness have never been investigated and may be particularly important for annual plants which do not have the opportunity for a delayed compensatory response across years. In this study we analysed the effects of plant size on proportional feeding damage for different plant components along an interspecific plant size gradient and, most importantly, we analysed the effect of size-related feeding damage on plant reproductive fitness. Plant size was measured 
as plant height of 21 closely related annual brassicaceous plant species. We thereby determined proportional feeding damage to every aboveground plant component (i.e. to flowers, fruits, leaves and stems) and simultaneously involved component characteristics, such as size, biomass and number, as covariables in the analyses. This does not only disentangle effects of plant size and component characteristics such as leaf number, but also accounts for potential species specific differences. Regarding other plant characteristics, such as flower structure or secondary plant substances, we chose species being similar to each other to minimise plant size confounded differences among used species. As our study is conducted as common garden experiment, plants are grown in a standardised way and effects of habitat and landscape are avoided. Thus, with our study we are able to draw a comprehensive picture of the effects of plant size on feeding damage and plant fitness under standardised conditions and come to more general conclusions using a broader plant size gradient than it would be possible using only single plant species. Following hypotheses are tested:

(1) Proportional feeding damage to the different plant components increases with increasing plant size, as well as with increasing resource availability, i.e. component number and biomass.

(2) Proportional feeding damage to the different plant components, particularly to reproductive components (flowers and fruits), negatively affects plant reproductive fitness.

(3) Plant reproductive fitness decreases with increasing plant size.

\section{MATERIAL AND METHODS}

\section{Study site and sampling design}

The common garden experiment (Supplemental material Figure S1) was established on a grassland area dominated by grasses and herbs, including brassicaceous herbs, in Göttingen (Lower Saxony, Germany) in the 2010 summer. A total of 25 species from the family Brassicaceae were chosen that differed in size. Plant species that did not flower between midJune and mid-July 2010 were excluded from the dataset to avoid phenological dissimilarity in 
the local insect community of the study area. The remaining 21 plant species covered a gradient in plant size from $12.65 \mathrm{~cm} \pm 1.05 \mathrm{~cm}$ (Diplotaxis muralis (L.) DC.) to $120.50 \mathrm{~cm} \pm$ $2.95 \mathrm{~cm}$ (Raphanus sativus L. oleiformis) (Figure 1f). Many plant characteristics were similar among the tested plant species, such as flower structure, the presence of glucosinolates as secondary plant substances and their pollination ecology in that insect pollination increases seed set (http://www.floraweb.de, last visited January 2014). The plant species we used are all common German annuals, allowing us to directly assess their response to herbivory in contrast to perennial species, which may respond across years (e.g. Buchanan and Underwood, 2013). Used plant species include neophytes (four species), cultivated plants (eight species) and indigenous weeds (nine species). Four plots per plant species, in total 100 plots, were arranged in monoculture in a completely randomised design. Plots measured $1 \mathrm{~m}^{2}$ and were separated by $30 \mathrm{~cm}$. Plants were managed in their plant density to cover approximately $100 \%$ of the plot until they were fully blooming and were prevented from exceeding plot borders. Potential effects of plant height thereby were disentangled from area covered by the plants, implying a negative relationship between plant size and plant density per area, which commonly occurs under natural conditions. Nevertheless we accounted for the differences in plant density by involving the number and biomass per plot of components of interest, such as the number of leaves per plot in terms of leaf herbivory, to the analyses (described below). All plots were fertilised once equally (with NPK fertiliser 15:6:12) and regularly watered and weeded. We did not apply any pesticides during the course of the experiment.

\section{Plant appearance and chemistry traits}

Plant size (height from the ground to the top of the plant) and the number of flowers, leaves and stems of first and second order were recorded per plant individual for five randomly selected plant individuals per plot at the time of full blossom. Number of fruits was counted at the time of full ripeness. Flower size was measured as petal length, leaf size in $\mathrm{cm}^{2}$ (we always measured the lowest living leaf as leaf size depends on its position) and stem diameter in $\mathrm{mm}$ (measured at ground level). Size of fruits was measured when fully ripe as length $\mathrm{x}$ width in mm. Mean plant size and mean size of the different plant components (flowers, fruits, leaves and stems) were calculated for each plot. The number of flowers, fruits, leaves 
and stems of five plant individuals were extrapolated to plot level (mean per plant individual $\mathrm{x}$ number of plants in the plot). Flower colour depended on the plant species (yellow or white). To measure component biomass we harvested fruits, leaves and stems from plants in one quarter of each plot. To assess flower biomass we harvested flowers from plants in one quarter of each of two randomly selected plots per plant species. Flowers were picked at the time of full blossom, stems and leaves were harvested at the time of early ripening and fruits were harvested at the time of full ripeness of each plot. Harvested plant individuals were counted and components were oven-dried for $48 \mathrm{~h}$ at $60{ }^{\circ} \mathrm{C}$ to get dry biomass weights. Biomass of the different components per plot was extrapolated by multiplying the mean biomass per plant individual of the relevant plot with its plant individual number. Since only two randomly selected plots per plant species were sampled to assess flower biomass, we extrapolated flower biomass of the remaining two plots per plant species by multiplying their plant individual number with the averaged flower biomass per plant individual of the two sampled plots. Additionally, we assessed chemical traits of leaves, namely nitrogen, carbon and glucosinolate content (Supplemental material S2).

Only leaves and stems for biomass assessment were taken from identical plant individuals as the point in time of harvest was identical, while we excluded invasively treated plants from further examinations (i.e. leaves and stems, flowers and fruits were each harvested from different individuals). When harvesting the different plant components we left five randomly selected and individually marked plant individuals per plot intended to develop pods for the measurement of fitness parameters.

\section{Plant reproductive fitness}

Plant reproductive fitness can be measured as the number of seeds a plant individual produces, referring to the number of its potential descendants. Thousand seed weight, i.e. the weight of a single seed times 1000, is often used as an indicator for the fitness of the produced seeds, while the product of seed number and seed weight refers to the overall seed output, the yield in terms of crops. To assess plant reproductive fitness a subset of 20 randomly selected fruits from the five randomly selected plant individuals per plot was opened. Seeds of ripe and closed fruits were counted and oven-dried for $48 \mathrm{~h}$ at $60{ }^{\circ} \mathrm{C}$ to measure their thousand seed weight. The number of seeds per plant individual was estimated by multiplying the mean seed 
number per pod with the total number of pods of the plant individual. Total seed weight per individual was assessed by multiplying the seed number per individual with the thousand seed weight divided by 1000 (the single seed weight) for the plant individual. Further, mean values per plot for seed number, thousand seed weight and total seed weight per individual were calculated.

The natural capabilities of the different plant species regarding seed number, thousand seed weight and total seed weight differ. These differences were accounted for by using relative rather than total values for the plant reproductive fitness parameters. Seed number (\%), thousand seed weight (\%) and total seed weight per individual (\%) refer to the percentage of the maximal capability for each plant species. The maximal capability of a species was determined as the mean of the ten maximal values observed in our study, using a total of 40 plant individuals per species. Thereby these values refer to the natural capabilities of the specific breeding lines and varieties of the plants used in our experiment under the specific natural conditions of our experimental site. They originate from plant individuals with access by pollinating insects and below-average levels of herbivory (63.65 $\pm 26.04 \%, 64.24 \pm 23.86$ $\%$ and $94.21 \pm 34.37 \%$ of the mean proportional feeding damage per plant species regarding seed number, total seed weight and thousand seed weight).

\section{Feeding damage to the different plant components}

Feeding damage to plant components was recorded from five randomly selected plant individuals per plot. Feeding damage to flowers, fruits and leaves was recorded from the same individuals as plant reproductive fitness parameters, while feeding damage to stems was assessed from different individuals as we dissected the first and second order stems at the time of full blossom. To assess flower feeding damage, the numbers of podless stalks and developed fruits per plant individual were counted at the time of full ripeness. Podless stalks occur when buds and flowers are fed on (Williams, 2010). Therefore, feeding damage to flowers was defined as percentage of podless stalks based on the number of potential fruits (developed fruits plus podless stalks). Additionally a subset of 20 ripe fruits per sampled plant individual was opened and categorised as damaged by herbivores if we found loopholes, galleries, pitted seeds or an animal inside the fruit. Fruit feeding damage was defined as the percentage of damaged fruits. Leaf feeding damage (percentage of the damaged leaf surface) 
was estimated during the time of full blossom using all leaves from the sampled individuals. Feeding damage to stems was defined as percentage of the stem sections with mines or loopholes. Means of feeding damage for the different plant components were calculated for each plot.

\section{Statistics}

The effect of plant size on feeding damage (\%) to flowers, fruits, leaves and stems was analysed using linear mixed effects models (nlme R package, Pinheiro et al., 2011; R version 2.12.2, R Development Core Team, 2011). As covariates the number and biomass of the relevant plant component (flowers, fruits, leaves or stems), flower colour regarding the analysis of feeding damage to flowers, and all two-way-interactions were included. Size of the plant components was not part of the models due to high correlation with other explanatory variables (Supplemental material Table S3a). Plant species was used as a random effect in models to avoid pseudoreplication (four plots per plant species).

The effect of feeding damage on plant fitness was likewise analysed using linear mixed effects models with plant species as a random effect. Seed number (\%), thousand seed weight (\%) and total seed weight (\%) were used as response variables and feeding damage to flowers, fruits, leaves and stems (\%, the latter as binomial variable), including all two-wayinteractions, as explanatory variables. The net effect of plant size on plant fitness was analogously analysed, using linear mixed effects models and plant size as explanatory variable.

Correlations between explanatory variables were tested for each model and we found significant correlations ( $\mathrm{p}$-value $<0.05$ ) between several variables (Supplemental material Table S3a-b). Multicollinearity of explanatory variables was controlled and did not exceed the value of three for the variance inflation factor in any model (single exception: 3.17 for the model testing the effect of plant size, stem number and biomass on feeding damage to stems), allowing their parallel use in models (HH-package, Heiberger, 2009; Zuur et al., 2010). Diagnostic plots were examined and variables transformed (log-, square-root- or arcsinesquare-root-transformations were used) whenever necessary to avoid heteroscedasticity or non-normal distribution of errors. 
Models were simplified by calculating AICc values for all full model subsets using the dredge function in the muMIn package (Barton, 2011). With respect to the non-independence between some explanatory variables (Supplemental material Table S3a-b), parameter weights were used for the identification of explanatory variables and interactions that consistently contributed to the models' explanatory power. Parameter weights were computed by averaging models with $\triangle \mathrm{AICc}<2$ (Burnham and Anderson, 2002; Grueber et al., 2011). We defined parameters with a parameter weight $\geq 0.6$ as important for the explication of the response variable's variance. Summary output of the model with the lowest AICc including all explanatory variables with a parameter weight $\geq 0.6$ led to given estimates with standard errors (Tables 1-2) that are centred and standardised to improve their interpretability (Schielzeth, 2010).

\section{RESULTS}

\section{Effects of plant size and component characteristics on feeding damage to the different plant components}

We recorded overall feeding damage to flowers of $29.82 \pm 2.83 \%$ (arithmetic mean and standard error), feeding damage to fruits of $5.10 \pm 0.91 \%$, feeding damage to leaves of $1.13 \pm$ $0.17 \%$ and feeding damage to stems of $0.88 \pm 0.22 \%$ (see Supplemental material Table S4ac for all). Based on our observations feeding damage to flowers was attributed to pollen beetles and their larvae (Meligethes aeneus FABRICIUS) and feeding damage to fruits mainly to weevils (cabbage seedpod weevil Ceutorhynchus obstrictus MARSHAM and C. floralis PAYKULL) and to a lesser extend to the brassica pod midge (Dasineura brassicae WINNERTZ). Feeding damage by leaf chewers was composed of a mainly point-wise feeding pattern, but we also observed fenestration feeding and leaf mining patterns. Flea beetles (Phyllotreta nemorum L. and P. nigripes (FABRICIUS) caused the most feeding damage to leaves, while damage to stems was done by weevils ( $C$. pallidactylus MARSHAM and $C$. napi GYLLENHAAL). In general, most observed herbivorous species were specialised on the family of Brassicaceae, but had no strong specialisation on single plant species of the experiment.

Plants along the plant size gradient were similar in characteristics such as their defensive compounds or nitrogen content of leaves (Supplemental material S2). Some characteristics of 
single plant components were not independent from plant size and consequently were involved in the analyses as covariables whenever possible to disentangle their effects from plant size effects. Thereby we found that proportional flower feeding damage was positively influenced by plant size, while number, biomass and colour of flowers had no effect (Table 1, Figure 1a). Proportional fruit feeding damage was also (even though weakly) positively affected by plant size, while the number and biomass of fruits had no influence (Table 1, Figure 1b). Contrarily, proportional leaf and stem feeding damage were positively affected by component biomass, but plant size had no influence (Table 1, Figure 1c,e). Only feeding damage to leaves was affected by component number, as feeding damage tended to decrease with increasing leaf number (Table 1, Figure 1d).

\section{Effects of feeding damage to the different plant components on plant reproductive}

\section{fitness}

Plant reproductive fitness parameters refer to the degree $(\%)$ to which a plant individual met the maximal capability of its plant species. We recorded mean seed number as $57.43 \pm 2.82$ $\%$, mean thousand seed weight as $62.14 \pm 1.81 \%$ and mean total seed weight as $51.85 \pm 2.91$ $\%$ (see Supplemental material Table S4a-c for all). Seed number per individual (\%), thousand seed weight $(\%)$ and total seed weight per individual $(\%)$ decreased with increasing flower feeding damage (Table 2, Figure 2a,b,d). Interestingly, we found interaction effects between flower and stem feeding damage: the negative effect of flower feeding damage on seed number $(\%)$ and on total seed weight $(\%)$ was stronger on plots with stem feeding damage than on plots without stem feeding damage (Table 2, Figure 2a,d). Thousand seed weight (\%) was not influenced by stem feeding damage (Table 2). Leaf feeding damage had no influence on seed number $(\%)$ and total seed weight $(\%)$ but a slight positive influence on thousand seed weight (\%) (Table 2, Figure 2c). Fruit feeding damage had no effect on any plant reproductive fitness parameter (Table 2).

\section{Net effect of plant size on plant reproductive fitness}

To assess the overall fitness consequences of being large or small, we analysed the effect of plant size on plant reproductive fitness, namely on seed number per individual (\%), thousand 
seed weight (\%) and total seed weight per individual (\%). We thereby found a negative net effect of plant size on thousand seed weight $(\%)$ (parameter weight $=1$; estimate $=0.127$, standard error $=0.043)$, but not on seed number $(\%)($ parameter weight $=0)$ or total seed weight $(\%)($ parameter weight $=0)$.
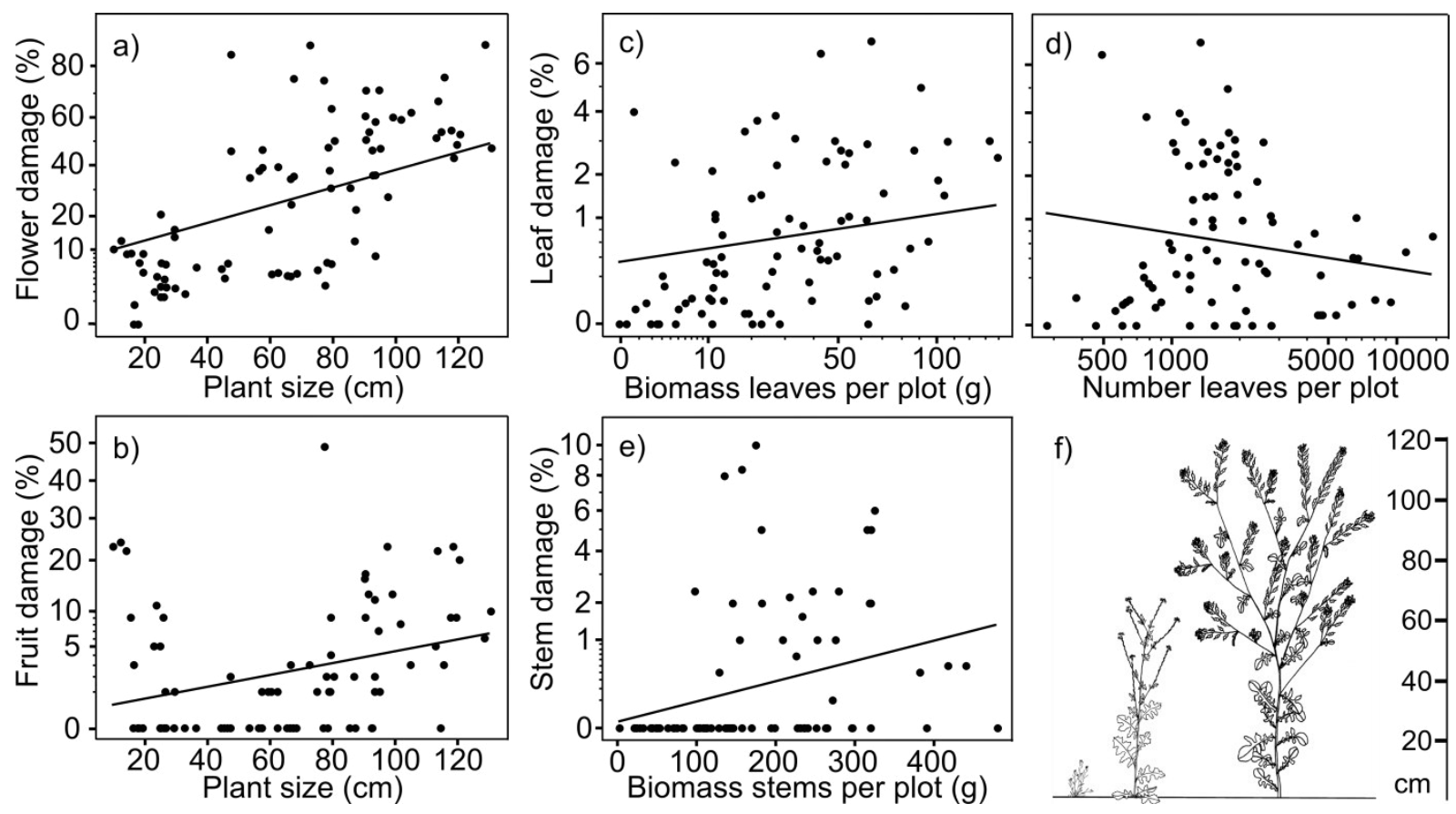

Figure 1. Effects of plant size, component biomass and number on feeding damage to a) flowers, b) fruits, c-d) leaves and e) stems. Axes of variables were transformed corresponding to analyses (feeding damage to the different components: asin-sqrt-transformation; biomass leaves per plot: sqrttransformation; number leaves per plot: log-transformation). Predictions derive from the model with the lowest AICc including all explanatory variables with a parameter weight $\geq 0.6$. f) Plant size of the smallest, an intermediate and the largest species of the study is shown relative to one another (Diplotaxis muralis (L.) DC. $12.65 \mathrm{~cm} \pm 1.05 \mathrm{~cm}$, Sisymbrium officinale L. $69.80 \mathrm{~cm} \pm 3.10 \mathrm{~cm}$ and Raphanus sativus L. oleiformis $120.50 \mathrm{~cm} \pm 2.95 \mathrm{~cm}$ ). Single pictures are taken from Schlinkert (2014). 

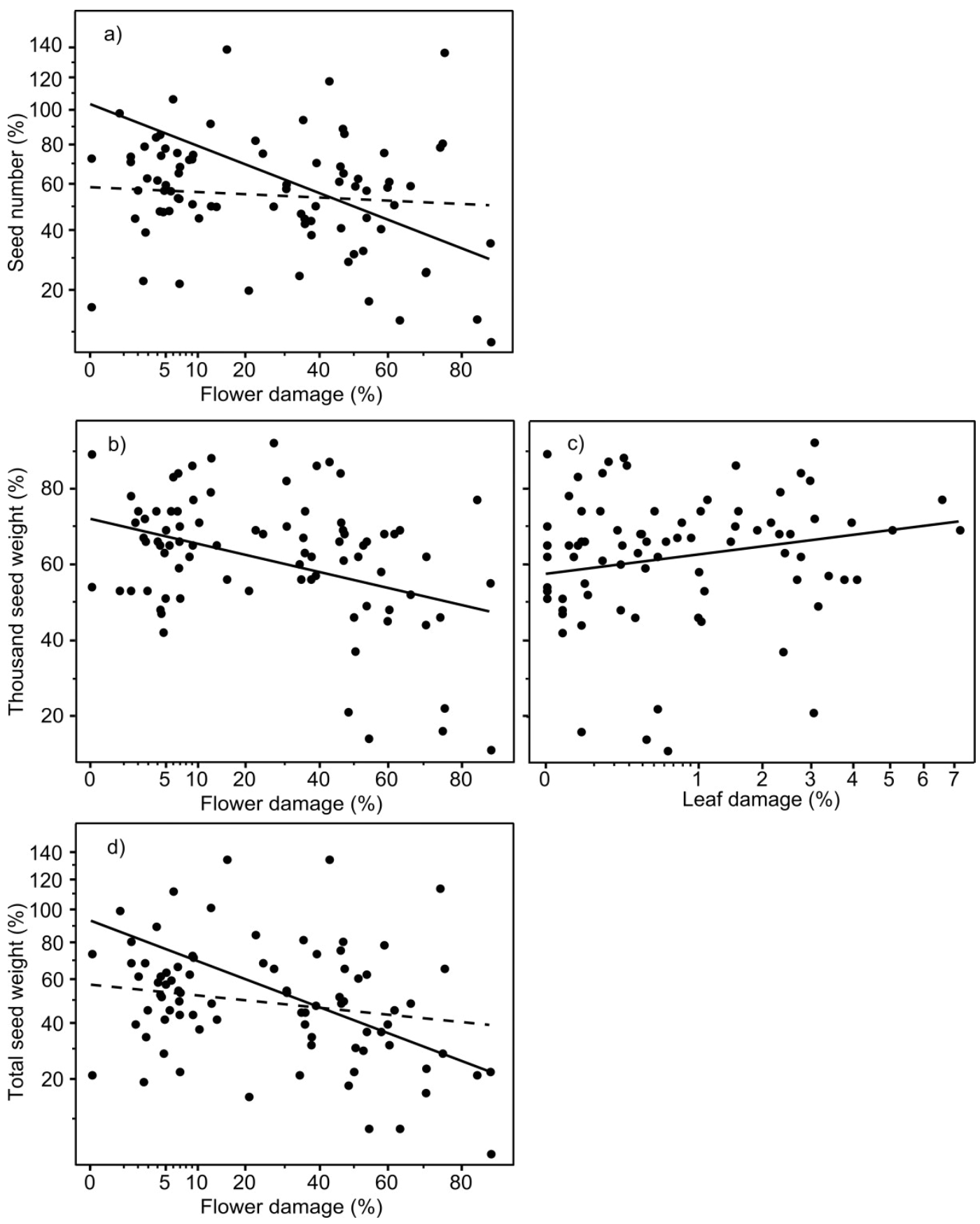

Figure 2. Effects of feeding damage to the different plant components on a) seed number (\% of the species' maximum), b-c) thousand seed weight (\%) and d) total seed weight (\%). Axes of variables were transformed corresponding to analyses (feeding damage to the different components, seed number (\%) and total seed weight (\%): asin-sqrttransformation). Predictions derive from the model with the lowest AICc including all explanatory variables with a parameter weight $\geq 0.6$. Solid line: plants with stem damage; dashed line: plants without stem damage. 
Table 1. Effects of plant size and covariables on feeding damage (\%) to the different plant components. We defined parameters with parameter weights $(\mathrm{pw}) \geq 0.6$ (bold), referring to a delta AICc of two, as important for the relevant response variable. Centred and standardised estimates (est.) with standard errors (SE) derived from the summary table of the model with the lowest AICc including all explanatory variables with a parameter weight $\geq 0.6$. Damage to the different plant components was asin-sqrt-transformed, number of the different plant components was logtransformed, and biomass of flowers and leaves was sqrt-transformed. Variables which were not involved in the relevant full model are marked as grey cells.

\begin{tabular}{|c|c|c|c|c|c|c|c|c|c|c|c|}
\hline & & 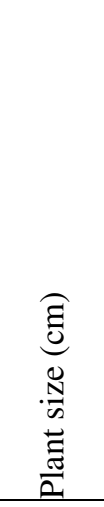 & 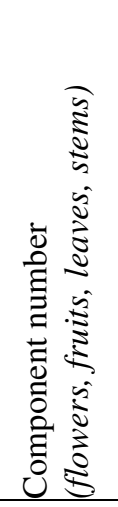 & 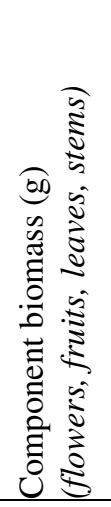 & 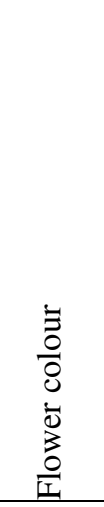 & 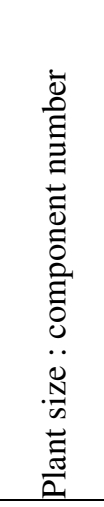 & 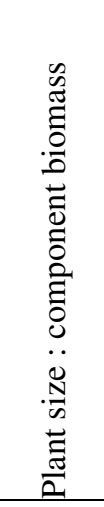 & 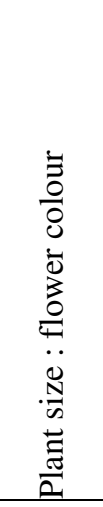 & 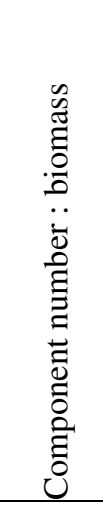 & 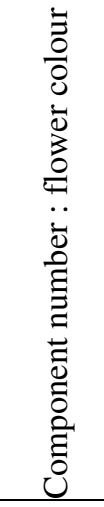 & 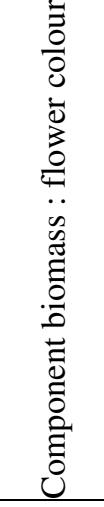 \\
\hline \multirow[t]{3}{*}{ Flower damage (\%) } & pw & 1.000 & 0.220 & 0.000 & 0.240 & 0.000 & 0.000 & 0.000 & 0.000 & 0.000 & 0.000 \\
\hline & est. & 0.128 & - & - & - & - & - & - & - & - & - \\
\hline & SE & 0.043 & - & - & - & - & - & - & - & - & - \\
\hline \multirow[t]{3}{*}{ Fruit damage (\%) } & pw & 0.820 & 0.150 & 0.260 & & 0.000 & 0.260 & & 0.000 & & \\
\hline & est. & 0.055 & - & - & & - & - & & - & & \\
\hline & SE & 0.028 & - & - & & - & - & & - & & \\
\hline \multirow[t]{3}{*}{ Leaf damage (\%) } & pw & 0.430 & 0.680 & 0.820 & & 0.140 & 0.150 & & 0.400 & & \\
\hline & est. & - & -0.012 & 0.013 & & - & - & & - & & \\
\hline & SE & - & 0.009 & 0.008 & & - & - & & - & & \\
\hline \multirow[t]{3}{*}{ Stem damage (\%) } & pw & 0.000 & 0.280 & 1.000 & & 0.000 & 0.000 & & 0.000 & & \\
\hline & est. & - & - & 0.025 & & - & - & & - & & \\
\hline & SE & - & - & 0.010 & & - & - & & - & & \\
\hline
\end{tabular}


Table 2. Effects of feeding damage to the different plant components on plant reproductive fitness (\% of the plant species' maximum). We defined parameters with parameter weights ( $\mathrm{pw}) \geq 0.6$ (bold), referring to a delta AICc of two, as important for the relevant response variable. Centred and standardised estimates (est.) with standard errors (SE) derived from the summary table of the model with the lowest AICc including all explanatory variables with a parameter weight $\geq 0.6$. Damage to flowers, fruits and leaves were asin-sqrt-transformed as well as seed number (\%) and total seed weight (\%).

\begin{tabular}{|c|c|c|c|c|c|c|c|c|c|c|c|}
\hline & & 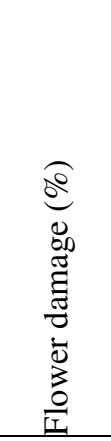 & 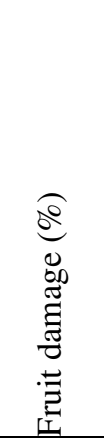 & 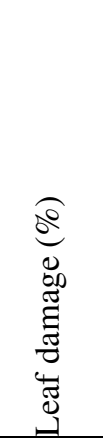 & 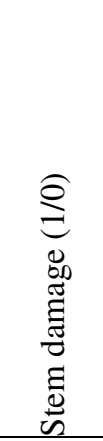 & 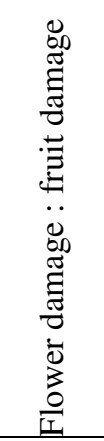 & 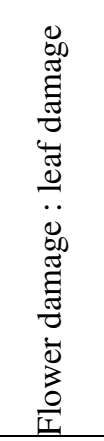 & 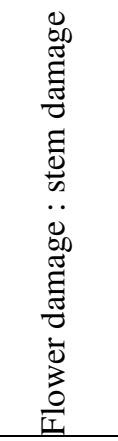 & 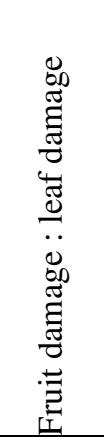 & 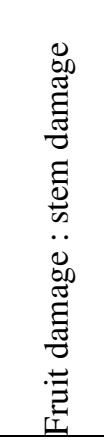 & 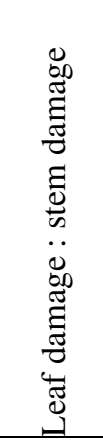 \\
\hline \multirow[t]{3}{*}{ Seed number $(\%)$} & pw & 1.000 & 0.270 & 0.530 & 0.870 & 0.270 & 0.530 & 0.870 & 0.000 & 0.270 & 0.000 \\
\hline & est. & -0.016 & - & - & 0.011 & - & - & -0.017 & - & - & - \\
\hline & SE & 0.006 & - & - & 0.007 & - & - & 0.007 & - & - & - \\
\hline \multirow[t]{3}{*}{1000 seed weight $(\%)$} & pw & 1.000 & 0.110 & 0.850 & 0.230 & 0.000 & 0.340 & 0.000 & 0.000 & 0.000 & 0.000 \\
\hline & est. & -6.577 & - & 3.540 & - & - & - & - & - & - & - \\
\hline & SE & 2.364 & - & 1.929 & - & - & - & - & - & - & - \\
\hline \multirow[t]{3}{*}{ Total seed weight (\%) } & pw & 1.000 & 0.500 & 0.000 & 0.750 & 0.500 & 0.000 & 0.750 & 0.000 & 0.500 & 0.000 \\
\hline & est. & -0.021 & - & - & 0.007 & - & - & -0.015 & - & - & - \\
\hline & SE & 0.007 & - & - & 0.007 & - & - & 0.007 & - & - & - \\
\hline
\end{tabular}

\section{DISCUSSION}

Proportional feeding damage to the different plant components was hypothesised to increase with increasing plant size. However, we found different effects for the specific plant components. Proportional feeding damage to flowers and fruits increased with increasing plant size and was not influenced by resource availability, i.e. component number and biomass. In contrast, feeding damage to leaves and stems increased only with increasing biomass of leaves and stems but not with plant size. The influence of herbivory on plant reproductive fitness was depending on the type of feeding damage. Flower feeding damage had the strongest effect on reproductive fitness as it reduced seed number (\%), thousand seed weight $(\%)$ and total seed weight $(\%)$. Feeding damage to leaves and stems played a minor role and feeding damage to fruits had no influence on any fitness parameter. Regarding the overall effects of plant size on reproductive fitness, we found a negative net effect of plant size on thousand seed weight $(\%)$ only, while seed number $(\%)$ and total seed weight $(\%)$ 
remained unaffected. These findings generally support our hypotheses, but also indicate specific effects of plant size on the proportional feeding damage of individual plant components and also specific consequences for plant reproductive fitness.

\section{Effects of plant size and component characteristics on feeding damage to the different plant components}

Large plants are highly apparent and attractive to associated animals due to their wide range of resources and niches, and are thus expected to be easily found and colonised by numerous herbivores (Feeny, 1976; Lawton, 1983). A positive effect of plant size on herbivore species richness has been shown several times (Haysom and Coulson, 1998; Lawton and Price, 1979; Neuvonen and Niemelä, 1981), but studies testing its effect on feeding damage are rare and less general due to their focus on a single type of feeding damage and single plant species (e.g. Alonso and Herrera, 1996; Castagneyrol et al., 2013; Tenow and Larsson, 1987). Feeding damage to flowers and fruits were strongly affected by plant size across the 21 tested plant species, as yet only shown for an intraspecific plant size gradient in species such as oilseed rape (Brassica napus L.) (Williams and Free, 1979) and scarlet gilia (Ipomopsis aggregata (PURSH) V.E.GRANT) (Hainsworth et al., 1984).

In contrast, feeding damage to leaves and stems were correlated to respective component biomass, but not to plant size. Component biomass is composed of the number, size and mass density and is a measurement of the quantity of resources that can be expected to attract herbivores (Araujo et al., 2006; Lawton, 1983). Studies that tested for an effect of total plant biomass on leaf and stem herbivores such as galling insects, which are specialised on a specific plant resource like young tissue of meristems, failed to detect any relationship (Espírito-Santo et al., 2007). However, biomass of the respective component instead of total plant biomass showed a positive effect on these herbivores (Araujo et al., 2006). This emphasises the importance of plant component biomass for feeding damage to a particular plant component. As biomass of leaves and stems were positively correlated with plant size, we should keep in mind that we cannot completely disentangle these effects (Lawton, 1983), even though these correlations were not too strong for a combined analysis. 
Nevertheless we can state that plant size was a more important driver for feeding damage to flowers and fruits than for feeding damage to leaves and stems. This is not surprising as large, highly attractive leaves and stems, the type most often damaged, are often situated on the lower part of the plant (personal observation; Collinge and Louda, 1988; Dechert and Ulber, 2004). Therefore, under natural conditions, they are often hidden from herbivores by neighbouring vegetation, independent of plant size. In contrast, flowers and fruits of the tested species are situated at the exposed top of the plant, where plant size is synonymous with inflorescence height. Flowers and fruits of large plants under natural conditions often overtop those of smaller plants, if their flowers and fruits are situated at the top of the plant, making smaller plants more hidden resulting in greater feeding damage for larger plants. The role of plant size regarding the search strategy of herbivores for food plants therefore may depend on the position of the component, on whether its visibility depends on plant size or not. The difference in search strategies, manifested under natural conditions, probably led to a high attractiveness of plots with large plants in our study for herbivores of flowers and fruits and a disinterest in plant size of herbivores which were looking for big leaves and stems.

It is interesting that number and biomass of flowers and fruits per plot did not influence feeding damage to these components, while results of increasing feeding damage to leaves and stems with increasing component biomass per plot supported the expected positive relationship to resource availability. Adult pollen beetles and their larvae feed mainly on pollen and pod miners feed on seeds, while flea beetles feed on the green tissue of the leaf blade and weevils feed on the inner parts of the stems and may even hollow them out completely (Juran et al., 2011; Williams, 2010). Thus, a minor part of flower and fruit biomass is edible, while the biomass of leaves and stems better reflects the amount of edible components. Component number had no effect on the feeding damage to flowers, fruits and stems. The mere number of entities within components may be of little value for many herbivores if component biomass is simultaneously considered, which comprises component size and mass density, besides number. Size and mass density of components may also be of importance regarding shelter from enemies, as for example stem mining larvae take refuge from parasitoids in stems with a large diameter and high amount of biomass, being beyond the reach of their ovipositors (Ulber, 2003). We only detected an influence of the number of entities within components for feeding damage to leaves. As leaf feeding damage was attributed mainly to mobile herbivores like flea beetles (personal observations), leaf number 
may represent resource availability, indicated by increasing clutch size of different butterflies with increasing number of food plant leaves (Reudler Talsma et al., 2008; Vasconcellos-Neto and Ferreira Monteiro, 1993). Surprisingly, the feeding damage to leaves in our study was not positively, but negatively affected by leaf number. Leaf herbivory can affect plants early in the season as already leaves of seedlings and young plants are attacked by cabbage flea beetles (personal observations; Alford et al., 2003). Plant species may cope with early herbivory by investment in defence mechanisms (resistance) or in regrowth (tolerance), while plants with a high regrowth capacity are known for overcompensation (Strauss and Agrawal, 1999). The negative relationship between feeding damage to leaves and leaf number was possibly caused by overcompensatory creation of leaves (i.e. assimilation capacity) as a response to leaf damage (glucosinolate composition of leaves was not correlated with leaf damage, Supplemental material Table S2).

Feeding damage to flowers was not significantly influenced by flower colour, although pollen beetles, the major florivores in our study, are known to favour yellow flowers due to visual or physiological colour-related aspects of flowers such as production of volatiles (Giamoustaris and Mithen, 1996). Abundance of larvae and adult pollen beetles was observed to be higher on yellow flowers than on white flowers but did not translate to increased flower feeding damage. However, adult pollen beetles have been shown to avoid buds for feeding that have the preferred size for oviposition (Ekbom and Borg, 1996) and may avoid flowers already occupied by their larvae. Since their home range for feeding is wider than for oviposition (Ekbom and Borg, 1996), adults may have laid eggs mainly in yellow buds and may have switched regularly to white flowers for feeding, leading to similar damages to yellow and white flowers.

\section{Effects of feeding damage to the different plant components on plant reproductive fitness}

Flower feeding damage had the biggest influence on reproductive fitness as it significantly reduced seed number ( $\%$ of the plant species' maximum), thousand seed weight ( $\%)$ and total seed weight (\%). The negative effects of flower feeding damage on seed number $(\%)$ and total seed weight $(\%)$ were strongest on plots which also had feeding damage to stems. Feeding damage to leaves and stems played a minor role, the former indicating overcompensation, the 
latter strengthening the negative effect of feeding damage to flowers on seed number (\%) and total seed weight $(\%)$. Surprisingly, feeding damage to fruits had no effect on any fitness parameter.

Our finding that feeding damage to flowers negatively affected plant reproductive fitness agrees with results from other studies (McCall and Irwin, 2006 and studies cited therein). Feeding on pollen and flower components by pollen beetles and their larvae is known to lead to podless stalks and weakened pods (Free and Williams, 1979; Williams, 2010). Consequently feeding damage to flowers often leads to a reduction of the total seed number (Steffan-Dewenter and Tscharntke, 1999; Williams, 2010). Florivory may additionally have an indirect negative effect on seed number in reducing the attractiveness of flowers to pollinators and the availability of pollen, followed by decreased effectiveness of pollination by insects and wind (McCall and Irwin, 2006). Plants with a high amount of damaged flowers, for example due to pollen beetles, may compensate by producing new flowers but at the expense of the remaining flowers' thousand seed weight (Trumble et al., 1993). The negative effects of feeding damage to flowers on seed number $(\%)$ and total seed weight $(\%)$ were reinforced by feeding damage to stems. Tunnelling of stem mining flea beetle larvae may cause distortion of tissue and consequent loss of plant vigour (Juran et al., 2011 and studies cited therein). Additionally, holes caused by the female's ovipositor and by larvae emerging from stems often provide gateways for fungal infestations (Juran et al., 2011 and studies cited therein). Both plant vigour loss and fungal infestations as a consequence of stem mining may weaken a plant and reduce its ability to compensate for flower damage.

A slight stimulating effect on the thousand seed weight (\%) could be ascribed to feeding damage to leaves. Overcompensation has been described for many brassicaceous species and genera used in our study, such as Raphanus raphanistrum L., B. napus, Sinapis alba L. and several more (Agrawal, 2001; Gavloski and Lamb, 2000 and others) in that feeding damage to leaves can increase plant reproductive fitness, including via increased seed weight (e.g. Agrawal, 2001). Another explanation might be that the thousand seed weight (\%) could have been positively influenced by high leaf biomass rather than by high feeding damage to leaves, as feeding damage to leaves was positively related to leaf biomass (Table 1). High leaf biomass implies high photosynthetic potential and a larger supply of carbon for reproduction. Plant reproductive effort (the ratio of reproductive biomass to total biomass) is in general higher in monocarpic than polycarpic species since the former allocate their energy mainly to 
reproduction and the latter mainly to competition and predator avoidance (Kawano and Nagai, 1975). Hence, high leaf biomass may lead to high seed weight particularly in monocarpic plants, which were used in our study.

Feeding damage to fruits has a negative effect on the seed number of several species like $I$. aggregata (Hainsworth et al., 1984), Oenothera biennis L. (McArt et al., 2013) and others. Cabbage seedpod weevils often cause severe seed losses through feeding on seeds of Brassicaceae, particularly as forerunners of the brassica pod midge or secondary infestations by fungal pathogens (Alford et al., 2003; Moyes and Raybould, 1997; Williams, 2010). Contrarily, many studies analysing brassicaceous species found little effect of pre-dispersal seed predation on seed number (Williams and Free 1979; Free et al. 1983; Duggan 1985, but see Williams and Free 1978), consistent with results from our study. We observed cabbage seed weevil larvae causing the bigger part of feeding damage to fruits but infrequent secondary infestations of pods by brassica pod midges. We further observed relatively high parasitism rates of cabbage seedpod weevil larvae (on average $78.03 \% \pm 4.44 \%$ ) by chalcid wasps, which may reduce the consumption by host larvae (Moyes and Raybould, 1997). Due to infrequent secondary infestations by brassica pod midges and potentially low consumption rates by parasitised weevil larvae, the expected negative effect of feeding damage to fruits on plant reproductive fitness may have been weak and consequently compensated for by the plants (Williams and Free, 1979).

\section{Net effect of plant size on plant reproductive fitness}

We hypothesised a negative net effect of plant size on plant reproductive fitness as a consequence of increased herbivory (hypothesis 1) and consequently reduced plant fitness (hypothesis 2). Although size-related feeding damage to flowers resulted in reduced seed number ( $\%$ of the plant species' maximum), thousand seed weight $(\%)$ and total seed weight (\%), we could only demonstrate a negative net effect of plant size on thousand seed weight $(\%)$. The other two fitness parameters, seed number (\%) and total seed weight (\%), which was probably mainly influenced by seed number, remained unaffected by plant size. Fitness costs for large plants in terms of seed loss due to herbivores may be counterbalanced by benefits of large plants, including greater abilities for compensation (Strauss and Agrawal 1999, 
Williams and Free 1979), higher competitiveness for light and other resources (Weiner, 1985) or high conspicuousness to pollinators (Donnelly et al., 1998).

\section{CONCLUSIONS}

Detailed analyses of feeding damage to different plant components in relation to plant size and the linkage of size related feeding damage to fitness consequences led to comprehensive conclusions. We showed a component specific effect of plant size on feeding damage. Herbivore damage to components at the top of the plant, i.e. to flowers and fruits, was sensitive to plant size. Contrastingly, component biomass played the most important role, independently of plant size, for herbivores of the more hidden leaves and stems. We conclude that the search strategy of herbivores for food plants depends on the component of interest, particularly on its position on the plant.

The effect of feeding damage to the different plant components on plant reproductive fitness was likewise not uniform. Flower herbivory played the by far the most important role in reducing plant reproductive fitness and negatively affected seed number, thousand seed weight and total seed weight. Due to the increase in feeding damage to flowers with increasing plant size and its strong negative effect on plant fitness, we could demonstrate a negative net effect of plant size on thousand seed weight. Thus, being large and thereby highly conspicuous and attractive to herbivores caused a disadvantage regarding thousand seed weight. Regarding seed number and total seed weight, fitness costs for large plants caused by herbivore damage have been counterbalanced by benefits of large plants, which can assumed to be high competitiveness for light and other resources (Weiner, 1985), high conspicuousness to pollinators (Donnelly et al., 1998) or a greater ability to compensate for feeding damage, indicating a growth-defence trade off through the production of more numerous seeds. These conclusions are of great relevance as our findings are drawn from patterns across 21 plant species within a highly standardised experiment. 


\section{ACKNOWLEDGEMENTS}

Special thanks for help in the field go to Susanne Jahn and Brigitte Jünemann, as well as to Christiane Schlinkert, Eugen Schlinkert, Barbara Scheid, Christina Fischer, Verena Rösch, Georg Everwand, Jenny Osterburg, Annabelle Rohlfing, Anna-Katharina Franke, Petra Kubisch, Alexandra Arndt, Carina Burmeister and Felix Steinmeyer. KWS SAAT AG and the botanical gardens of the universities of Bayreuth and Göttingen provided parts of the seeds. We thank Carsten Thies for advice and Kristy Udy for linguistic improvements of the manuscript and two anonymous reviewers for their comments and suggestions, which improved the manuscript. H.S. was supported by the Ministry of Science and Culture of Lower Saxony.

\section{REFERENCES}

Agrawal, A.A., 2001. Transgenerational consequences of plant responses to herbivory: an adaptive maternal effect? Am. Nat. 157, 555-569.

Alford, D. V, Nilsson, C., Ulber, B., 2003. Insect pests of oilseed rape crops, in: Alford, D. V (Ed.), Biocontrol of Oilseed Rape Pests. Blackwell Science Ltd, Oxford, pp. 9-31.

Alonso, C., Herrera, C.M., 1996. Variation in herbivory within and among plants of Daphne laureola (Thymelaeaceae): correlation with plant size and architecture. J. Ecol. 84, 495502.

Araujo, A.P.A., D’arc de Paula, J., Carneiro, M.A.A., Schoereder, J.H., 2006. Effects of host plant architecture on colonization by galling insects. Austral Ecol. 31, 343-348.

Barton, K., 2011. MuMIn: multi-model inference. R package version 1.5.2. http://CRAN.Rproject.org/package=MuMIn.

Blanckenhorn, W.U., 2000. The evolution of body size: what keeps organisms small? Q. Rev. Biol. 75, 385-407.

Brown, J.H., Maurer, B.A., 1986. Body size, ecological dominance and Cope's rule. Nature $324,248-250$.

Buchanan, A.L., Underwood, N., 2013. Attracting pollinators and avoiding herbivores: insects influence plant traits within and across years. Oecologia 173, 473-82.

Burnham, K.P., Anderson, D.R., 2002. Model selection and multi-model inference: a practical information-theoretic approach, 2nd ed. Springer New York, New York.

Castagneyrol, B., Giffard, B., Péré, C., Jactel, H., 2013. Plant apparency, an overlooked driver of associational resistance to insect herbivory. J. Ecol. 101, 418-429. 
Collinge, S.K., Louda, S.M., 1988. Patterns of resource use by a drosophilid (Diptera) leaf miner on a native crucifer. Ann. Entomol. Soc. Am.

Dechert, G., Ulber, B., 2004. Interactions between the stem-mining weevils Ceutorhynchus napi Gyll. and Ceutorhynchus pallidactylus (Marsh.) (Coleoptera: Curculionidae) in oilseed rape. Agric. For. Entomol. 6, 193-198.

Donnelly, S.E., Lortie, C.J., Aarssen, L.W., 1998. Pollination in Verbascum thapsus (Scrophulariaceae): the advantage of being tall. Am. J. Bot. 85, 1618-1625.

Duggan, A.E., 1985. Pre-dispersal seed predation by Anthocharis cardamines (Pieridae) in the population dynamics of the perennial Cardamine pratensis (Brassicaceae). Oikos 44, 99-106.

Ekbom, B., Borg, A., 1996. Pollen beetle (Meligethes aeneus) oviposition and feeding preference on different host plant species. Entomol. Exp. Appl. 78, 291-299.

Endara, M.-J., Coley, P.D., 2011. The resource availability hypothesis revisited: a metaanalysis. Funct. Ecol. 25, 389-398.

Espírito-Santo, M.M., Neves, F.D.S., Andrade-Neto, F.R., Fernandes, G.W., 2007. Plant architecture and meristem dynamics as the mechanisms determining the diversity of gall-inducing insects. Oecologia 153, 353-364.

Feeny, P., 1976. Plant apparency and chemical defense, in: Wallace, J.W., Mansell, R.L. (Eds.), Biochemical Interaction Between Plants and Insects. Springer US, New York, pp. 1-40.

Free, J.B., Ferguson, A.W., Winfield, S., 1983. Effect of various levels of infestation by the seed weevil (Ceutorhynchus assimilis Payk.) on the seed yield of oil-seed rape (Brassica napus L.). J. Agric. Sci. 101, 589-596.

Free, J.B., Williams, I.H., 1979. The distribution of insect pests on crops of oil-seed rape (Brassica napus L.) and the damage they cause. J. Agric. Sci. 92, 139-149.

Gavloski, J., Lamb, R., 2000. Compensation for herbivory in cruciferous plants: specific responses to three defoliating insects. Environ. Entomol. 29, 1258-1267.

Giamoustaris, A., Mithen, R., 1996. The effect of flower colour and glucosinolates on the interaction between oilseed rape and pollen beetles. Entomol. Exp. Appl. 80, 206-208.

Grueber, C.E., Nakagawa, S., Laws, R.J., Jamieson, I.G., 2011. Multimodel inference in ecology and evolution: challenges and solutions. J. Evol. Biol. 24, 699-711.

Hainsworth, F.R., Wolf, L.L., Mercier, T., 1984. Pollination and pre-dispersal seed predation: net effects on reproduction and inflorescence characteristics in Ipomopsis aggregata Oecologia 63, 405-409.

Haysom, K.A., Coulson, J.C., 1998. The Lepidoptera fauna associated with Calluna vulgaris: effects of plant architecture on abundance and diversity. Ecol. Entomol. 23, 377-385.

Heiberger, R.M., 2009. HH: statistical analysis and data display: Heiberger and Holland. R package version 2.1-32. http://CRAN.R-project.org/package=HH. 
Hemptinne, J.-L., Magro, A., Evans, E.W., Dixon, A.F.G., 2012. Body size and the rate of spread of invasive ladybird beetles in North America. Biol. Invasions 14, 595-605.

Herms, D., Mattson, W., 1992. The dilemma of plants: to grow or defend. Q. Rev. Biol. 67, 283-335.

Juran, I., Gothlin Čuljak, T., Grubišić, D., 2011. Rape stem weevil (Ceutorhynchus napi Gyll. 1837) and cabbage stem weevil (Ceutorhynchus pallidactylus Marsh. 1802)(Coleoptera: Curculionidae) - important oilseed rape pests. Agric. Conspec. Sci. 76, 93-100.

Kawano, S., Nagai, Y., 1975. The productive and reproductive biology of flowering plants, 1: life history strategies of three Allium species in Japan. Bot. Mag. 88, 281-318.

Lawton, J.H., 1983. Plant architecture and the diversity of phytophagous insects. Annu. Rev. Entomol. 28, 23-39.

Lawton, J.H., Price, P.W., 1979. Species richness of parasites on hosts: agromyzid flies on the British Umbelliferae. J. Anim. Ecol. 48, 619-637.

McArt, S.H., Halitschke, R., Salminen, J.P., Thaler, J.S., 2013. Leaf herbivory increases plant fitness via induced resistance to seed predators. Ecology 94, 966-975.

McCall, A.C., Irwin, R.E., 2006. Florivory: the intersection of pollination and herbivory. Ecol. Lett. 9, 1351-1365.

Moyes, C.L., Raybould, A.F., 1997. Herbivory by the cabbage seed weevil (Ceutorhynchus assimilis) in natural populations of Brassica oleracea Int. Symp. Brassica 97, Xth Crucif. Genet. Work. 459 315-322.

Neuvonen, S., Niemelä, P., 1981. Species richness of Macrolepidoptera on Finnish deciduous trees and shrubs. Oecologia 51, 364-370.

Peters, R.H., 1983. The ecological implications of body size. Cambridge University Press, Cambridge.

Pinheiro, J., Bates, D., DebRoy, S., Sarkar, D., R Development Core Team, 2011. nlme: linear and nonlinear mixed effects models. R package version 3.1-98.

Puentes, A., Ågren, J., 2012. Additive and non-additive effects of simulated leaf and inflorescence damage on survival, growth and reproduction of the perennial herb Arabidopsis lyrata. Oecologia 169, 1033-1042.

R Development Core Team, 2011. R: a language and environment for statistical computing. R Foundation for Statistical Computing, Vienna, Austria. ISBN 3-900051-07-0, URL http://www.R-project.org/.

Remmel, T., Tammaru, T., 2009. Size-dependent predation risk in tree-feeding insects with different colouration strategies: a field experiment. J. Anim. Ecol. 78, 973-980.

Reudler Talsma, J.H., Biere, A., Harvey, J.A., van Nouhuys, S., 2008. Oviposition cues for a specialist butterfly-plant chemistry and size. J. Chem. Ecol. 34, 1202-1212.

Schielzeth, H., 2010. Simple means to improve the interpretability of regression coefficients. Methods Ecol. Evol. 1, 103-113. 
Schlinkert, H., 2014. Plant size gradient in Brassicaceae. Figshare, http://dx.doi.org/10.6084/m9.figshare.12.

Steffan-Dewenter, I., Tscharntke, T., 1999. Effects of habitat isolation on pollinator communities and seed set. Oecologia 121, 432-440.

Strauss, S.Y., Agrawal, A.A., 1999. The ecology and evolution of plant tolerance to herbivory. Trends Ecol. Evol. 14, 179-185.

Tenow, O., Larsson, S., 1987. Consumption by needle-eating insects on Scots pine in relation to season and stand age. Ecography (Cop.). 10, 249-260.

Trumble, J.T., Kolodny-Hirsch, D.M., Ting, I.P., 1993. Plant compensation for arthropod herbivory. Annu. Rev. Entomol. 38, 93-119.

Ulber, B., 2003. Parasitoids of Ceutorhynchid stem weevils, in: Alford, D. V (Ed.), Biocontrol of Oilseed Rape Pests. Blackwell Science Ltd, Oxford, pp. 87-96.

Vasconcellos-Neto, J., Ferreira Monteiro, R., 1993. Inspection and evaluation of host plant by the butterfly Mechanitis lysimnia (Nymph., Ithomiinae) before laying eggs: a mechanism to reduce intraspecific competition. Oecologia 95, 431-438.

Weiner, J., 1985. Size hierarchies in experimental populations of annual plants. Ecology 66, 743-752.

Williams, I.H., 2010. The major insect pests of oilseed rape in Europe and their management: an overview, in: Williams, I.H. (Ed.), Biocontrol-Based Integrated Management of Oilseed Rape Pests. Springer Netherlands, Dordrecht, pp. 1-44.

Williams, I.H., Free, J.B., 1978. The feeding and mating behaviour of pollen beetles (Meligethes aeneus Fab.) and seed weevils (Ceutorhynchus assimilis Payk.) on oil-seed rape (Brassica napus L.). J. Agric. Sci. 91, 453-459.

Williams, I.H., Free, J.B., 1979. Compensation of oil-seed rape (Brassica napus L.) plants after damage to their buds and pods. J. Agric. Sci. 92, 53-59.

Zuur, A.F., Ieno, E.N., Elphick, C.S., 2010. A protocol for data exploration to avoid common statistical problems. Methods Ecol. Evol. 1, 3-14. 


\section{SUPPLEMENTAL MATERIAL}

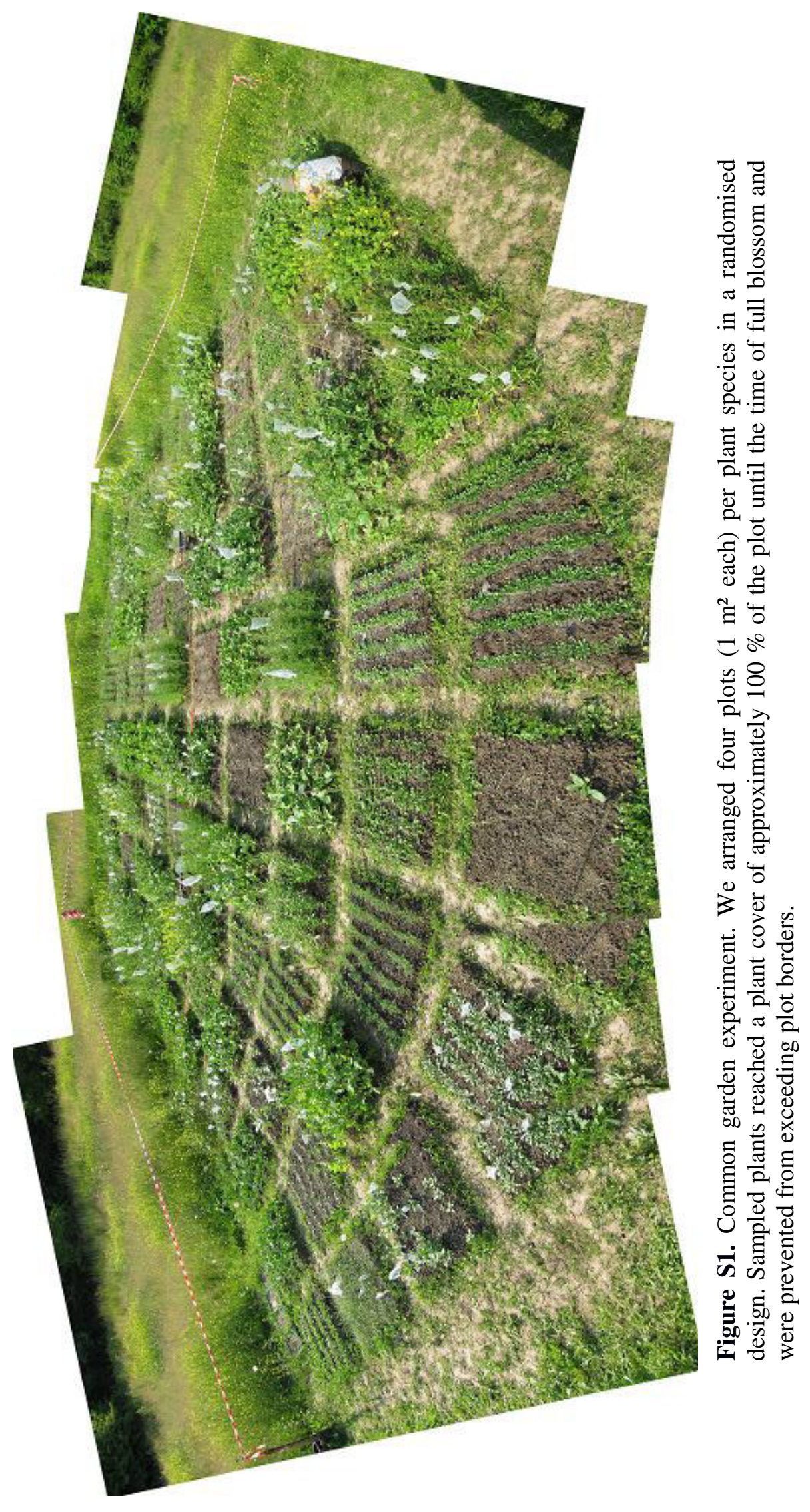




\section{S2. Leaf contents}

\section{Methods leaf contents}

We harvested leaves of one quarter of each plot at the time of full blossom to determine their nitrogen, carbon and glucosinolate content. Harvested leaves were frozen $\left(-20{ }^{\circ} \mathrm{C}\right)$ immediately after collection, freeze-dried and pulverised. One part of the sample was used to determine nitrogen and carbon content, 50-100 $\mathrm{mg}$ were used to determine glucosinolate content. Extraction and purification of glucosinolates followed the methods described in Kabouw et al. (2010). We used high-performance liquid chromatography (HPLC) to identify and measure the content of glucosinolates as described in Kabouw et al. (2010).

We conducted a correlation analysis to test for a potential correlation of plant size with nitrogen content and $\mathrm{C} / \mathrm{N}$ ratio respectively. Additionally we tested for interrelations among the glucosinolate content and plant size as well as other sampled plant traits, feeding damage and fitness parameters using a non-metric multidimensional scaling (NMDS) (Oksanen et al., 2011) as a common unconstrained ordination method (Minchin, 1987). The plant speciesglucosinolate matrix (average glucosinolate contents per plant species, Jaccard dissimilarity) was calculated independently, which offers the option to superimpose vectors of sampled plant traits, feeding damage and fitness parameters onto the ordination diagram to identify relationships to glucosinolate composition. p-values were computed by 1000 permutations.

\section{References}

Kabouw, P., Biere, A., van der Putten, W.H., Van Dam, N.M., 2010. Intraspecific differences in root and shoot glucosinolate profiles among white cabbage (Brassica oleracea var. capitata) cultivars. J. Acricultural Food Chem. 58, 411-417.

Minchin, P.R., 1987. An evaluation of relative robustness of techniques for ecological ordination. Vegetatio 71, 145-146.

Oksanen, J., Blanchet, F.G., Kindt, R., Legendre, P., Minchin, P.R., O’Hara, R.B., Simpson, G.L., Solymos, P.H., Stevens, M.H., Wagner, H., 2011. vegan: community ecology package. R package version 2.0-1. http://CRAN.R-project.org/package=vegan. 


\section{Results leaf contents}

Plant size was correlated neither to nitrogen content ( $\mathrm{p}$-value $=0.116$, cor $=-0.363$ ) nor to $\mathrm{C} / \mathrm{N}$ ratio of leaves $(\mathrm{p}$-value $=0.192$, cor $=0.304)$. Glucosinolate composition analysed by NMDS (stress value $=0.175$ ) showed close relationships between glucosinolate compositions of closely related plant species. The ordination analysis showed no significant relationship between glucosinolate composition and plant size, but a relation to nitrate per dry matter, total glucosinolate content and number of flowers and fruits on the one side, and size of flowers and fruits on the other side (Table S2, Figure S2).

Table S2. Leaf contents. Results of NMDS analysing interrelations among the glucosinolate content and plant size as well as other sampled plant traits, feeding damage and fitness parameters. Levels of significance are given with $* p<0.05$ and $* * \mathrm{p}<0.01$.

\begin{tabular}{|c|c|c|c|c|c|}
\hline & NMDS1 & NMDS2 & $\mathrm{r}^{2}$ & $\operatorname{Pr}(>r)$ & \\
\hline Plant size $(\mathrm{cm})$ & -0.739 & -0.674 & 0.098 & 0.421 & \\
\hline Plant biomass (g) & -0.735 & -0.678 & 0.018 & 0.858 & \\
\hline Number leaves ${ }^{\text {a }}$ & 0.915 & -0.403 & 0.213 & 0.114 & \\
\hline Size leaves $\left(\mathrm{cm}^{2}\right)$ & -0.903 & -0.429 & 0.121 & 0.341 & \\
\hline Biomass leaves $(\mathrm{g})^{\mathrm{b}}$ & 0.970 & 0.243 & 0.019 & 0.855 & \\
\hline Nitrogen $(\mathrm{mg} / \mathrm{g})^{\mathrm{a}}$ & 0.998 & 0.066 & 0.425 & 0.010 & $* *$ \\
\hline Number flowers ${ }^{a}$ & 0.945 & -0.326 & 0.440 & 0.008 & $* *$ \\
\hline Size flowers $(\mathrm{mm})^{\mathrm{a}}$ & -0.740 & 0.673 & 0.361 & 0.021 & $*$ \\
\hline Biomass flowers $(\mathrm{g})^{\mathrm{b}}$ & -0.285 & 0.959 & 0.077 & 0.518 & \\
\hline Number stems ${ }^{\text {a }}$ & 0.578 & 0.816 & 0.146 & 0.283 & \\
\hline Size stems (mm) & -0.473 & -0.881 & 0.142 & 0.285 & \\
\hline Biomass stems (g) & -0.683 & -0.731 & 0.045 & 0.679 & \\
\hline Number fruits ${ }^{a}$ & 0.931 & -0.366 & 0.324 & 0.036 & $*$ \\
\hline Biomass fruits (g) & 0.485 & 0.874 & 0.077 & 0.515 & \\
\hline Size fruits $\left(\mathrm{mm}^{2}\right)^{\mathrm{a}}$ & -0.888 & 0.460 & 0.329 & 0.036 & $*$ \\
\hline Feeding damage to leaves $(\%)^{\mathrm{c}}$ & 0.592 & 0.806 & 0.111 & 0.374 & \\
\hline Feeding damage to flowers $(\%)^{\mathrm{c}}$ & -0.942 & 0.336 & 0.084 & 0.486 & \\
\hline Feeding damage to stems $(\%)^{\mathrm{c}}$ & -0.425 & 0.905 & 0.009 & 0.928 & \\
\hline Feeding damage to fruits $(\%)^{\mathrm{c}}$ & -0.985 & 0.170 & 0.145 & 0.249 & \\
\hline Thousand seed weight (\%) & -0.034 & 0.999 & 0.102 & 0.407 & \\
\hline Seed number $(\%)^{\mathrm{c}}$ & -0.530 & 0.848 & 0.031 & 0.776 & \\
\hline Total seed weight $(\%)^{\mathrm{c}}$ & -0.669 & 0.744 & 0.092 & 0.445 & \\
\hline Glucosinolate content sum $(\mathrm{mol} / \mathrm{g})$ & 0.996 & -0.085 & 0.503 & 0.004 & $* *$ \\
\hline
\end{tabular}

${ }^{\mathrm{a}} \log$-transformed, ${ }^{\mathrm{b}}$ sqrt-transformed, ${ }^{\mathrm{c}}$ asin-sqrt-transformed 


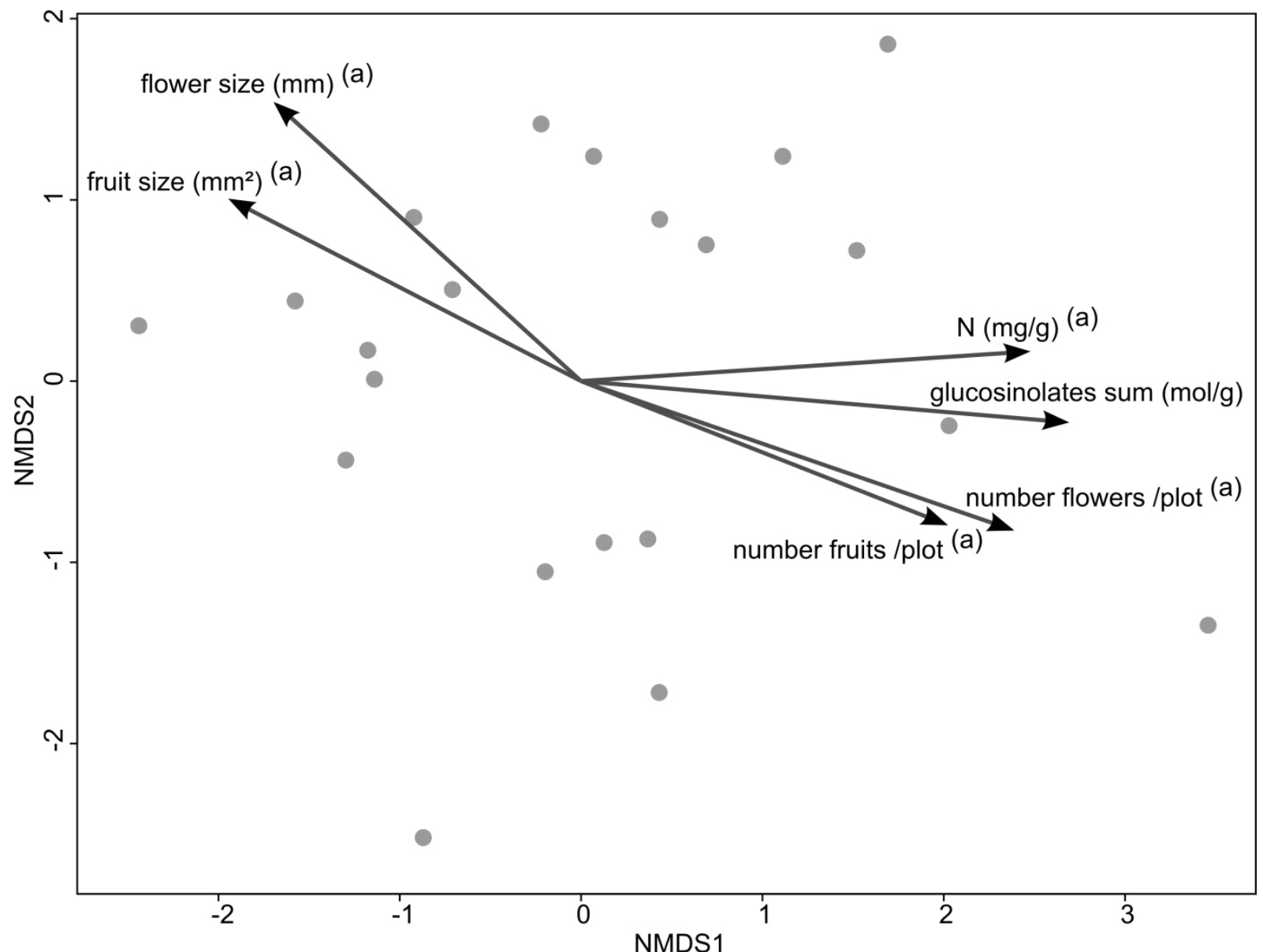

Figure S2. Leaf contents. Results of NMDS analysing interrelations among the glucosinolate content and plant size as well as other sampled plant traits, feeding damage and fitness parameters. (a) indicates log-transformation of data. 
Table S3a. Correlations among plant characteristics. Pearson correlation coefficients and levels of significance are given with (.) $\mathrm{p}<0.1, * \mathrm{p}<0.05, * * \mathrm{p}<0.01$ and $* * * \mathrm{p}<0.001$. Component size (bold) was not included in analyses due to its relationships to the other parameters. Not tested combinations of variables are marked as grey cells.

\begin{tabular}{|c|c|c|c|c|}
\hline & 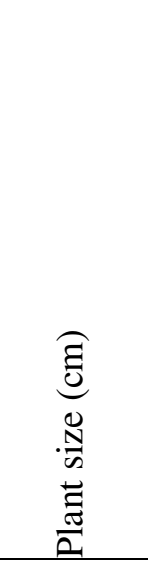 & 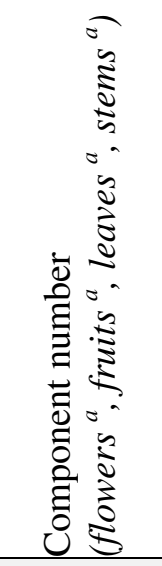 & 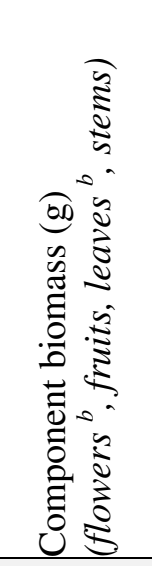 & $\begin{array}{l}\vdots \\
\overline{0} \\
0 \\
\dot{0} \\
\vdots \\
\frac{0}{I}\end{array}$ \\
\hline Flower number ${ }^{a}$ & -0.2 & & & \\
\hline Flower biomass $(\mathrm{g})^{\mathrm{b}}$ & 0.27 & 0.004 & & \\
\hline Flower colour & -0.27 & 0.17 & 0.22 & \\
\hline Flower size $(\mathbf{m m})^{a}$ & $0.51 *$ & $-0.66^{* *}$ & 0.36 & -0.04 \\
\hline Fruit number $^{\mathrm{a}}$ & $-0.51 *$ & & & \\
\hline Fruit biomass (g) & 0.17 & -0.02 & & \\
\hline Fruit size $\left(\mathbf{m m}^{2}\right)^{a}$ & $0.47 *$ & $-0.91 * * *$ & 0.31 & \\
\hline Leaf number ${ }^{a}$ & -0.29 & & & \\
\hline Leaf biomass $(\mathrm{g})^{\mathrm{b}}$ & $0.61 * *$ & 0.002 & & \\
\hline Leaf size $\left(\mathrm{cm}^{2}\right)$ & $\mathbf{0 . 8 2} * * *$ & $-0.42()$. & $0.46 *$ & \\
\hline Stem number ${ }^{a}$ & $-0.62 * *$ & & & \\
\hline Stem biomass (g) & $0.78 * * *$ & $-0.49 *$ & & \\
\hline Stem size (mm) & $0.87 * * *$ & $-0.66 * *$ & $0.83 * * *$ & \\
\hline
\end{tabular}

${ }^{\mathrm{a}} \log$-transformed, ${ }^{\mathrm{b}}$ sqrt-transformed 
Table S3b. Correlations among feeding damage to the different components. Pearson correlation coefficients and levels of significance are given with $* p<0.05$. Not tested combinations of variables are marked as grey cells.

\begin{tabular}{|c|c|c|c|c|}
\hline & 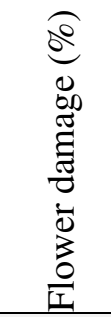 & 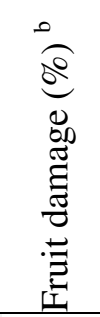 & 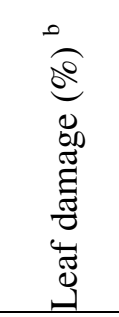 & 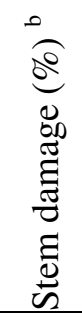 \\
\hline Flower damage (\%) ${ }^{\mathrm{b}}$ & & 0.29 & $0.47 *$ & 0.35 \\
\hline Fruit damage $(\%)^{\mathrm{b}}$ & 0.29 & & -0.21 & 0.23 \\
\hline Leaf damage $(\%)^{\mathrm{b}}$ & $0.47 *$ & -0.21 & & 0.19 \\
\hline Stem damage $(\%)^{\mathrm{b}}$ & 0.35 & 0.23 & 0.19 & \\
\hline
\end{tabular}




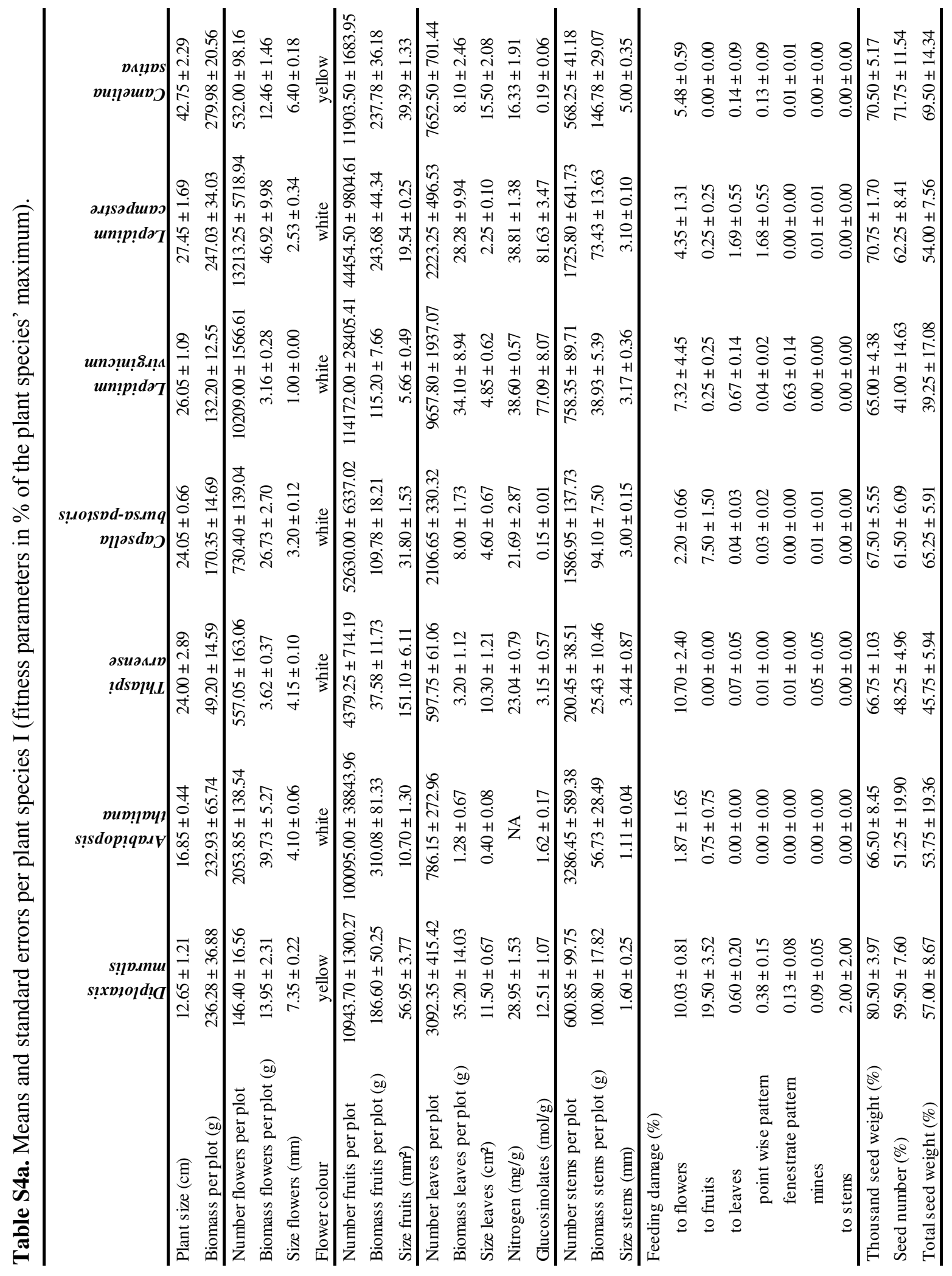




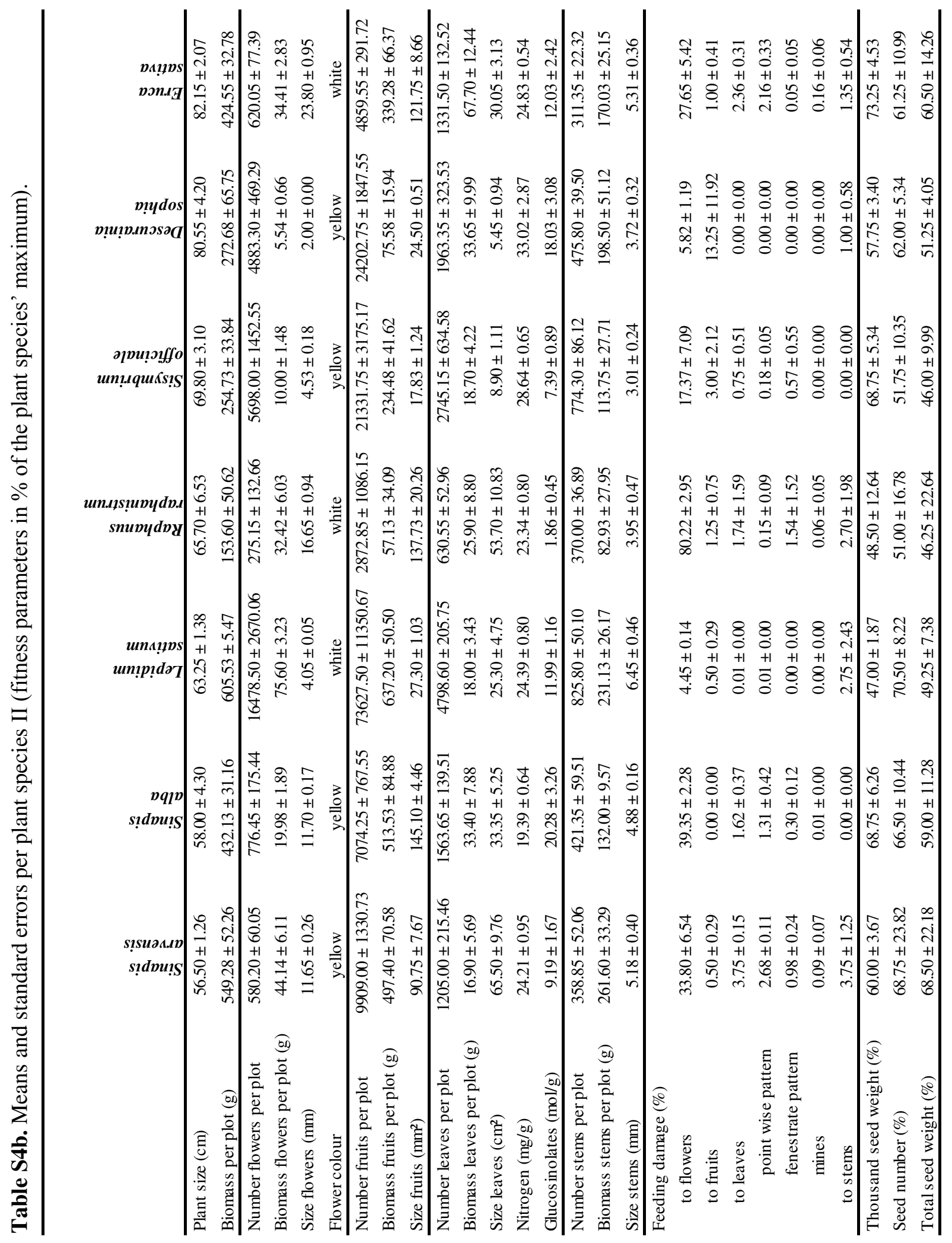




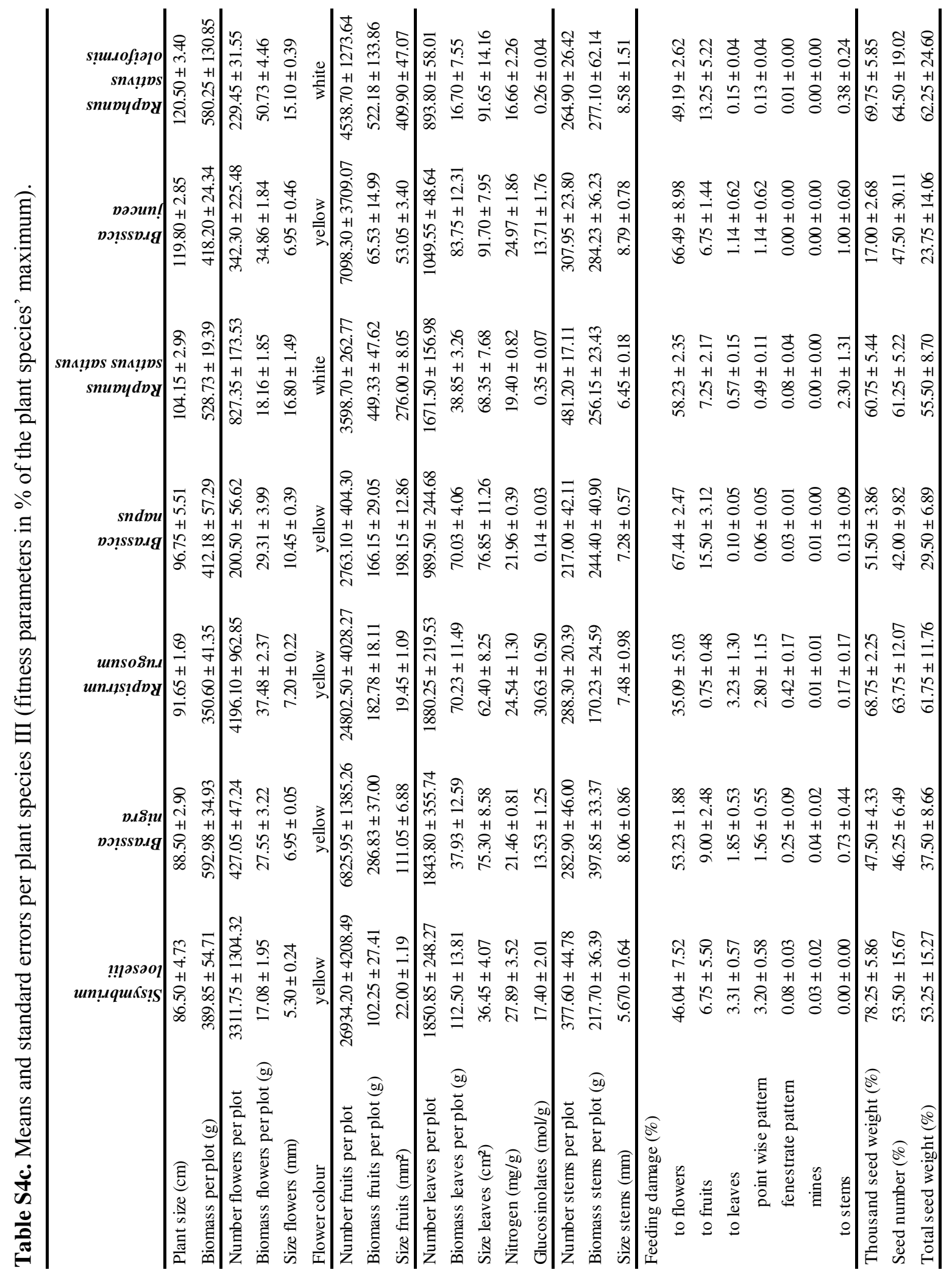




\title{
Chapter 4
}

\author{
Plant SIZE AS Determinant OF
}

\section{MUTUALISTIC VERSUS ANTAGONISTIC INTERACTIONS}

\author{
AND REPRODUCTIVE FITNESS
}

\section{ACROSS 21 BRASSICACEAE SPECIES}

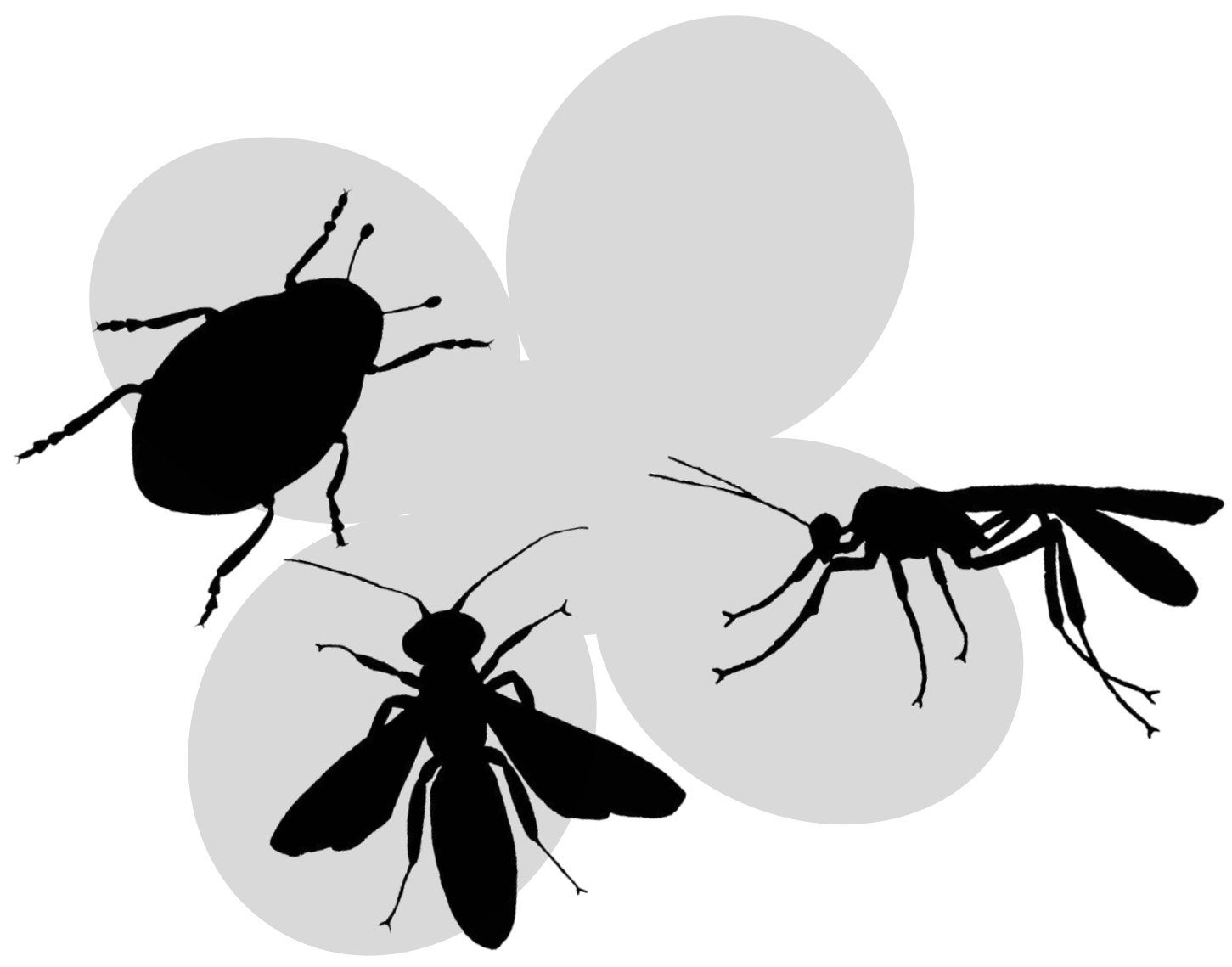

Hella Schlinkert, Catrin Westphal, Yann Clough, Juliane Helmerichs, Teja Tscharntke 


\section{SUMMARY}

Plant size can be hypothesised to be a major driver of biotic interactions. However, it is little explored, how plant size affects mutualists versus antagonists and the plant's resulting reproductive fitness. We established a common garden experiment with a plant size gradient (from 10 to $130 \mathrm{~cm}$ length) among 21 annual Brassicaceae species (standardising features of habitat and surrounding landscape) and assessed flower visiting pollinators, pollen beetles, their parasitism and the plant reproductive fitness. Plant size was positively related to abundance and species richness of flower visiting insects, both the pollinators (but only when flowers were not superabundant) as well as pollen beetles, despite the higher pollen beetles' parasitism rates. Pollen beetles had a negative effect on seed number as well as on thousand seed weight, whereas pollinators had a positive effect on seed number only. Overall, plant size negatively affected thousand seed weight but not seed number, indicating a compensation of pollen beetle damage by enhancement of seed set through pollinators. In conclusion, plants suffer from being large regarding thousand seed weight, but benefit with respect to seed number particularly in pollinator dominated locations with small densities of herbivorous flower visitors.

\section{Keywords}

bees (Apoidea), herbivory, Meligethes aeneus, multitrophic interactions, pollen beetles, pollination 


\section{INTRODUCTION}

Body size is a well-known and major predictor of patterns and processes in ecology, with predator and prey body masses determining food-web and population dynamics (Brose, 2010). This is not only true for animals, but also for plants, where intraspecific as well as interspecific length differs greatly and can be a major predictor of richness of associated organisms and niches filled (Feeny, 1976; Lawton, 1983). Large plants are more conspicuous and may be more attractive for organisms since they offer a greater quantity and variety of resources, enhancing number and size of populations and thereby offering a greater range of biotic interaction partners (Feeny, 1976; Lawton, 1983). Positive impacts of plant size on the abundance and diversity of associated insects are known from mainly intraspecific field studies (Donnelly et al., 1998; Gómez, 2003; Haysom and Coulson, 1998 and others). However, biotic interactions and resulting differences in the plant reproductive success have not yet been studied across a broad range of closely related plant species.

General patterns of interactions and their underlying mechanisms are a major topic in ecology and an important basis for conserving biodiversity (Ritchie and Johnson, 2009), predicting species distribution and responses to climate change (Van der Putten et al., 2010) and improving biological control (Cortesero et al., 2000). Mutualistic and antagonistic interactions are common among plants and associated insects (e.g. Parsche et al., 2011). Insect pollination often leads to an increase in number and quality of seeds and fruits (e.g. Bommarco et al., 2012) and is of great importance for the reproductive fitness of many plant species, including crops (Garibaldi et al., 2013). A decline in pollinating bee species may even lead to a decline in insect-pollinated plant species (Biesmeijer et al., 2006). On the other hand, antagonists like pollen beetles (Meligethes aeneus FAB.) may reduce the reproductive fitness of plants. Larvae of pollen beetles feed on pollen, while adults feed on different flower components; in both cases, feeding damage results in podless stalks or weakened pods and therefore in reduced seed numbers (Williams, 2010).

Provided that large plants attract more insects than small plants, the benefits of numerous mutualistic interactions with pollinators may be counterbalanced by the disadvantages of numerous antagonistic interactions - but what is actually more important for the plant reproductive fitness? Are mutualists and antagonists equally attracted by large plants? Is it after all an advantage for a plant to be large? Flower parameters like size, cover, amount or 
colour can attract flower visiting insects, pollinators as well as pollen beetles (Giamoustaris and Mithen, 1996; Hegland and Totland, 2005; Scheid et al., 2011). In contrast, studies testing the effects of plant size (i.e. the exposition height of flowers) on mutualistic and antagonistic flower visiting insects are scarce, focusing either on pollinators (Donnelly et al., 1998; Gómez, 2003; Klinkhamer et al., 1989) or on feeding damage by flower herbivores (Sletvold and Grindeland, 2008; Williams and Free, 1979). Moreover, we don't know any study investigating the relative importance of mutualistic vs. antagonistic flower visiting insects in relation to plant size and assessing the final outcome in terms of the plant reproductive fitness (final plant fitness only: Dickson and Petit, 2006; O’Connell and Johnston, 1998; combination of pollinators and final plant fitness, but not florivores: Ehrlén et al., 2012; Gómez, 2003; all studies focused on intraspecific plant size gradients).

The present study focuses on antagonistic and mutualistic flower visiting insects along a plant size gradient, comparing 21 plant species of the family Brassicaceae in a common garden experiment. We test the following hypotheses:

(1) Increasing plant size enhances the abundance and species richness of flower visiting pollinators, the abundance of pollen beetle adults and larvae and parasitism rates of pollen beetle larvae.

(2) Mutualistic and antagonistic interactions tend to have contrasting effects on the plant reproductive fitness, measured as number of seeds, proportion of podless stalks, thousand seed weight and total seed weight per individual.

Finally, we address the question whether there is a trade-off between beneficial and detrimental effects of mutualists and antagonists along the plant size gradient.

\section{MATERIAL AND METHODS}

\section{Study site and sampling design}

A common garden experiment was established in summer 2010 in Göttingen (Lower Saxony, Germany). The study site was located in a grassland area dominated by grasses and herbs, including herbs of the family Brassicaceae. We chose 25 brassicaceous plant species covering a plant size gradient and excluded plant species from the data set that could not be brought to 
full flowering between mid-June and mid-July 2010 in order to avoid phenological differences in the local insect community of the study area. Nonetheless, the remaining 21 plant species covered a gradient in plant size from $12.65 \mathrm{~cm} \pm 1.21 \mathrm{~cm}$ (Diplotaxis muralis (L.) DC.) to $120.50 \pm 3.40$ (Raphanus sativus L. oleiformis) (mean size of the different plant species shown relative to one another in Supplemental material Figure S1). Chosen species are similar in many characteristics such as the typical flower shape of the family and secondary plant substances (glucosinolates), as well as their pollination ecology, since insect pollinators increase seed set of all species (http://www.floraweb.de, last visited January 2014). Chosen species are annual plants, wide-spread in Germany, particularly in Lower Saxony, and include neophytes (four species), cultivated plants (eight species) and indigenous weeds (nine species). We established a field of 100 plots with a size of $1 \mathrm{~m}^{2}$ and a distance of $30 \mathrm{~cm}$ to each other (Supplemental material Figure S2). Four plots per plant species were arranged in monoculture in a completely randomised design. We irrigated and weeded regularly, fertilised once all plots equally (NPK fertiliser with the ratio of 15:6:12) and managed the plants to reach a plant cover about $100 \%$ of the plot until the time of full blossom and to not exceed plot borders.

\section{Mutualists and antagonists associated with the flowers}

As potential pollinators, we sampled flower visiting hymenopteran, dipteran and lepidopteran insects on every plot during its specific period of full blossom, conducting three runs with varying day time (morning, midday, afternoon) and excluding cold or wet days. Each run consisted of a 5 min. observation period (for authentic abundance) and a catching period (net 5 min., handling time not included). Pollinators were pooled for each plot.

Abundance of pollen beetle adults was recorded once on five randomly chosen and individually marked plant individuals on every plot at its time of full blossom. Abundance of pollen beetle adults per plot was extrapolated by multiplying the mean abundance per plant individual of each plot with its number of plant individuals.

To assess the abundance of pollen beetle larvae per plot, we harvested all inflorescences from one quarter of each of two randomly selected plots per plant species. The harvest of inflorescences took place at the time of full blossom of each plot, after flower visiting insects 
and flower cover were sampled and the number of plant individuals per plot was recorded. Thereby we left five individually marked plant individuals so that they could develop pods. Inflorescences were stored at $-20{ }^{\circ} \mathrm{C}$ until buds $>2 \mathrm{~mm}$ and flowers were dissected to collect the pollen beetle larvae. Abundance per plot was extrapolated by multiplying the mean abundance of pollen beetle larvae per plant individual of each plot with its plant individual number.

The parasitism rate of pollen beetle larvae was determined by dissecting up to 30, but at least 10 , randomly selected pollen beetle larvae of the second instar per plot. A pollen beetle larva was defined as parasitised if a larva or an egg of a parasitoid was found inside.

\section{Plant traits}

Plant size (i.e. plant height from the ground to the top of the plant), petal length and flower quantity per plant individual were recorded at the time of full blossom at five randomly selected plant individuals and flowers of each plot. Mean values of plant size and petal length were calculated for each plot, flower quantity per plot was extrapolated by multiplying the mean number of flowers per plant individual of the relevant plot with its plant individual number. Flower cover was estimated per plot. Flower colour was species dependent and either yellow or white.

\section{Plant reproductive fitness}

At the plants' individual time of full ripeness we counted the pods, flowers and buds as well as the podless stalks of the five individually marked plant individuals. A subset of 20 randomly selected ripe and still closed fruits per plant individual was opened, seeds per fruit were counted, oven-dried for $48 \mathrm{~h}$ at $60{ }^{\circ} \mathrm{C}$ and the thousand seed weight per plant individual recorded.

Number of seeds per plant individual was extrapolated by multiplying the number of seeds per pod with the number of pods per plant individual. The proportion of podless stalks per potential pods (pods in addition to podless stalks) was calculated per plant individual. Finally we extrapolated the total seed weight per individual by multiplying the weight of one seed 
(thousand seed weight divided by 1000) with the number of seeds per individual. Mean values of all plant reproductive fitness parameters per plot, namely seed number, proportion of podless stalks, thousand seed weight and total seed weight, were calculated.

In order to compare the plant reproductive fitness parameters between different plant species, we accounted for the species-specific potential using the realised percent of their potential instead of absolute values (relationships between absolute values of plant characteristics and plant size are shown in Supplemental material Figure S3). The potential of a plant species was defined as the mean of 10 maximum values based on 40 individuals per species. In the following we refer to the percentage in which one plant individual realised the species' maximum potential as seed number (\%), thousand seed weight (\%) and total seed weight (\%).

\section{Statistics}

We first tested for effects of plant size on flower visiting insects, using linear mixed effects models in the nlme package (Pinheiro et al., 2011) for R (R Development Core Team, 2011). Response variables were abundance and species richness of pollinators, abundance of pollen beetle adults, their larvae and parasitism rates per plot. As covariates we included flower size, quantity and colour with their two way interactions but omitted flower cover since this results from and is positively correlated to flower number (results of a multiple regression using means per plant species: $\mathrm{p}$-value $=0.009$, centred and standardised estimate $\pm \mathrm{SE}=0.870 \pm$ 0.299 ) and flower size ( $p$-value $=0.014$, centred and standardised estimate $\pm \mathrm{SE}=0.816 \pm$ 0.299). Testing the effect of plant size on parasitism rate, we added the number of pollen beetle larvae as explanatory variable as second order polynomial to the model to account for density dependence of parasitoids. Furthermore we had to omit flower colour as explanatory variable in this model, as we only included plots with a minimum number of 10 pollen beetle larvae of second instar and too few pollen beetle larvae were found in white flowers for a statistically sound analysis. Plant species was included as random effect in each model to avoid pseudoreplication (four plots per plant species).

In a second step, we tested the effect of flower visiting insects on seed number ( $\%$ of the species' maximum), proportion of podless stalks, thousand seed weight (\%) and total seed weight (\%) (hereafter called plant reproductive fitness parameters) using linear mixed models. 
Abundance of pollinators (strongly correlated to their species richness, results of a simple correlation using means per plant species: Pearson's correlation coefficient $=0.919, \mathrm{p}$-value $=$ $<0.001$ ), abundance of pollen beetle adults and their larvae including two way interactions were used as explanatory variables. Finally, we analysed the net effect of plant size on plant reproductive fitness parameters, using the same modelling approach (i.e. linear mixed models).

Testing the correlations of explanatory variables of each model we found significant relationships (p-value $<0.05$ ) between plant size and log-transformed petal length (Pearson's correlation coefficient $=0.51$ ) and between log-transformed petal length and log-transformed flower quantity (Pearson's correlation coefficient $=-0.66$ ), as well as between the logtransformed abundance of pollinators and pollen beetle adults (Pearson's correlation coefficient $=0.59)$ and between the log-transformed abundance of pollen beetle adults and pollen beetle larvae (Pearson's correlation coefficient $=0.60$ ). Multicollinearity was not an issue as variance inflation factors were below 3 for all models in this study (HH-package, Heiberger, 2009; Zuur et al., 2010). Response and explanatory variables were either log- or arcsine-square-root-transformed whenever necessary to account for homoscedasticity and normal error distribution, which was confirmed by examining diagnostic plots. AICc values were calculated for all subsets of the full model (for models including parasitism rate, which were based on a subset of 20 plots, we restricted the number of variables to a maximum of six to preserve explanatory power) using the dredge function in the MuMIn package of $\mathrm{R}$ (Barton, 2011). To account for non-independency between some of the explanatory variables (see above), we used parameter weights to identify variables and interactions between variables that consistently contributed to the information content of the models. Parameter weights were calculated by averaging models with $\triangle \mathrm{AICc}<2$ (Burnham and Anderson, 2002; Grueber et al., 2011). Explanatory variables and interactions with a parameter weight $\geq 0.6$ were defined as important for the relevant response variable and are presented in the results. Estimates with standard errors were assessed from the summary table of the model with the lowest AICc involving all explanatory variables with a parameter weight $\geq 0.6$ and are centred and standardised to improve their interpretability (Schielzeth, 2010) (parameter weights, estimates and standard errors of all tested variables of every calculated model are provided in Tables 1-3). 


\section{RESULTS}

\section{Effects of plant size on flower visiting insects}

We recorded overall 3538 pollinators of 79 species, dominated by 2526 individuals of 26 bee species (arithmetic mean \pm SE $25.24 \pm 2.41$ pollinator individuals and $8.49 \pm 0.43$ pollinator species per plot), 7322 pollen beetle adults (613.11 \pm 107.97 extrapolated individuals per plot), 8182 pollen beetle larvae (1106.57 \pm 323.39 extrapolated individuals per plot $)$ as well as 349 parasitoid larvae and 20 parasitoid eggs in dissected pollen beetle larvae resulting in a mean parasitism rate of $43 \% \pm 6 \%$ (see Supplemental material Table S4a-c for all parameters per plant species).

Plant size had an overall positive effect on all flower visiting insects as well as on the parasitism rate of pollen beetle larvae (Figure 1, for parameter weights and estimates with standard errors of all tested variables of every model see Table 1). Further, the covariates petal length and flower quantity had a positive impact on flower visiting insects in many models (Figure 1). The flower colour yellow played a major role in the abundance of pollen beetle adults and their larvae (Figure 1).

Species richness of pollinators increased with increasing plant size, notably on plots with small flowers and on plots with few flowers, while plant size had no effect on pollinator species richness on plots with large flowers and on plots with many flowers (Figures 1a-b). Additionally, petal length had a positive influence on species richness of pollinators, mainly on plots with few flowers (Figure 1c). Abundance of pollinators increased with increasing plant size, notably on plots with small flowers and on plots with few flowers, but decreased with increasing plant size on plots with large flowers and on plots with many flowers (Figures 1d-e). The abundance of pollen beetle adults increased with increasing plant size, while plots with yellow flowers showed the strongest increase (Figure 1f). Further, pollen beetle abundance was positively related to petal length, especially on plots with few flowers (Figure 1g). The abundance of pollen beetle larvae was positively related to plant size (Figure $1 \mathrm{~h}$ ). Additionally, petal length had a positive influence on the abundance of pollen beetle larvae, mainly on plots with yellow flowers (Figure 1i). Parasitism rates of pollen beetle larvae were positively influenced by plant size and followed the abundance of pollen beetle larvae as an optimum curve (Figures $1 \mathrm{j}-\mathrm{k}$ ). 

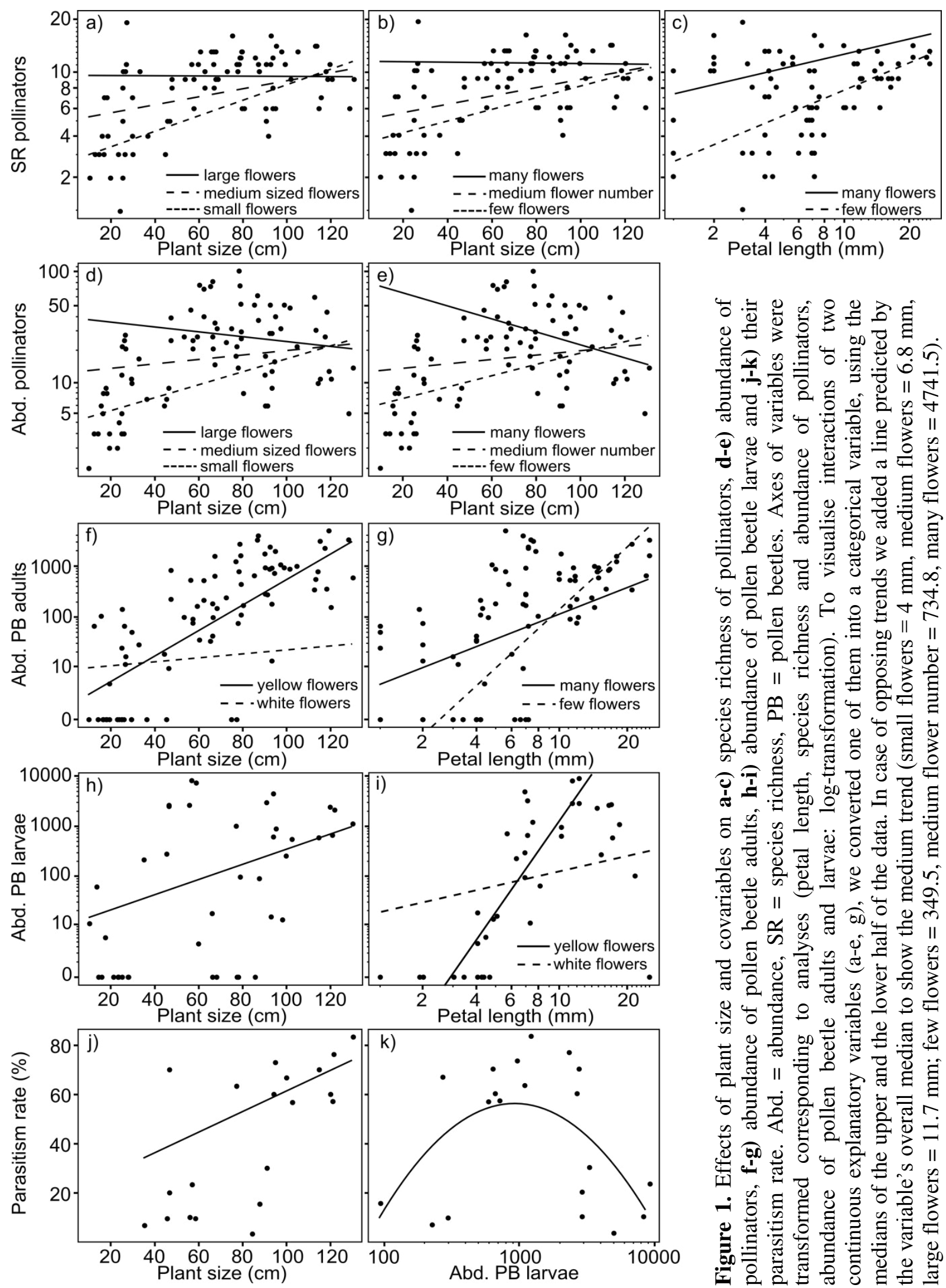
Table 1. Effects of plant size and covariables on flower visiting insects. Abundance $=$ Abd.; species richness $=$ SR; pollen beetle parasitism rate $=$ Paras. rate; pollen beetles $=$ PB. Parameter weights (pw) refer to a delta 2 AICc range. Explanatory variables and interactions with a parameter weight $\geq 0.6$ (bold) were defined as important for the relevant response variable and will be discussed. Estimates (est.) with standard errors (SE) were assessed from the summary table of the lme-model with the lowest AICc involving all explanatory variables with a parameter weight $\geq 0.6$ and are centred and standardised to improve their interpretability. Variables which were not involved in the relevant full model are marked as grey cells.

\begin{tabular}{|c|c|c|c|c|c|c|c|c|c|c|c|c|c|}
\hline & & 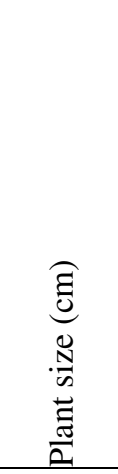 & 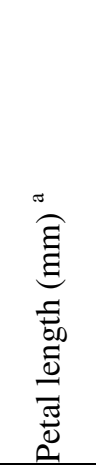 & 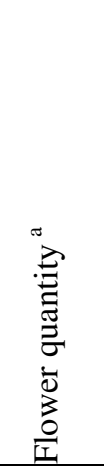 & 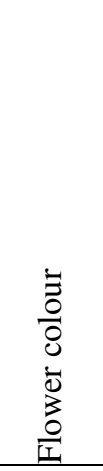 & 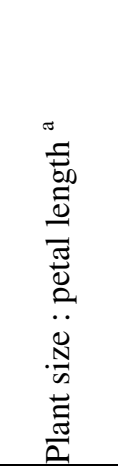 & 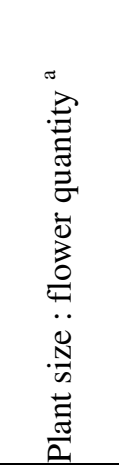 & 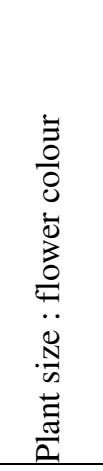 & 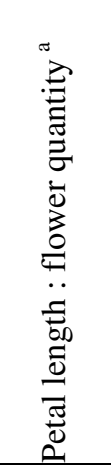 & 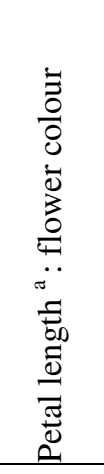 & 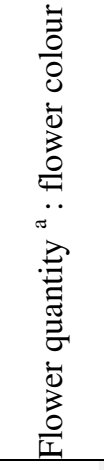 & 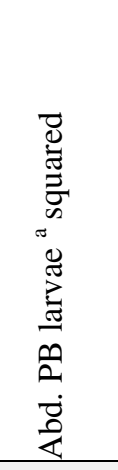 & 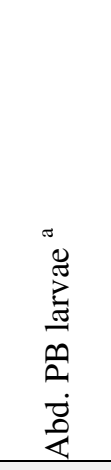 \\
\hline \multirow[t]{3}{*}{ Abd. pollinators ${ }^{a}$} & $\mathrm{pw}$ & 1.000 & 1.000 & 1.000 & 0.450 & 1.000 & 1.000 & 0.220 & 0.000 & 0.000 & 0.000 & & \\
\hline & est. & 0.064 & 0.668 & 0.609 & - & -0.410 & -0.492 & - & - & - & - & & \\
\hline & SE & 0.117 & 0.139 & 0.104 & - & 0.124 & 0.096 & - & - & - & - & & \\
\hline \multirow[t]{3}{*}{ SR pollinators ${ }^{\mathrm{a}}$} & pw & 1.000 & 1.000 & 1.000 & 0.190 & 1.000 & 1.000 & 0.000 & 0.650 & 0.000 & 0.000 & & \\
\hline & est. & 0.148 & 0.279 & 0.318 & - & -0.219 & -0.150 & - & -0.085 & - & - & & \\
\hline & SE & 0.049 & 0.058 & 0.051 & - & $\mathbf{0 . 0 5 7}$ & 0.053 & - & 0.056 & - & - & & \\
\hline \multirow[t]{3}{*}{ Abd. PB adults ${ }^{a}$} & $\mathrm{pw}$ & 1.000 & 1.000 & 1.000 & 1.000 & 0.290 & 0.110 & 1.000 & 1.000 & 0.240 & 0.340 & & \\
\hline & est. & 1.153 & 2.111 & 0.428 & 0.657 & - & - & 0.818 & -0.942 & - & - & & \\
\hline & SE & 0.307 & 0.415 & 0.254 & 0.283 & - & - & 0.316 & 0.283 & - & - & & \\
\hline \multirow[t]{3}{*}{ Abd. PB larvae ${ }^{a}$} & pw & 0.810 & 1.000 & 0.000 & 1.000 & 0.450 & 0.000 & 0.000 & 0.000 & 1.000 & 0.000 & & \\
\hline & est. & 1.334 & 2.716 & - & 0.074 & - & - & - & - & 1.910 & - & & \\
\hline & SE & 0.538 & 0.491 & - & 0.595 & - & - & - & - & 0.562 & - & & \\
\hline \multirow[t]{3}{*}{ Paras. rate (\%) } & pw & 0.700 & 0.580 & 0.090 & & 0.120 & 0.000 & & 0.000 & & & 0.730 & 0.730 \\
\hline & est. & 12.522 & - & - & & - & - & & - & & & -7.032 & 94.974 \\
\hline & SE & 4.686 & - & - & & - & - & & - & & & 2.459 & 34.010 \\
\hline
\end{tabular}

a $\log$-transformed 


\section{Effects of flower visiting insects on plant reproductive fitness}

On average, the plant species realised $57.43 \% \pm 2.82 \%$ of their species' maximal seed number with a relatively high proportion of podless stalks $(29.86 \% \pm 2.83 \%)$. We further recorded a mean realised thousand seed weight of $62.14 \% \pm 1.81 \%$ and a mean total seed weight of $51.85 \% \pm 2.91 \%$ of the species maximum (see Supplemental material Table S4a-c for all). Proportion of podless stalks was positively influenced by pollen beetle abundance, in particular on plots with high abundance of pollen beetle larvae (Figure 2a, for parameter weights and estimates with standard errors of all tested variables of every model see Table 2). Seed number ( $\%$ of the species' maximum) decreased with increasing pollen beetle abundance, particularly on plots with high abundance of pollen beetle larvae, and increased with increasing pollinator abundance (Figure 2b-c). Thousand seed weight (\%) was negatively related to pollen beetle abundance (Figure 2d), while total seed weight (\%) was not affected by the abundance of pollinators, pollen beetle adults or pollen beetle larvae.

\section{Effects of plant size on plant reproductive fitness}

We could not show an effect of plant size on the seed number (\% of the species' maximum) or the total seed weight (\%). The proportion of podless stalks increased and the thousand seed weight $(\%)$ decreased with increasing plant size (Figure 3, for parameter weights and estimates with standard errors of all tested variables of every model see Table 3). 


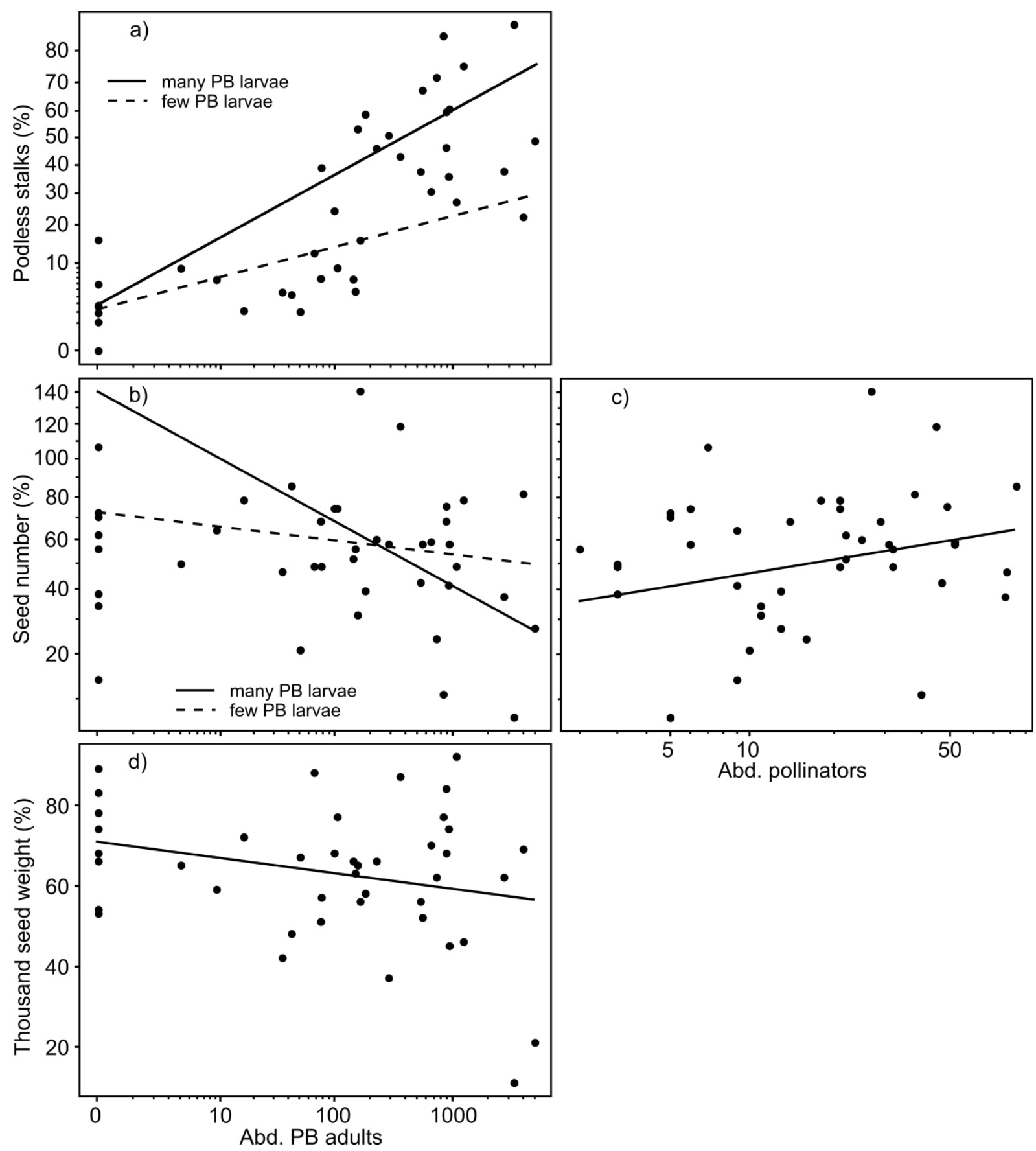

Figure 2. Effects of flower visiting insects on plant reproductive fitness, namely on a) proportion of podless stalks, b-c) seed number (\% of the species' maximum) and d) thousand seed weight (\%). Abd. = Abundance, $\mathrm{PB}=$ pollen beetles. Axes of variables were transformed corresponding to analyses (podless stalks and seed number: asin-sqrt-transformation; abundance of pollen beetle adults and pollinators: log-transformation). To visualise interactions of two continuous explanatory variables (a-b), we converted one of them into a categorical variable, using the medians of the upper and the lower half of the data (few pollen beetle larvae $=6$, many pollen beetle larvae $=2207$ ). 
Table 2. Effects of flower visiting insects on plant reproductive fitness (\% podless stalks per potential pods; seed number, thousand seed weight and total seed weight in $\%$ of the species' maximum). Abundance $=$ Abd.; pollen beetles $=$ PB . Parameter weights $(\mathrm{pw})$ refer to a delta 2 AICc range. Explanatory variables and interactions with a parameter weight $\geq 0.6$ (bold) were defined as important for the relevant response variable and will be discussed. Estimates (est.) with standard errors (SE) were assessed from the summary table of the lme-model with the lowest AICc involving all explanatory variables with a parameter weight $\geq 0.6$ and are centred and standardised to improve their interpretability.

\begin{tabular}{|c|c|c|c|c|c|c|c|}
\hline & & 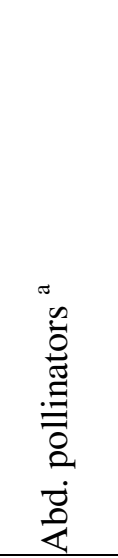 & 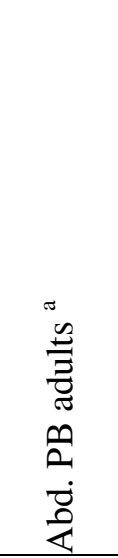 & 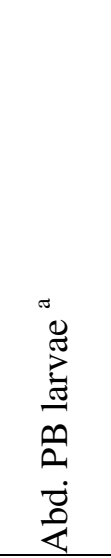 & 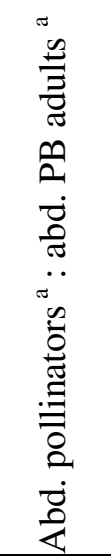 & 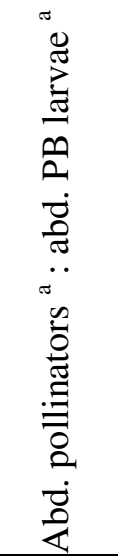 & 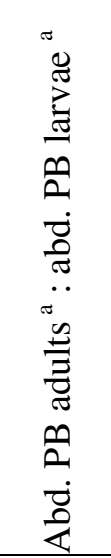 \\
\hline \multirow{3}{*}{ Podless stalks $(\%)^{\mathrm{b}}$} & pw & 0.000 & 1.000 & 1.000 & 0.000 & 0.000 & 0.720 \\
\hline & est. & - & 0.182 & 0.153 & - & - & 0.083 \\
\hline & SE & - & 0.038 & 0.035 & - & - & 0.040 \\
\hline \multirow[t]{3}{*}{ Seed number $(\%)^{b}$} & pw & 0.660 & 0.780 & 0.670 & 0.100 & 0.150 & 0.670 \\
\hline & est. & 0.017 & $-\mathbf{0 . 0 3 3}$ & 0.011 & - & - & $-\mathbf{0 . 0 3 0}$ \\
\hline & SE & 0.010 & 0.013 & 0.011 & - & - & 0.013 \\
\hline \multirow[t]{3}{*}{ Thousand seed weight (\%) } & pw & 0.460 & 0.680 & 0.370 & 0.090 & 0.240 & 0.240 \\
\hline & est. & - & -4.834 & - & - & - & - \\
\hline & SE & - & 2.917 & - & - & - & - \\
\hline \multirow[t]{3}{*}{ Total seed weight $(\%)^{b}$} & pw & 0.430 & 0.410 & 0.250 & 0.000 & 0.250 & 0.250 \\
\hline & est. & - & - & - & - & - & - \\
\hline & SE & - & - & - & - & - & - \\
\hline
\end{tabular}

${ }^{\mathrm{a}} \log$-transformed, ${ }^{\mathrm{b}}$ asin-sqrt-transformation 

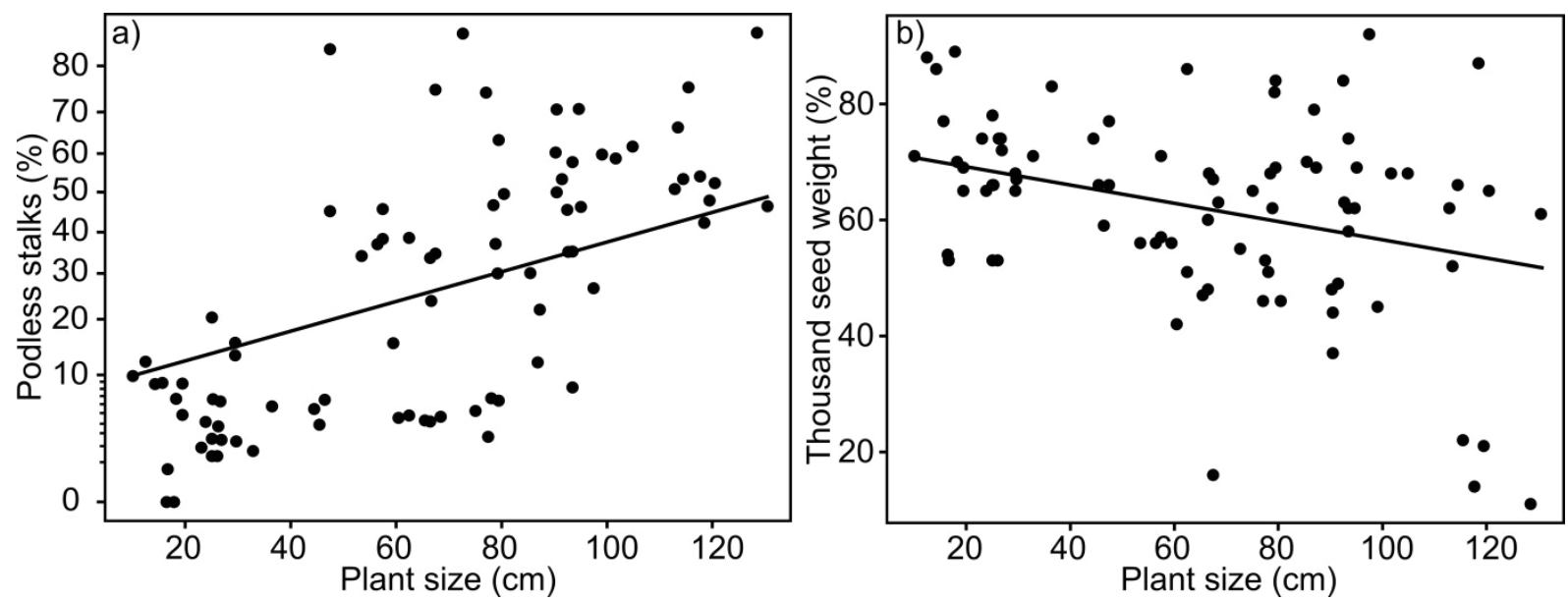

Figure 3. Effect of plant size on plant reproductive fitness, on a) proportion of podless stalks and b) thousand seed weight ( $\%$ of the species' maximum). Axes of variables were transformed corresponding to analyses (podless stalks: asin-sqrt-transformation).

Table 3. Effect of plant size on plant reproductive fitness $(\%$ podless stalks per potential pods; seed number, thousand seed weight and total seed weight in $\%$ of the species' maximum). Parameter weights (pw) refer to a delta 2 AICc range. Explanatory variables and interactions with a parameter weight $\geq$ 0.6 (bold) were defined as important for the relevant response variable and will be discussed. Estimates (est.) with standard errors (SE) were assessed from the summary table of the lme-model with the lowest AICc involving all explanatory variables with a parameter weight $\geq 0.6$ and are centred and standardised to improve their interpretability.

Plant size

$(\mathrm{cm})$

\begin{tabular}{|c|c|c|}
\hline Podless stalks $(\%)^{b}$ & $\begin{array}{l}\text { pw } \\
\text { est. } \\
\text { SE }\end{array}$ & $\begin{array}{l}1.000 \\
0.127 \\
0.043 \\
\end{array}$ \\
\hline Seed number $(\%)^{b}$ & pw & 0.000 \\
\hline & $\begin{array}{l}\text { est. } \\
\text { SE }\end{array}$ & - \\
\hline Thousand seed weight (\%) & $\begin{array}{l}\text { pw } \\
\text { est. } \\
\text { SE }\end{array}$ & $\begin{array}{r}1.000 \\
-5.291 \\
2.650 \\
\end{array}$ \\
\hline Total seed weight $(\%)^{b}$ & $\begin{array}{l}\text { pw } \\
\text { est. } \\
\text { SE }\end{array}$ & $\begin{array}{c}0.000 \\
- \\
-\end{array}$ \\
\hline
\end{tabular}

${ }^{\mathrm{b}}$ asin-sqrt-transformation 


\section{DiSCUSSION}

The results of this study supported our hypothesis that plant size is a major driver of biotic interactions: Plant size had a positive effect on abundance and species richness of mutualistic pollinators (when flowers were not superabundant) as well as on the abundance of antagonistic pollen beetle adults and larvae and their parasitism rates. We found a negative effect of pollen beetle abundance (mainly of adults) on seed number (\% of the species' maximum) as well as on thousand seed weight (\%). Pollinator abundance positively affected seed number $(\%)$ but had no effect on thousand seed weight $(\%)$. In line with our hypothesis, mutualistic and antagonistic interactions had contrasting effects on the plant reproductive fitness in terms of seed number (\%), while thousand seed weight (\%) was influenced by antagonists only and total seed weight (\%) showed no clear influence of neither antagonists nor mutualists. Finally plant size did not affect seed number (\%) and total seed weight (\%), but positively affected proportion of podless stalks and negatively affected the thousand seed weight $(\%)$.

\section{Positive effect of plant size on flower visiting insects}

In support of our hypothesis, plant size positively affected abundance and species richness of flower visiting insects. Mutualistic pollinators as well as antagonistic pollen beetle adults and pollen beetle larvae were more abundant on large than on small plants in accordance to studies testing the effect of differences in intraspecific plant size on pollinators (Donnelly et al., 1998; Geber, 1985; Gómez, 2003) and on feeding damage to flowers (Sletvold and Grindeland, 2008; Williams and Free, 1979). However, plant size had no or an even negative effect on pollinator species richness and abundance if a threshold of flower number or size was exceeded. Parasitism rates of pollen beetle larvae increased also with increasing plant size. Large plants may be more apparent to insects, followed by higher finding rates, as they are more exposed than smaller plants (Feeny, 1976; Lawton, 1983). Additionally, large plants may be more attractive to flower visiting insects in that they are often more exposed to the sun than small plants that are often shaded by the larger ones (Klinkhamer et al., 1989).

The covariates petal length and flower quantity were of importance for flower visiting insects, especially petal length influenced positively the abundance and species richness of 
pollinators, the abundance of pollen beetle adults and their larvae. Long petals may be seen as signal of reward as flower size is often positively related to nectar and pollen production (Cohen and Shmida, 1993) and, independently of reward, enhances the detectability of the flower, leading to reduced searching time for flower visiting insects particularly in areas with low flower densities (Cohen and Shmida, 1993; Hegland and Totland, 2005). Flower quantity had a positive effect on the abundance and species richness of pollinators and the abundance of pollen beetle adults, presumably because of the large number of food opportunities with low movement costs and reduced competition among flower visiting insects (Klinkhamer et al., 1989; Ohashi and Yahara, 2002; Scheid et al., 2011). Particularly the interaction of petal length and flower quantity affected abundance of pollen beetle adults as well as species richness of pollinators, implying that high flower cover, combining the advantages of large and numerous flowers, were an attractive signal for flower visiting insects. The abundance of pollen beetle larvae and their parasitism rates were not affected by flower quantity. Oviposition of pollen beetles appeared to be more related to the quality of flowers and buds. Parasitoids locate their hosts in two steps, first locating the hosts' habitat and second locating the host within the habitat via short-distance olfactory cues (Williams and Cook, 2010). The process of locating the hosts' habitat is in accordance to our results showing a positive effect of plant size. The process of locating the host within the habitat was in accordance to our findings of a hump-shaped effect of pollen beetle larvae abundance on parasitism rates. Parasitism rates increased with increasing host larvae abundance due to their olfactory cues, as shown by Zaller et al. (2009). From a certain abundance of host larvae onwards, the parasitism rate decreased (Billqvist and Ekbom, 2001), probably because of increasingly longer searching time for non-parasitised hosts and a limited number of eggs.

Abundances of pollen beetle adults and their larvae were higher on plots with yellow flowers in comparison to plots with white flowers. A preference for yellow colours by pollen beetles has been already shown (Giamoustaris and Mithen, 1996). They also seem to have a highly restricted host range for oviposition (Ekbom and Borg, 1996). Contrarily pollinators showed no colour preference, although, for example Pieris and Eristalis adults, also present in our study in moderate numbers $(3.24 \% \pm 0.68 \%$ of total pollinator abundance, which was dominated by bees), have been shown to prefer yellow to white flower morphs of wild radish (Kay, 1976). 
The interactions between plant size and the covariates petal length, flower quantity and flower colour affected the strength of the plant size effect on flower visiting insects. The generally positive effect of plant size was weakened, neutralised or even strengthened (Figures 1a-b, de) by highly attractive traits like large petals or numerous flowers: The attractiveness of plots with large or many flowers on pollinators was high, diminishing the influence of plant size in comparison to plots with small or few flowers. This emphasises the great importance of petal length and flower number for pollinators (Hegland and Totland, 2005). The signal effect of yellow flowers on pollen beetles was strengthened by increasing plant size (Figure 1f), probably due to free visibility of exposed flowers, while white flowers were less attractive even if plants were tall.

\section{Effects of flower visiting insects on plant reproductive fitness}

In support of our hypothesis, mutualistic and antagonistic interactions turned out to have contrasting effects on the plant reproductive fitness such as seed number. Abundance of pollen beetle adults had a positive effect on the proportion of podless stalks and negatively affected seed number ( $\%$ of the species' maximum), while pollinator abundance positively affected seed number (\%). Thousand seed weight $(\%)$ was negatively influenced by pollen beetle adults, while pollinators had no effect.

Although mainly adult pollen beetles cause damage, their pollen feeding larvae can weaken pods and cause podless stalks (Williams, 2010). The increase in podless stalks with increasing number of pollen beetle adults in our study was reinforced by a high abundance of pollen beetle larvae. We did not detect an effect of pollinator abundance on the number of podless stalks, showing that the abscission of flowers and young pods was ascribed to pollen beetles only.

Seed number (\%) was negatively influenced by pollen beetle abundance, particularly on plots with many pollen beetle larvae, probably driven by their effect on the podless stalks. Contrastingly, pollinator abundance had a positive effect on the seed number (\%) according to several studies (Morandin and Winston, 2005; Steffan-Dewenter and Tscharntke, 1999). Pollinator species richness, which was highly correlated to pollinator abundance, may have 
had a positive influence on seed set by complementary pollination (Hoehn et al., 2008; Klein et al., 2003).

Thousand seed weight (\%) was negatively affected by pollen beetle abundance. Plants with a high amount of damaged flowers may create compensatorily new flowers (Williams and Free, 1979), possibly at the expense of the remaining flowers' thousand seed weight. Thousand seed weight and seed number are often negatively correlated, as a plant may invest either in a high seed number or in a high seed weight (Gambín and Borrás, 2010). Possibly several of these multidirectional effects by pollinators, pollen beetle adults and their larvae on seed number (\%) and thousand seed weight (\%) may have been mixed, leading to no dominant pattern in the effect of flower visiting insects on total seed weight (\%).

\section{Effect of plant size on plant reproductive fitness}

Total seed weight (\%), which was not affected by the abundance of flower visiting insects, was likewise not influenced by plant size. Thousand seed weight $(\%)$ decreased and the proportion of podless stalks increased with increasing plant size, driven by the influence of increasing pollen beetle number. However, plant size did not affect seed number (\%). The negative impact of the antagonists on seed number (\%) has been apparently neutralised by the positive impact of the mutualists. Additionally, brassicaceous plants can compensate for pollen beetle damage (Williams and Free, 1979). Geber (1985) did also not find a difference in seed-set between flowers of large and small Mertensia plants, despite large plants attracted more bumblebees. The observed flower visiting bumblebees comprised not only mutualists but also nectar robbers (Geber, 1985), which may have a negative effect on seed set (Maloof and Inouye, 2000). Other studies showed positive (Dickson and Petit, 2006), negative (Ehrlén et al., 2012) or study site dependent effects (Gómez, 2003; O’Connell and Johnston, 1998) of intraspecific plant size or flower height on plant reproductive fitness. The different results of these studies suggest that species identity and study site matters whether it is an advantage for a plant to be tall or not. Both mutualists and antagonists are attracted by large plants, so the importance of plant size on plant reproductive fitness largely depends on the relative abundance of antagonists and mutualists in the habitat and surrounding landscape, which is often not standardised in published studies. 


\section{Conclusions}

Plant size turned out to be a most comprehensive driver of interactions between the plant and its flower visitors. Large plant species benefited from more pollinators and high pollen beetle parasitism rates, but simultaneously suffered seriously from more pollen beetles than small plant species. The natural community of flower visiting insects led to a balanced proportion of advantages and disadvantages for large plant species compared to small ones regarding seed number. Whether being larger or smaller than adjacent plants is an advantage for the plant appears to depend on the ratio of pollinating and plant feeding flower visiting insects in the habitat. It should be advantageous for a plant to be large in situations with low amount of herbivores and high amount of pollinators and vice versa (Figure 4). Our results illustrate the complexity of interaction networks among plants and their flower visiting mutualists and antagonists, which is rarely acknowledged in studies valuating plant traits.

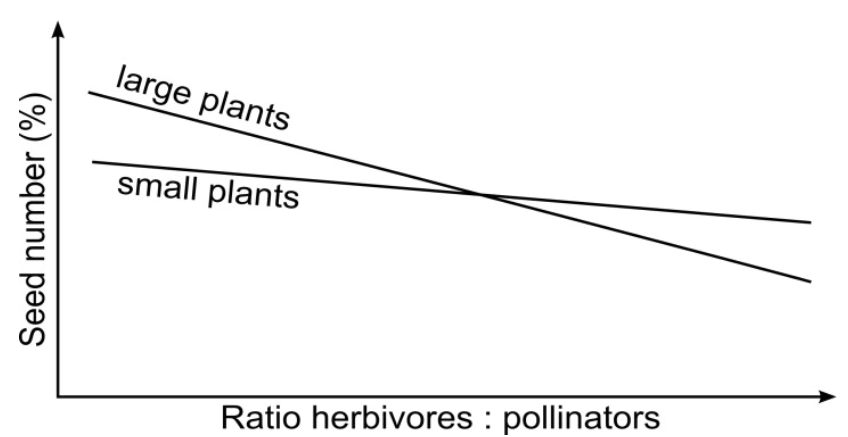

Figure 4. The herbivore to pollinator ratio is hypothesised to shape the relative advantage of plant size. High pressure by herbivores should favour small, but high pollinator densities large plants. The crossing point indicates the equilibrium of advantage (to the left of the crossing point) and disadvantage (to the right of the crossing point) for large plants we found at our study site regarding the seed number.

\section{ACKNOWLEDGEMENTS}

We thank Klaus Hövemeyer and Ines Vollhardt for help with identification of collected animals, Martin Ludwig and Urs Kormann for helpful discussions. Special thanks for help in the field and laboratory go to Susanne Jahn, Brigitte Jünemann and Ulrike Kierbaum, as well as to Christiane Schlinkert, Eugen Schlinkert, Barbara Scheid and Dorothea Mennerich. KWS SAAT AG and the botanical gardens of the universities of Bayreuth and Göttingen provided parts of the seeds. H.S. was supported by the Ministry of Science and Culture of Lower Saxony. 


\section{REFERENCES}

Barton, K., 2011. MuMIn: multi-model inference. R package version 1.5.2. http://CRAN.Rproject.org/package=MuMIn.

Biesmeijer, J.C., Roberts, S.P.M., Reemer, M., Ohlemüller, R., Edwards, M., Peeters, T., Schaffers, a P., Potts, S.G., Kleukers, R., Thomas, C.D., Settele, J., Kunin, W.E., 2006. Parallel declines in pollinators and insect-pollinated plants in Britain and the Netherlands. Science 313, 351-354.

Billqvist, A., Ekbom, B., 2001. The influence of host plant species on parasitism of pollen beetles (Meligethes spp.) by Phradis morionellus. Entomol. Exp. Appl. 98, 41-47.

Bommarco, R., Marini, L., Vaissière, B.E., 2012. Insect pollination enhances seed yield, quality, and market value in oilseed rape. Oecologia 169, 1025-1032.

Brose, U., 2010. Body-mass constraints on foraging behaviour determine population and food-web dynamics. Funct. Ecol. 24, 28-34.

Burnham, K.P., Anderson, D.R., 2002. Model selection and multi-model inference: a practical information-theoretic approach, 2nd ed. Springer New York, New York.

Cohen, D., Shmida, A., 1993. The evolution of flower display and reward. Evol. Biol. 27, 197-243.

Cortesero, A.M., Stapel, J.O., Lewis, W.J., 2000. Understanding and manipulating plant attributes to enhance biological control. Biol. Control 17, 35-49.

Dickson, C.R., Petit, S., 2006. Effect of individual height and labellum colour on the pollination of Caladenia (syn. Arachnorchis) behrii (Orchidaceae) in the northern Adelaide region, South Australia. Plant Syst. Evol. 262, 65-74.

Donnelly, S.E., Lortie, C.J., Aarssen, L.W., 1998. Pollination in Verbascum thapsus (Scrophulariaceae): the advantage of being tall. Am. J. Bot. 85, 1618-1625.

Ehrlén, J., Borg-Karlson, A.-K., Kolb, A., 2012. Selection on plant optical traits and floral scent: Effects via seed development and antagonistic interactions. Basic Appl. Ecol. 13, $509-515$.

Ekbom, B., Borg, A., 1996. Pollen beetle (Meligethes aeneus) oviposition and feeding preference on different host plant species. Entomol. Exp. Appl. 78, 291-299.

Feeny, P., 1976. Plant apparency and chemical defense, in: Wallace, J.W., Mansell, R.L. (Eds.), Biochemical Interaction Between Plants and Insects. Springer US, New York, pp. 1-40.

Gambín, B.L., Borrás, L., 2010. Resource distribution and the trade-off between seed number and seed weight: a comparison across crop species. Ann. Appl. Biol. 156, 91-102.

Garibaldi, L.A., Steffan-Dewenter, I., Winfree, R., Aizen, M.A., Bommarco, R., Cunningham, S. a, Kremen, C., Carvalheiro, L.G., Harder, L.D., Afik, O., Bartomeus, I., Benjamin, F., Boreux, V., Cariveau, D., Chacoff, N.P., Dudenhöffer, J.H., Freitas, B.M., Ghazoul, 
J., Greenleaf, S., Hipólito, J., Holzschuh, A., Howlett, B., Isaacs, R., Javorek, S.K., Kennedy, C.M., Krewenka, K.M., Krishnan, S., Mandelik, Y., Mayfield, M.M., Motzke, I., Munyuli, T., Nault, B. a, Otieno, M., Petersen, J., Pisanty, G., Potts, S.G., Rader, R., Ricketts, T.H., Rundlöf, M., Seymour, C.L., Schüepp, C., Szentgyörgyi, H., Taki, H., Tscharntke, T., Vergara, C.H., Viana, B.F., Wanger, T.C., Westphal, C., Williams, N., Klein, A.M., 2013. Wild pollinators enhance fruit set of crops regardless of honey bee abundance. Science 339, 1608-1611.

Geber, M.A., 1985. The relationship of plant size to self-pollination in Mertensia ciliata. Ecology 66, 762-772.

Giamoustaris, A., Mithen, R., 1996. The effect of flower colour and glucosinolates on the interaction between oilseed rape and pollen beetles. Entomol. Exp. Appl. 80, 206-208.

Gómez, J.M., 2003. Herbivory reduces the strength of pollinator-mediated selection in the Mediterranean herb Erysimum mediohispanicum: consequences for plant specialization. Am. Nat. 162, 242-256.

Grueber, C.E., Nakagawa, S., Laws, R.J., Jamieson, I.G., 2011. Multimodel inference in ecology and evolution: challenges and solutions. J. Evol. Biol. 24, 699-711.

Haysom, K.A., Coulson, J.C., 1998. The Lepidoptera fauna associated with Calluna vulgaris: effects of plant architecture on abundance and diversity. Ecol. Entomol. 23, 377-385.

Hegland, S.J., Totland, Ø., 2005. Relationships between species' floral traits and pollinator visitation in a temperate grassland. Oecologia 145, 586-594.

Heiberger, R.M., 2009. HH: statistical analysis and data display: Heiberger and Holland. R package version 2.1-32. http://CRAN.R-project.org/package=HH.

Hoehn, P., Tscharntke, T., Tylianakis, J.M., Steffan-Dewenter, I., 2008. Functional group diversity of bee pollinators increases crop yield. Proc. R. Soc. B 275, 2283-2291.

Kay, Q.O.N., 1976. Preferential pollination of yellow-flowered morphs of Raphanus raphanistrum by Pieris and Eristalis spp. Nature 261, 230-232.

Klein, A.-M., Steffan-Dewenter, I., Tscharntke, T., 2003. Fruit set of highland coffee increases with the diversity of pollinating bees. Proc. R. Soc. B 270, 955-961.

Klinkhamer, P.G.L., de Jong, T.J., de Bruyn, G.-J., 1989. Plant size and pollinator visitation in Cynoglossum officinale. Oikos 54, 201-204.

Lawton, J.H., 1983. Plant architecture and the diversity of phytophagous insects. Annu. Rev. Entomol. 28, 23-39.

Maloof, J.E., Inouye, D.W., 2000. Are nectar robbers cheaters or mutualists? Ecology 81, 2651-2661.

Morandin, L.A., Winston, M.L., 2005. Wild bee abundance and seed production in conventional, organic, and genetically modified canola. Ecol. Appl. 15, 871-881.

O'Connell, L.M., Johnston, M.O., 1998. Male and female pollination success in a deceptive orchid, a selection study. Ecology 79, 1246-1260. 
Ohashi, K., Yahara, T., 2002. Visit larger displays but probe proportionally fewer flowers: counterintuitive behaviour of nectar-collecting bumble bees achieves an ideal free distribution. Funct. Ecol. 16, 492-503.

Parsche, S., Fründ, J., Tscharntke, T., 2011. Experimental environmental change and mutualistic vs. antagonistic plant flower-visitor interactions. Perspect. Plant Ecol. Evol. Syst. 13, 27-35.

Pinheiro, J., Bates, D., DebRoy, S., Sarkar, D., R Development Core Team, 2011. nlme: linear and nonlinear mixed effects models. $\mathrm{R}$ package version 3.1-98.

R Development Core Team, 2011. R: a language and environment for statistical computing. R Foundation for Statistical Computing, Vienna, Austria. ISBN 3-900051-07-0, URL http://www.R-project.org/.

Ritchie, E.G., Johnson, C.N., 2009. Predator interactions, mesopredator release and biodiversity conservation. Ecol. Lett. 12, 982-998.

Scheid, B.E., Thies, C., Tscharntke, T., 2011. Enhancing rape pollen beetle parasitism within sown flower fields along a landscape complexity gradient. Agric. For. Entomol. 13, 173-179.

Schielzeth, H., 2010. Simple means to improve the interpretability of regression coefficients. Methods Ecol. Evol. 1, 103-113.

Sletvold, N., Grindeland, J.M., 2008. Floral herbivory increases with inflorescence size and local plant density in Digitalis purpurea. Acta Oecologica 34, 21-25.

Steffan-Dewenter, I., Tscharntke, T., 1999. Effects of habitat isolation on pollinator communities and seed set. Oecologia 121, 432-440.

Van der Putten, W.H., Macel, M., Visser, M.E., 2010. Predicting species distribution and abundance responses to climate change: why it is essential to include biotic interactions across trophic levels. Philos. Trans. R. Soc. Lond. B. Biol. Sci. 365, 2025-2034.

Williams, I.H., 2010. The major insect pests of oilseed rape in Europe and their management: an overview, in: Williams, I.H. (Ed.), Biocontrol-Based Integrated Management of Oilseed Rape Pests. Springer Netherlands, Dordrecht, pp. 1-44.

Williams, I.H., Cook, S.M., 2010. Crop location by oilseed rape pests and host location by their parasitoids, in: Williams, I.H. (Ed.), Biocontrol-Based Integrated Management of Oilseed Rape Pests. Springer Netherlands, Dordrecht, pp. 215-244.

Williams, I.H., Free, J.B., 1979. Compensation of oil-seed rape (Brassica napus L.) plants after damage to their buds and pods. J. Agric. Sci. 92, 53-59.

Zaller, J.G., Moser, D., Drapela, T., Schmöger, C., Frank, T., 2009. Parasitism of stem weevils and pollen beetles in winter oilseed rape is differentially affected by crop management and landscape characteristics. BioControl 54, 505-514.

Zuur, A.F., Ieno, E.N., Elphick, C.S., 2010. A protocol for data exploration to avoid common statistical problems. Methods Ecol. Evol. 1, 3-14. 


\section{SUPPLEMENTAL MATERIAL}

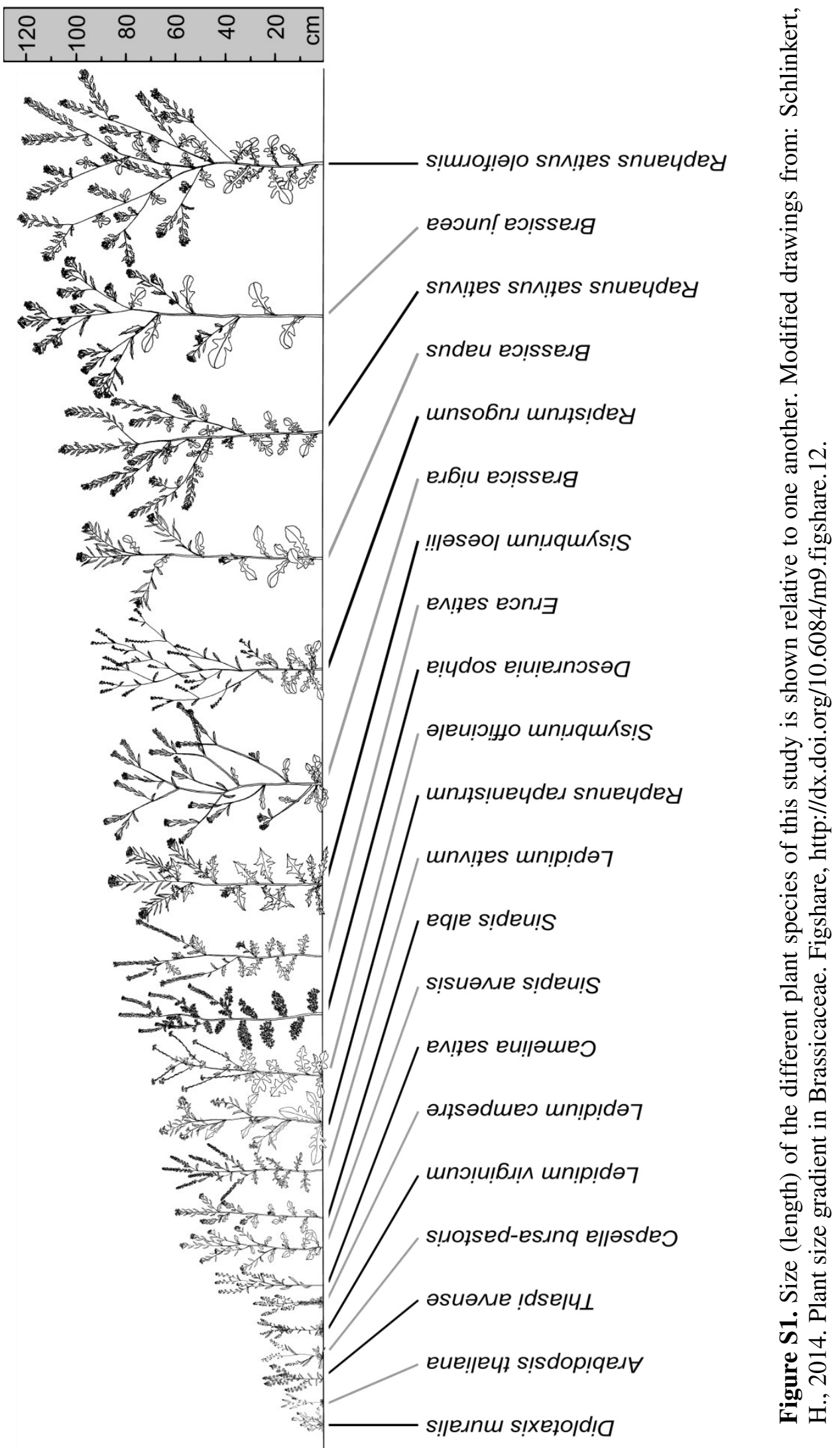




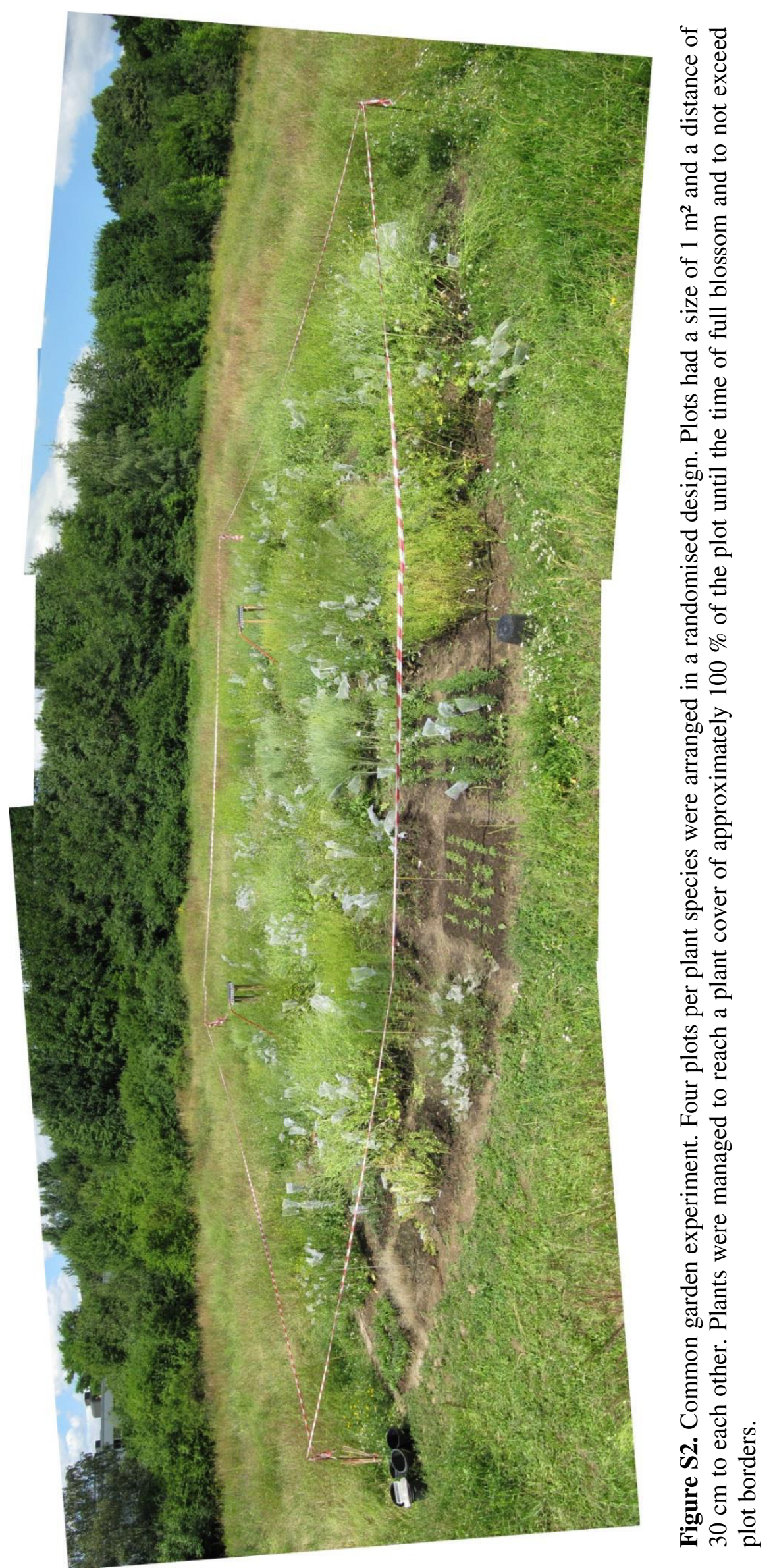




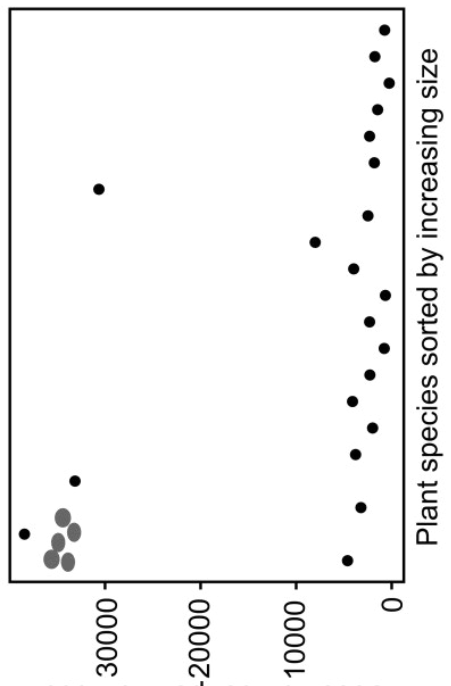

ןenp!ı!pu! ıəd ıəqunu pəəS

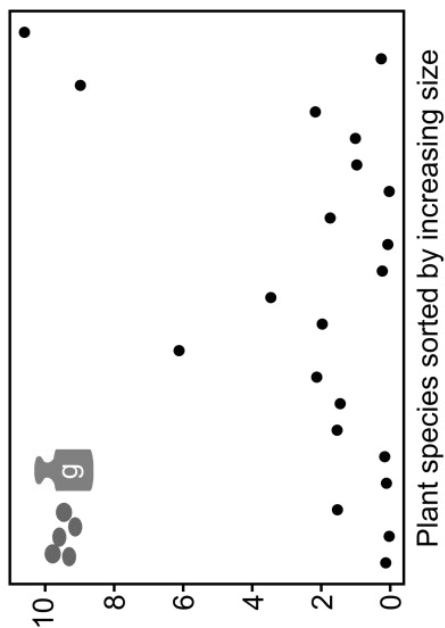

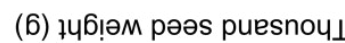

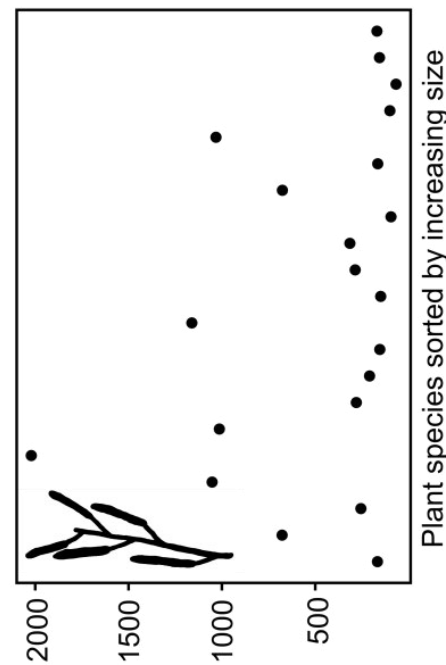

ןenp!n!pu! גəd spod

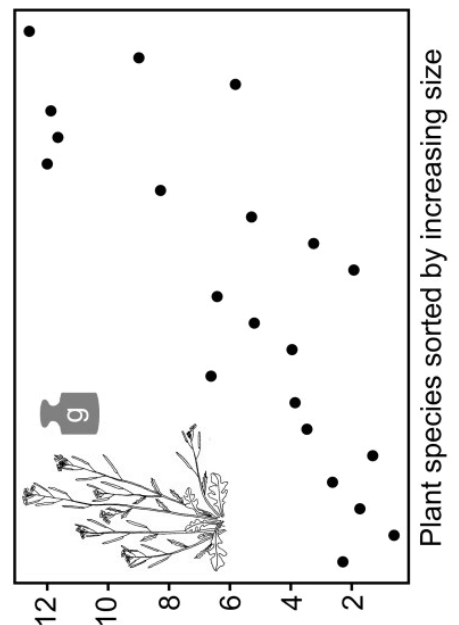

(6) ןenp!̣ı!pu! גəd ssemo!̣

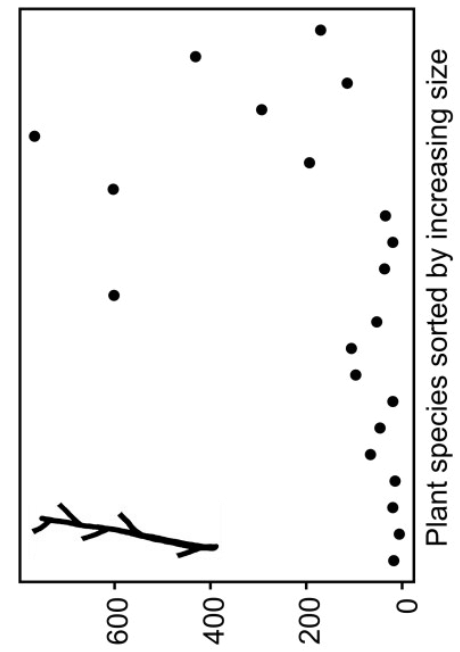

ןenp!̣!̣pu! גəd sy|ełs ssə|pod

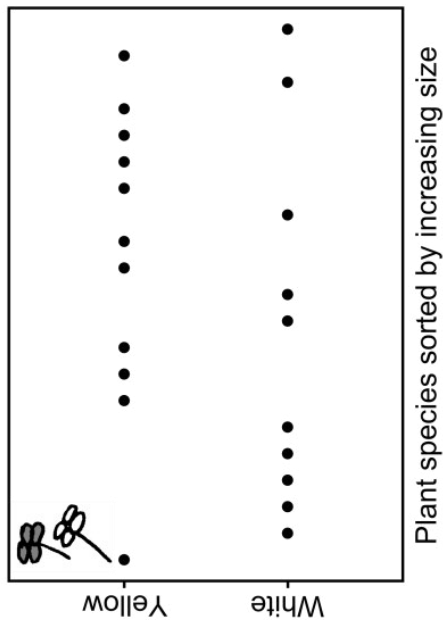

มnо이 əㅡ입
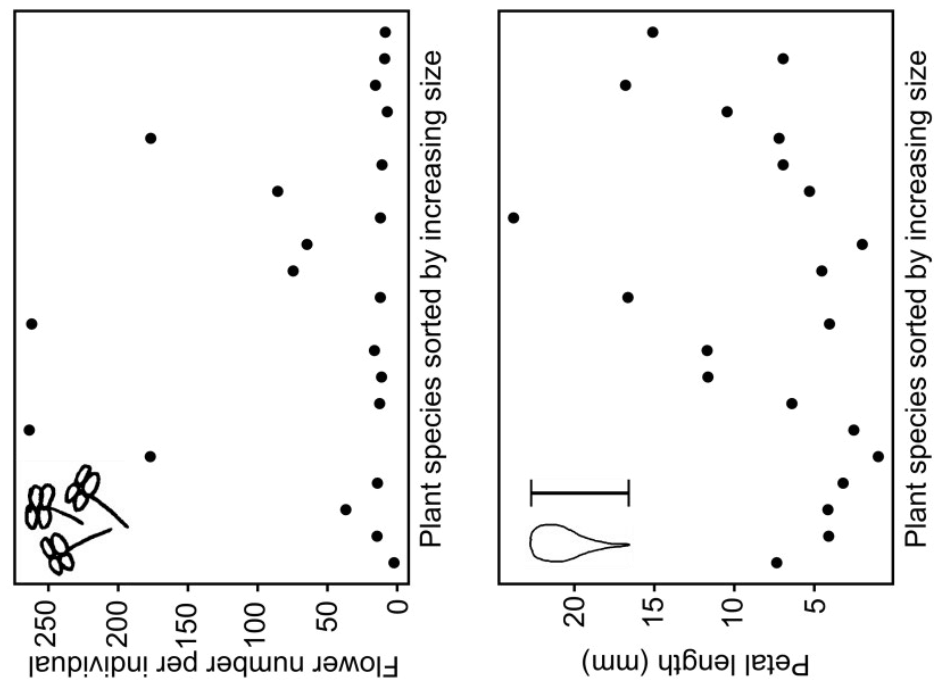

余 


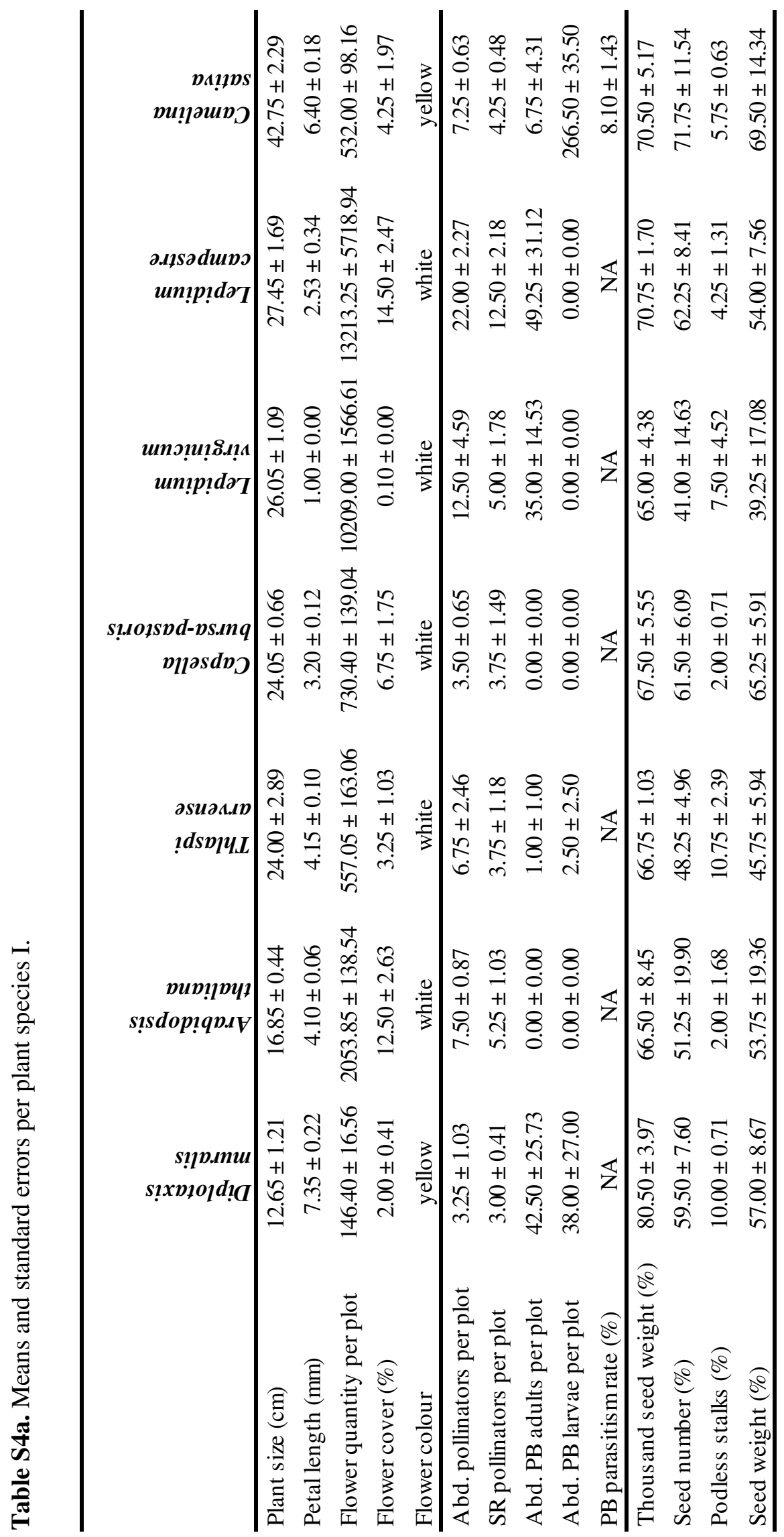




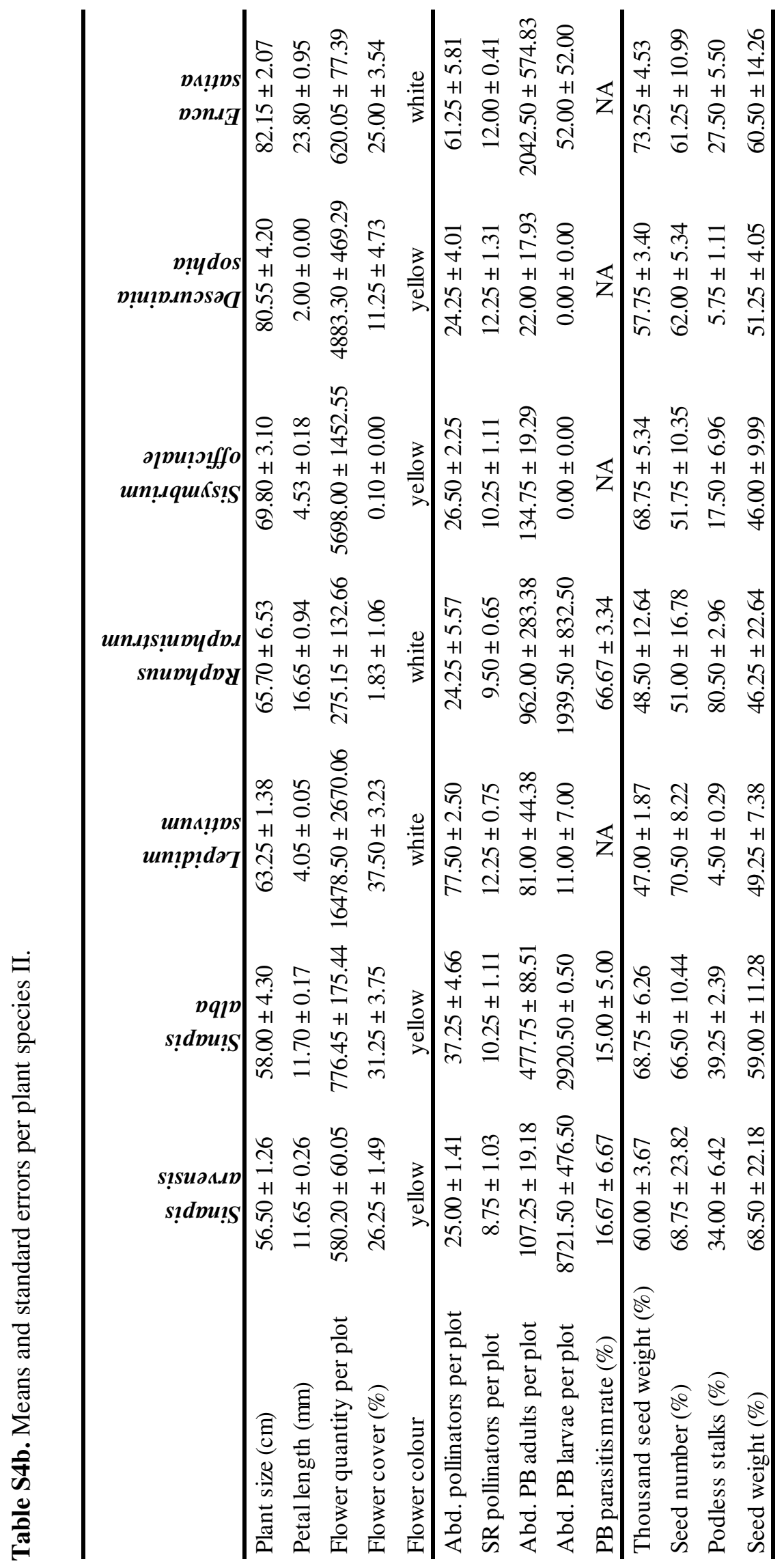




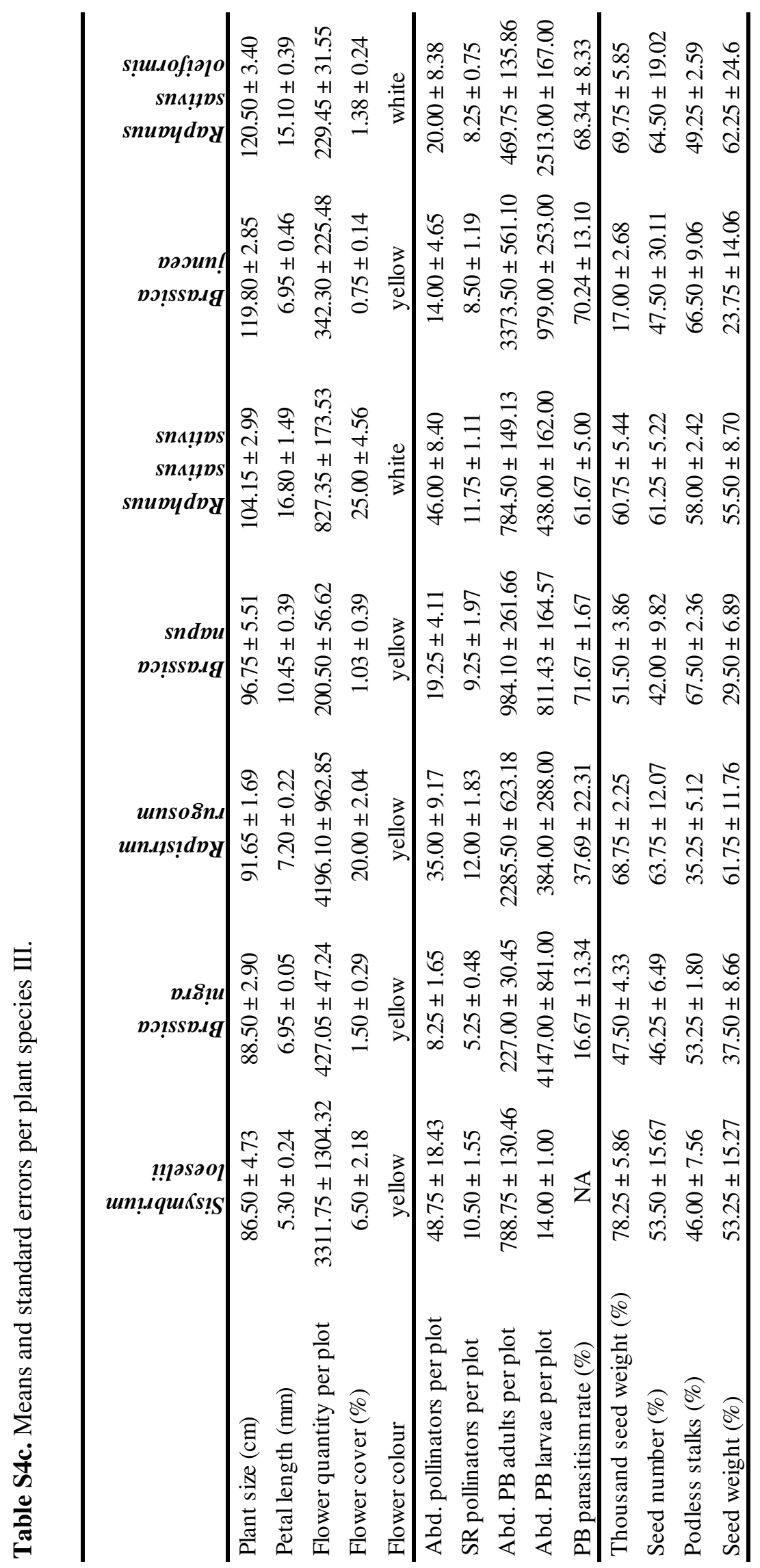




\section{GENERAL ACKNOWLEDGEMENTS}

Many helping hands, and brains, have left their marks on this project, which was supported by the Ministry of Science and Culture of Lower Saxony and the "Niedersächsisches Vorab" within the Cluster of Excellence "Functional Biodiversity Research". I am grateful for all of these marks and would like to take this opportunity to thank some people who left the deepest ones.

First of all, I sincerely thank Teja Tscharntke for giving me the opportunity to work on several, thematically quite different, projects: diploma and doctoral thesis, cooperation projects and teaching concerned ecological topics in basic and applied research, such as fragmentation, ecosystem functions, interaction patterns, species traits and landscape effects. I came in close contact with plants, invertebrates - such as bees, hoverflies, cabbage pests and their natural enemies - and vertebrates, such as small mammals. All these different projects had the high quality level of supervision in common - your demands, Teja, were sometimes pretty exhausting, and your support was always spurring, creating a nice diversity in terms of supervision.

I am deeply grateful to Catrin Westphal for her cordial supervision and support in countless situations. Catrin, you have been a great help in difficult moments, an amplifier of pleasure in joyful moments, a reliable break in high-speed moments and a powerful engine for my scientific and personal growth.

Once the data were ready to be analysed, Yann Clough has been an enormous help in statistics. Thank you, Yann, for your patient explanations and discussions of mixed effects models, variance inflation factors, parameter weights, estimators - and for your friendly advice (after my satisfied sight regarding a significant p-value) to encounter statistics with less emotions - I will gladly remember!

Special thanks for support in the field and laboratory go to numerous helpful people, particularly to Susanne Jahn, Brigitte Jünemann and Ulrike Kierbaum. You, Susanne, Brigitte and Ulrike, really knew how to facilitate my work, not only in the field and lab, by being an important support and by creating a nice working atmosphere! Also many other colleagues and friends helped in the field, laboratory and office and I particularly thank Alexandra Arndt, Péter Batáry, Maja Brunke, Carina Burmeister, Cecilia Cantor, Georg Everwand, Christina Fischer, Anna-Katharina Franke, Annika Fromme, Juliane Helmerichs, Nicola Holm, Gunda 
Jansen, Anita Kriegel, Petra Kubisch, Dorothea Mennerich, Claudia Normann, Jenny Osterburg, Annabelle Rohlfing, Verena Rösch, Barbara Scheid, Christoph Scherber, Birgit Sohnrey, Felix Steinmeyer and Bernd Ulber. Further I thank Klaus Hövemeyer, Zoltán László and Peter Sprick as well as Ines Vollhardt and Jochen Fründ for help with identification of animals and Patrick Kabouw, who performed well in explaining and conducting analyses of glucosinolate contents. I am grateful to Kristy Udy and David Perović for linguistic improvements of the manuscripts. Jutta Gilles managed tirelessly the bureaucrazy office in her warm manner. I thank Carsten Thies for his advice and encouragement in the beginning of the study, KWS SAAT AG and the botanical gardens of the universities of Bayreuth and Göttingen for providing parts of the seeds, Mathias Weitemeier from the "Fachdienst Umwelt" of the city of Göttingen for his cooperation and Ruth Zalesky for her short-term sewing of thousands of pollinator exclusion bags. I further like to thank Stefan Vidal and Johannes Isselstein for being part of my thesis committee.

During the time I spent in the office, I profited from an all-inclusive service provided by Wolfgang Ludwig in Dahle and from the great company of my Göttingen office members Urs Kormann, Tatiane Beduschi, Julia Tiede, Ellie Vockenhuber, Christine Venjakob and Lydia Betz. I thank you for many joyful hours, inspiring discussions and particularly thank you, Urs, for productive impulses and the numerous strange furnishings and sounds in our office! I also liked the outstanding parties and other leisure activities with you, former and actual Agrarökos!

One of these former Agrarökos is extremely important to me, on the one hand in being an extraordinary helpful colleague, always ready for support in preparing and performing an XXL field season, statistical assistance and intensive discussions. On the other hand you, Martin, are one of the most reliable and endearing persons I have ever met in my life - I am sincerely grateful that you are there!

During my life I always had the support and encouragement of my family, particularly of my parents and my brother. Thank you, Mama, Papa and Heiko, for always getting me back on the ground of non-scientific facts. Moreover, you have been a great help in the field by weeding, counting flowers and fixing pollinator exclusion bags, and later by highly effective assistance in data entry.

\section{Thank you all for your help!}




\section{THESIS DECLARATIONS}

\section{DECLARATION OF THE AUTHOR'S OWN CONTRIBUTION TO MANUSCRIPTS WITH MULTIPLE AUTHORS}

Chapters 2, 3 and 4 consist of manuscripts that have been or will be submitted to peerreviewed journals. I am the overall author of all manuscripts presented in this thesis. I personally have contributed to the study design and collected and statistically analysed the data for all manuscripts, developed the main ideas presented in the manuscripts, written all manuscripts, created tables, figures and appendices. The co-authors gave advices and contributed to various parts of the studies such as data collection and analysis, discussions and writing. All co-authors contributed to finalising the manuscripts.

\section{DECLARATION PLAGIARISM}

I hereby confirm that I have written this doctoral thesis independently, that I have not used other sources or facilities other than the ones mentioned, that I have not used unauthorised assistance and that I have not submitted this thesis previously in any form for another degree at any university or institution. 